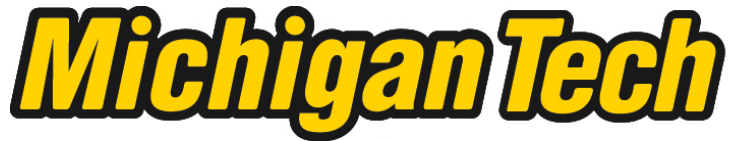 \\ Michigan Technological University Create the Future Digital Commons @ Michigan Tech
}

\section{Performance and emissions testing of a small two stroke engine using mid-level ethanol blends}

Ananth Padmanabha Rao Vemuri

Michigan Technological University

Follow this and additional works at: https://digitalcommons.mtu.edu/etds

Part of the Mechanical Engineering Commons

Copyright 2012 Ananth Padmanabha Rao Vemuri

\section{Recommended Citation}

Vemuri, Ananth Padmanabha Rao, "Performance and emissions testing of a small two stroke engine using mid-level ethanol blends", Master's report, Michigan Technological University, 2012.

https://doi.org/10.37099/mtu.dc.etds/561

Follow this and additional works at: https://digitalcommons.mtu.edu/etds

Part of the Mechanical Engineering Commons 
PERFORMANCE AND EMISSIONS TESTING OF A SMALL TWO STROKE ENGINE USING MIDLEVEL ETHANOL BLENDS

By

Ananth Padmanabha Rao Vemuri

\begin{abstract}
A REPORT
SUBMITTED In Partial Fulfillment Of The Requirements For The Degree Of MASTER OF SCIENCE

(Mechanical Engineering)
\end{abstract}

MICHIGAN TECHNOLOGICAL UNIVERSITY

2012

COPYRIGHT @ ANANTH VEMURI 2012 
This report, "Performance and emissions testing of a small two stroke engine using midlevel ethanol blends," is hereby approved in partial fulfillment of the requirements for the Degree of MASTER OF SCIENCE IN MECHANICAL ENGINEERING.

Department of Mechanical Engineering-Engineering Mechanics

Signatures:

Report Advisor

Dr. Scott A. Miers

Department Chair

Dr. William W. Predebon

Date 


\section{Table of Contents}

Chapter 1 Introduction........................................................................................................... 12

Chapter 2 Background/Literature Review.......................................................................... 14

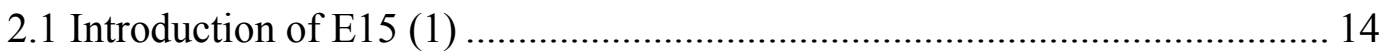

2.2 Energy independence and security act of 2007 (2)...................................... 14

2.3 Effects of intermediate ethanol blends on legacy vehicles and small non road

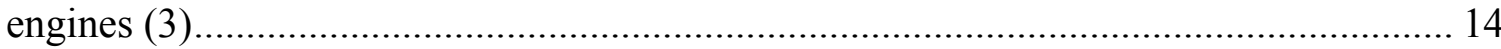

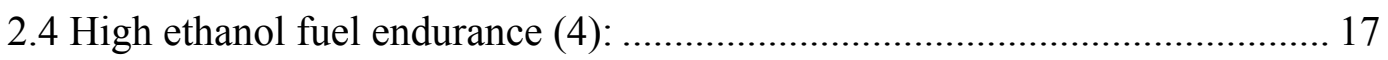

Chapter 3 Experimental Setup ................................................................................................ 19

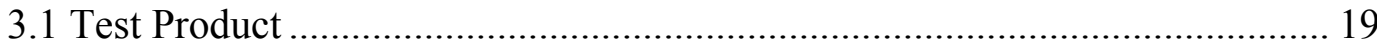

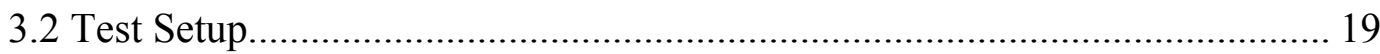

3.2.1 Engine speed measurement.............................................................. 20

3.2.2 Cylinder head temperature .............................................................. 20

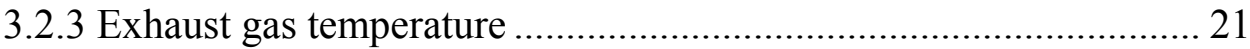

3.2.4 Exhaust sampling port............................................................... 22

3.3 Data Acquisition and Processing ................................................................ 24

3.3.1 National Instruments system........................................................ 24

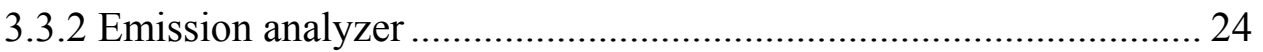

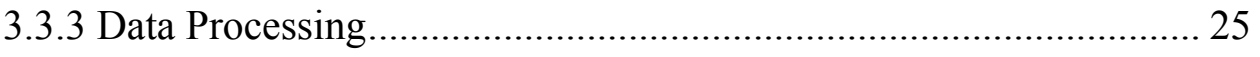

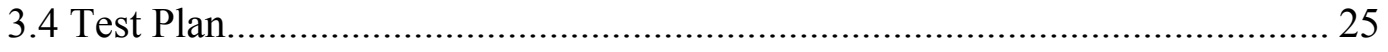

Chapter 4 Results..................................................................................................................... 28

4.1 0\% Throttle (Idle) Results......................................................................... 28

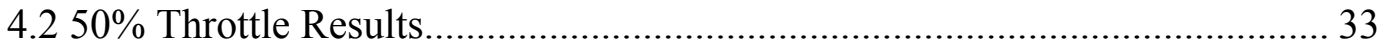




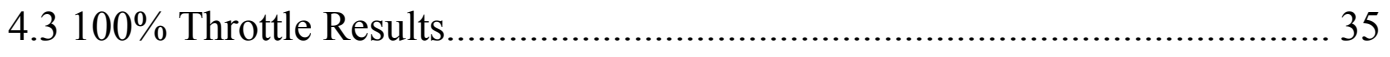

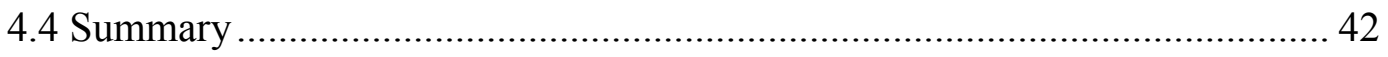

Chapter 5 Conclusions and Future Work ............................................................................. 44

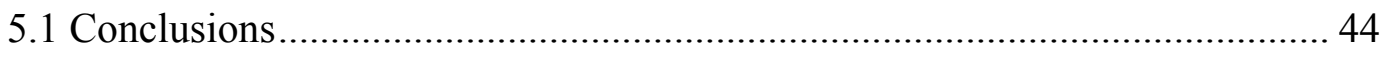

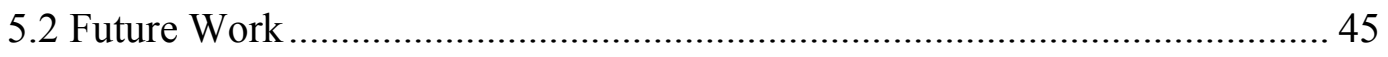

Appendix A ..................................................................................................................... 47

A.1 Matlab code for engine speed calculation................................................... 47

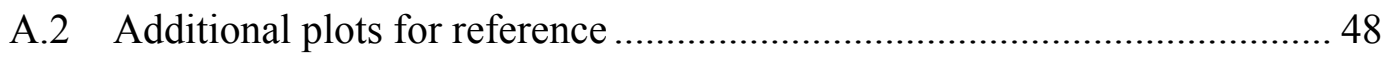

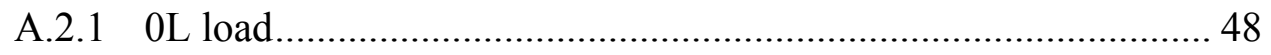

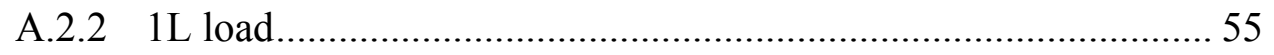

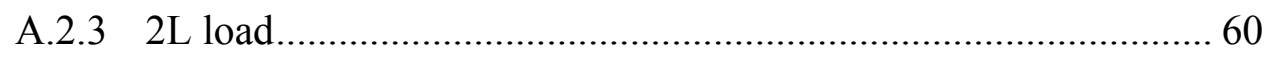

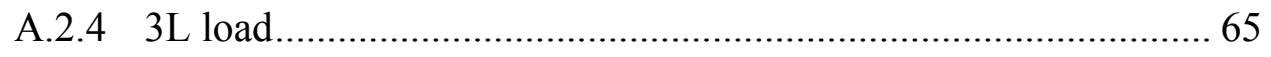

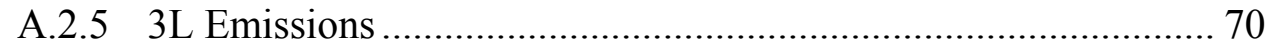

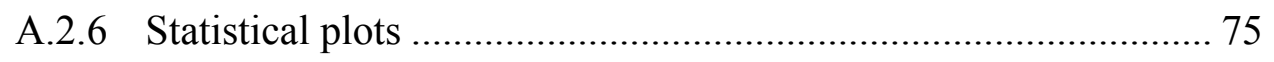




\section{List of Figures}

Figure 1.1: E3 (left) and stock (right) ground electrode difference .................................. 13

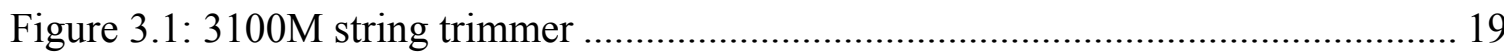

Figure 3.2: Current clamp placed on the spark plug wire with power supply unit........... 20

Figure 3.3: Cylinder head thermocouple installation...................................................... 21

Figure 3.4: Exhaust gas thermocouple installation ....................................................... 22

Figure 3.5: Emissions sample probe installation location ................................................ 23

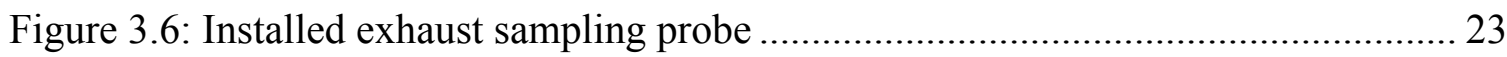

Figure 3.7: NI cDAQ chassis used for recording engine speed and temperatures ........... 24

Table 3.1: Semtech analyzer measurement range, accuracy, and resolution..................... 25

Figure 4.1: Engine speed for 0L load with 0\% throttle................................................. 29

Figure 4.2: Cylinder head temperature for 0L load with $0 \%$ throttle ............................... 30

Figure 4.3: Exhaust gas temperature for 0L load with 0\% throttle................................... 30

Figure 4.4: $\mathrm{CO} 2$ emissions for 0L load with 0\% throttle.................................................. 31

Figure 4.5: $\mathrm{CO}$ emissions for $0 \mathrm{~L}$ load with $0 \%$ throttle ................................................ 32

Figure 4.6: NO emissions for $0 \mathrm{~L}$ load with $0 \%$ throttle .................................................... 33

Figure 4.7: Comparison of engine speed for 50\% and 100\% throttle setting ................... 34

Figure 4.8: Data means for engine speed for different test variables ............................... 35

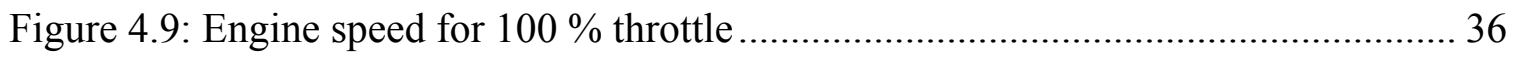

Figure 4.10: Cylinder head temperature for $100 \%$ throttle............................................. 37

Figure 4.11: Exhaust gas temperature for $100 \%$ throttle ................................................. 38

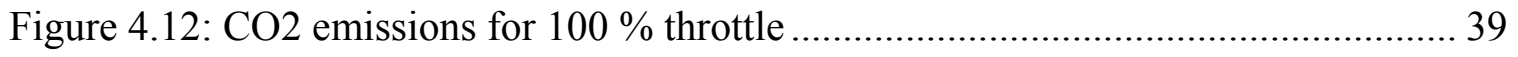

Figure 4.13: $\mathrm{CO}$ emissions for $100 \%$ throttle .................................................................. 40 


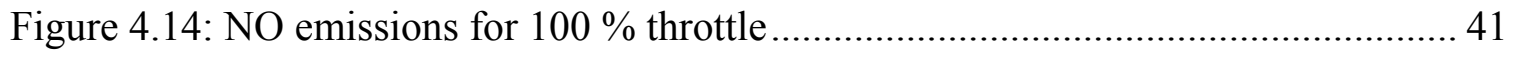

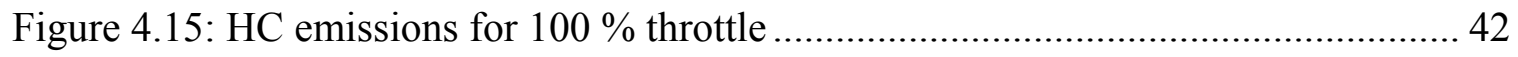

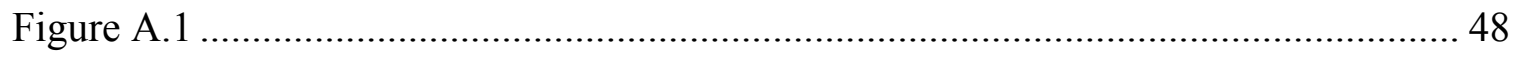

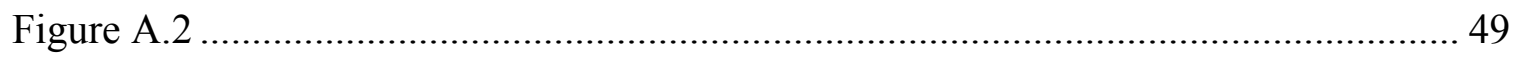

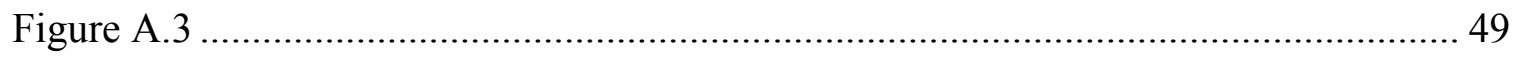

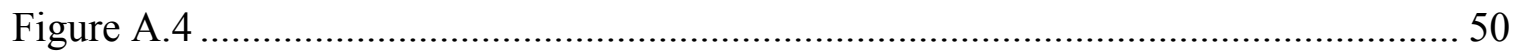

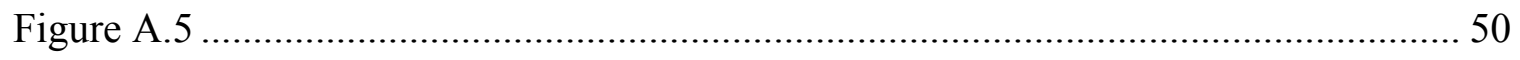

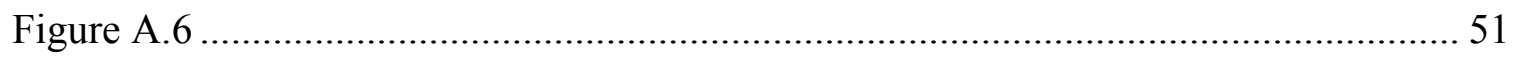

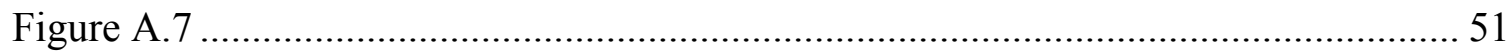

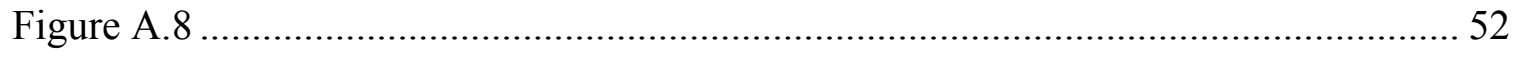

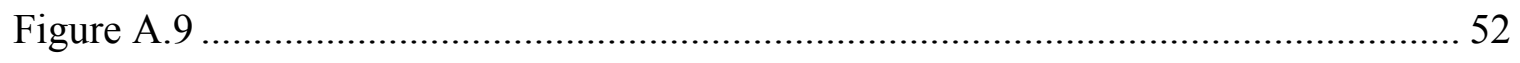

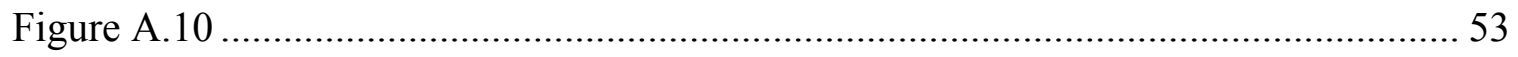

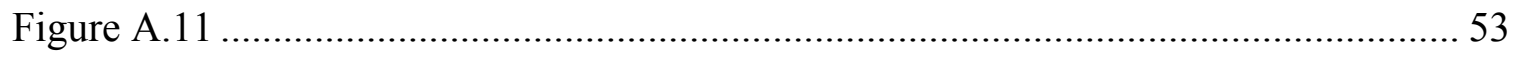

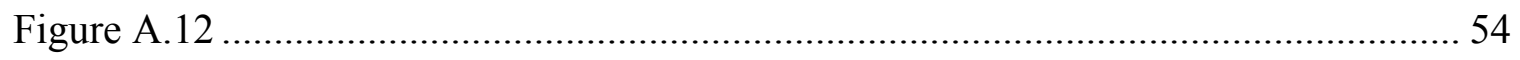

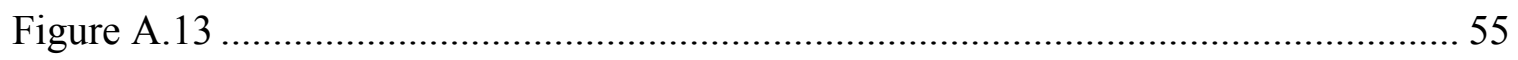

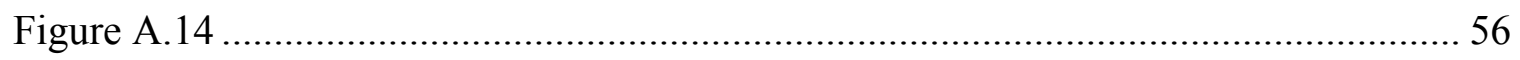

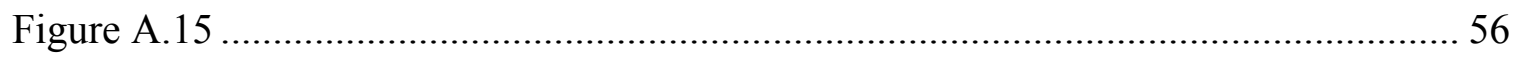

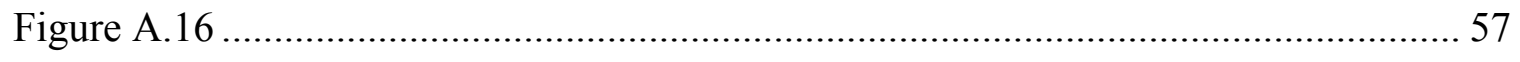

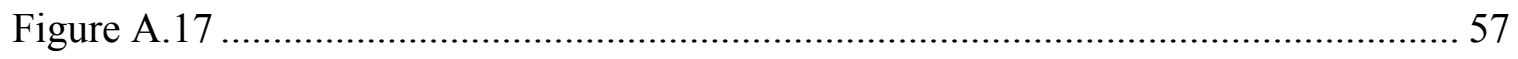

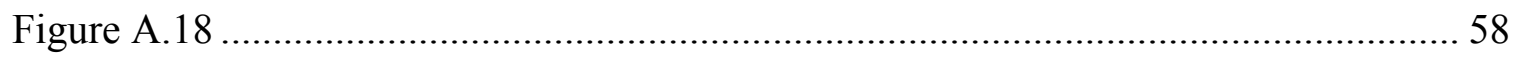

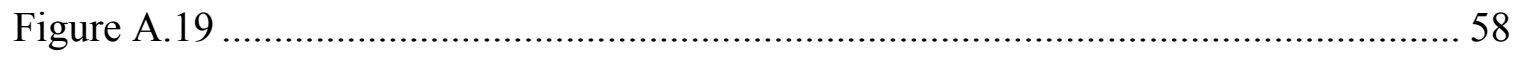

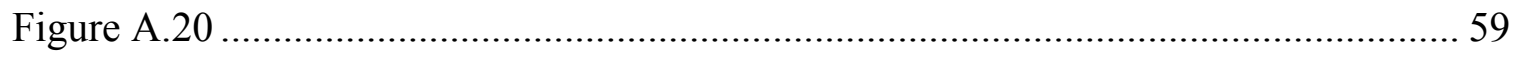

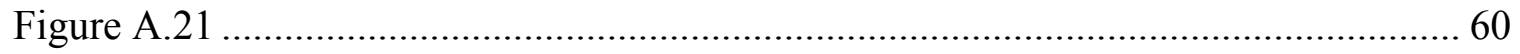




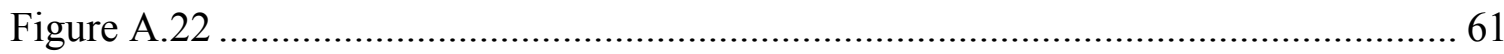

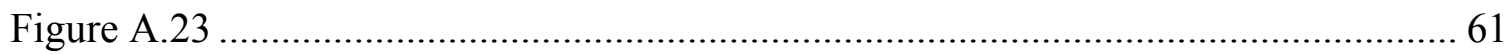

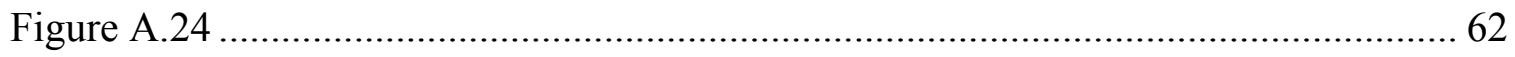

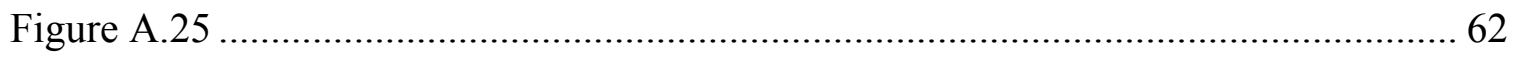

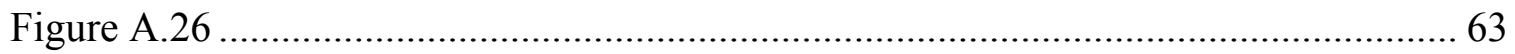

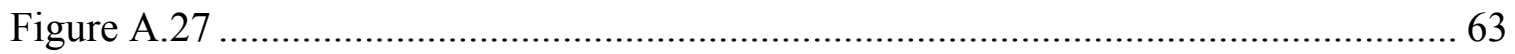

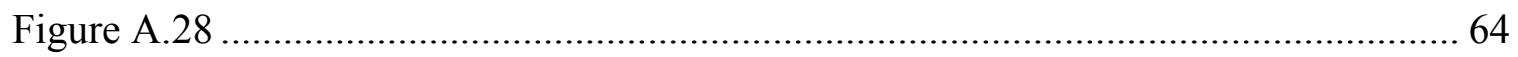

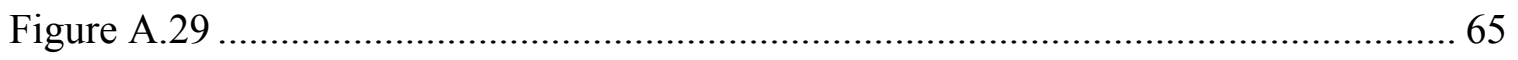

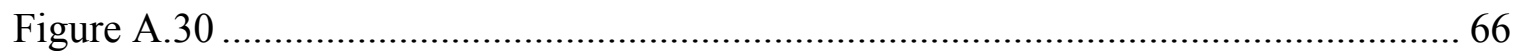

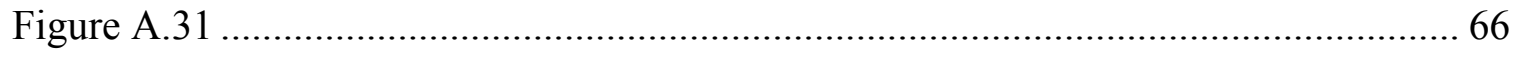

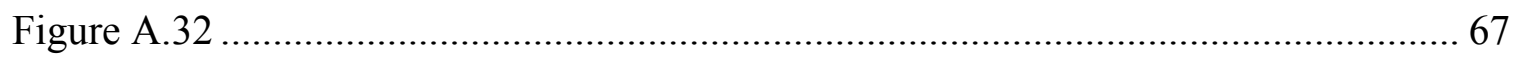

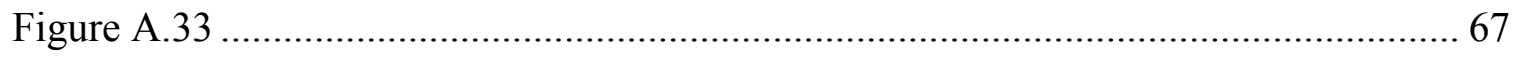

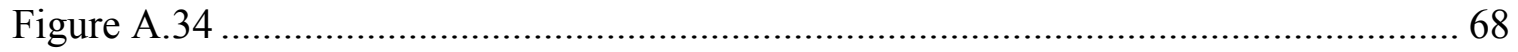

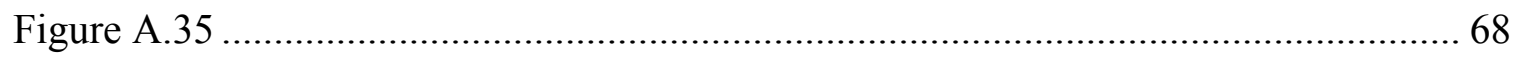

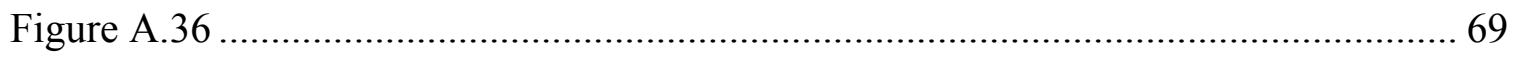

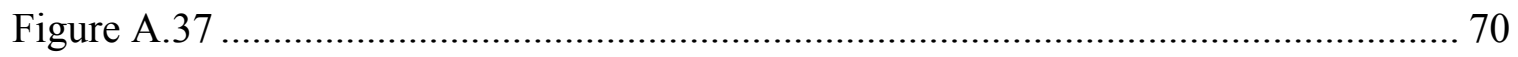

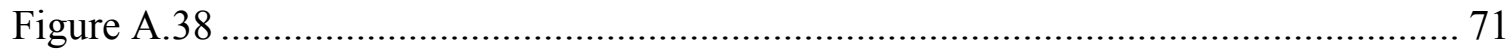

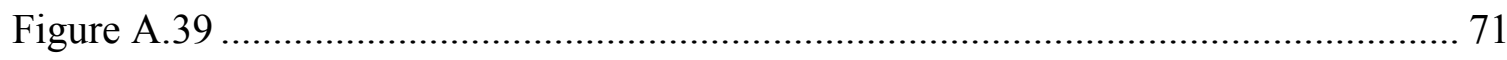

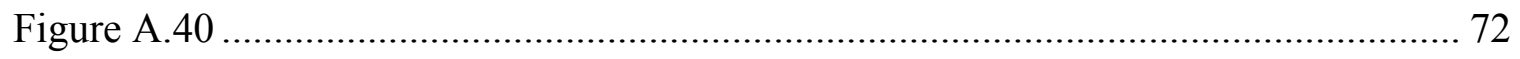

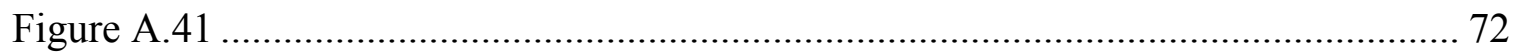

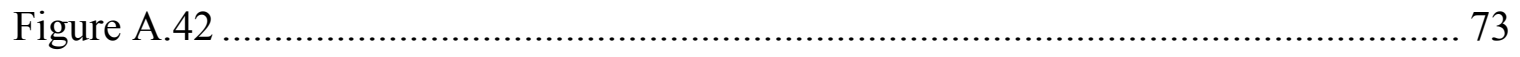

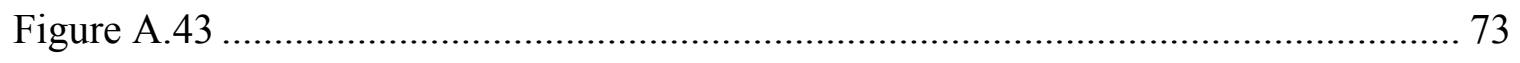

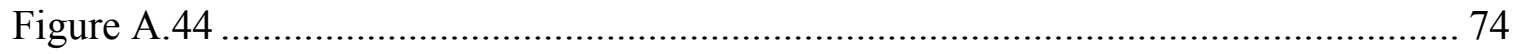




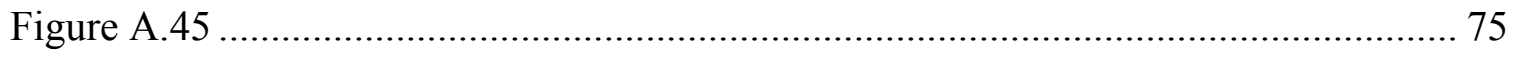

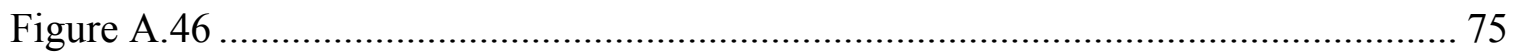

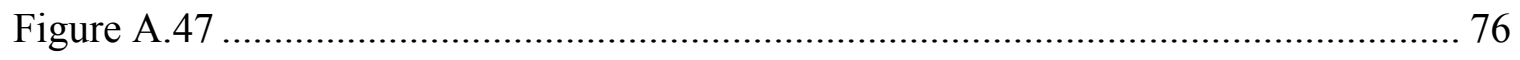

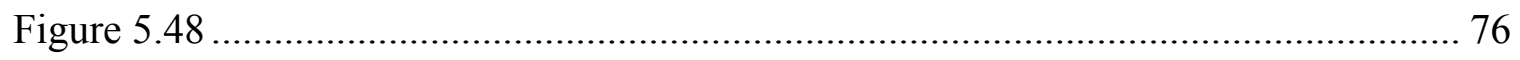

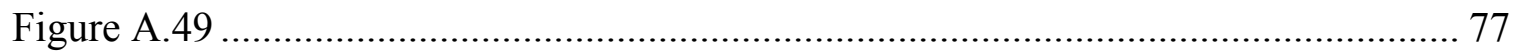

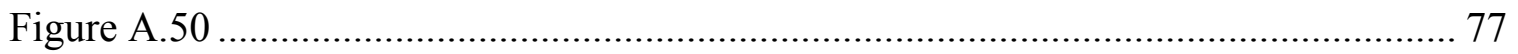




\section{List of Tables}

Table 2.1: Emissions results for two-stroke leaf blower........................................... 16

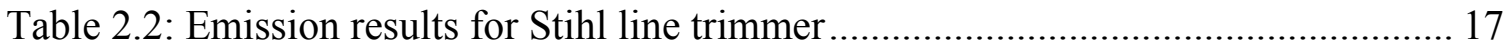

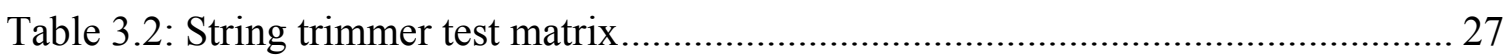

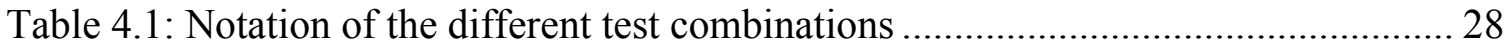




\section{Nomenclature}

0L: Standard Length $+0 "$

1L: Standard Length $+1 "$

2L: Standard Length +2 "

3L: Standard Length +3 "

cDAQ: Compact Data Aquicition

CHT: Cylinder Head Temperature

CO: Carbon Monoxide

CO2: Carbon Dioxide

DC: Direct Current

E10: 10\% Ethanol by volume in Gasoline

E15: 15\% Ethanol by volume in Gasoline

E3: E3 Spark Plug

EGT: Exhaust Gas Temperature

EPA: Envinormental Protection Agency

H/C: Hydrogen to Carbon Ratio

HC: Hydrocarbon

NI: National Instruments

NO: Nitrous Monoxide

NVH: Noise Vibration and Harshness

SP: Stock Plug

WOT: Wide Open Throttle 


\begin{abstract}
With the introduction of the mid-level ethanol blend gasoline fuel for commercial sale, the compatibility of different off-road engines is needed. This report details the test study of using one mid-level ethanol fuel in a two stroke hand held gasoline engine used to power line trimmers. The study sponsored by E3 is to test the effectiveness of an aftermarket spark plug from E3 Spark Plug when using a mid-level ethanol blend gasoline. A $15 \%$ ethanol by volume (E15) is the test mid-level ethanol used and the $10 \%$ ethanol by volume (E10) was used as the baseline fuel.

The testing comprises running the engine at different load points and throttle positions to evaluate the cylinder head temperature, exhaust temperature and engine speed. Raw gas emissions were also measured to determine the impact of the performance spark plug.

The low calorific value of the E15 fuel decreased the speed of the engine along with reduction in the fuel consumption and exhaust gas temperature. The HC emissions for E15 fuel and E3 spark plug increased when compared to the base line in most of the cases and NO formation was dependent on the cylinder head temperature. The E3 spark plug had a tendency to increase the temperature of the cylinder head irrespective of fuel type while reducing engine speed.
\end{abstract}




\section{Chapter 1 Introduction}

The EPA with certain limitation on the use of fuel has approved the use of E15. One of the limitations for the use of E15 fuel is that any off road spark ignited (SI) engine is prohibited from using E15. The present test subject involves a hand held string trimmer from Yard Machines used for cutting grass and weeds. This string trimmer uses a gasoline engine and is prohibited from using E15 fuel, per EPA regulations. Hence E3 Spark Plugs sponsored the study to test for the emissions while running on E3 plugs and E15 fuel in the event of miss-fueling from consumers. The Energy Independence and Security Act (EISA) of 2007 proposed the increase use of ethanol as a motor in the coming years. High ethanol gasoline is one of the major steps in realizing the EISA proposal of increased ethanol content and this might lead increased ethanol fuels and this report provides an insight on the 2-stroke engine performance with E15 fuel.

A trimmer was purchased according to the sponsor's requirement and instrumented for collecting engine speed, cylinder head temperature, exhaust gas temperature and exhaust emissions. The engine speed and temperatures were measured using National Instruments (NI) data acquisition system and the emissions were analyzed using a Semtech-DS analyzer. The emission components recorded by the analyzer were carbon dioxide $\left(\mathrm{CO}_{2}\right)$, carbon monoxide $(\mathrm{CO})$, nitrogen oxide $(\mathrm{NO})$, total hydrocarbons (THC) and oxygen $\left(\mathrm{O}_{2}\right)$. These raw emissions in percentage and ppm are further processed and normalized with the fuel consumption. The fuel consumption was measured with a high precision syringe and a scale capable of 1 gram resolution.

The testing consisted of three throttle positions $(0,50 \%, 100 \%)$ and four load points (varying string length). The throttle was controlled using custom made spacers and the load was applied by changing the string length of the trimmer. The string trimmer was mounted to a test stand so all tests were performed with the trimmer in the same configuration. Each of the throttle positions and load settings were tested three times with each combination of fuel and spark plug. 
The goal of the research was to study the impact of a midlevel ethanol blend and an aftermarket spark plug using a production two-stroke engine. A comparison of spark plug ground electrode designs is shown in Figure 1.1. The E3 plug has a diamond shaped ground electrode design which according to 'E3 spark plugs' helps in better flame kernel development and thus outperforms the stock plug. The flame produced from this new shape travels farther into the combustion chamber because there is no obstruction unlike the stock plug with the J-wire design. The E3 design also improves the transfer of energy from the spark plug to the combustion gases and reduces the ignition delay (5).
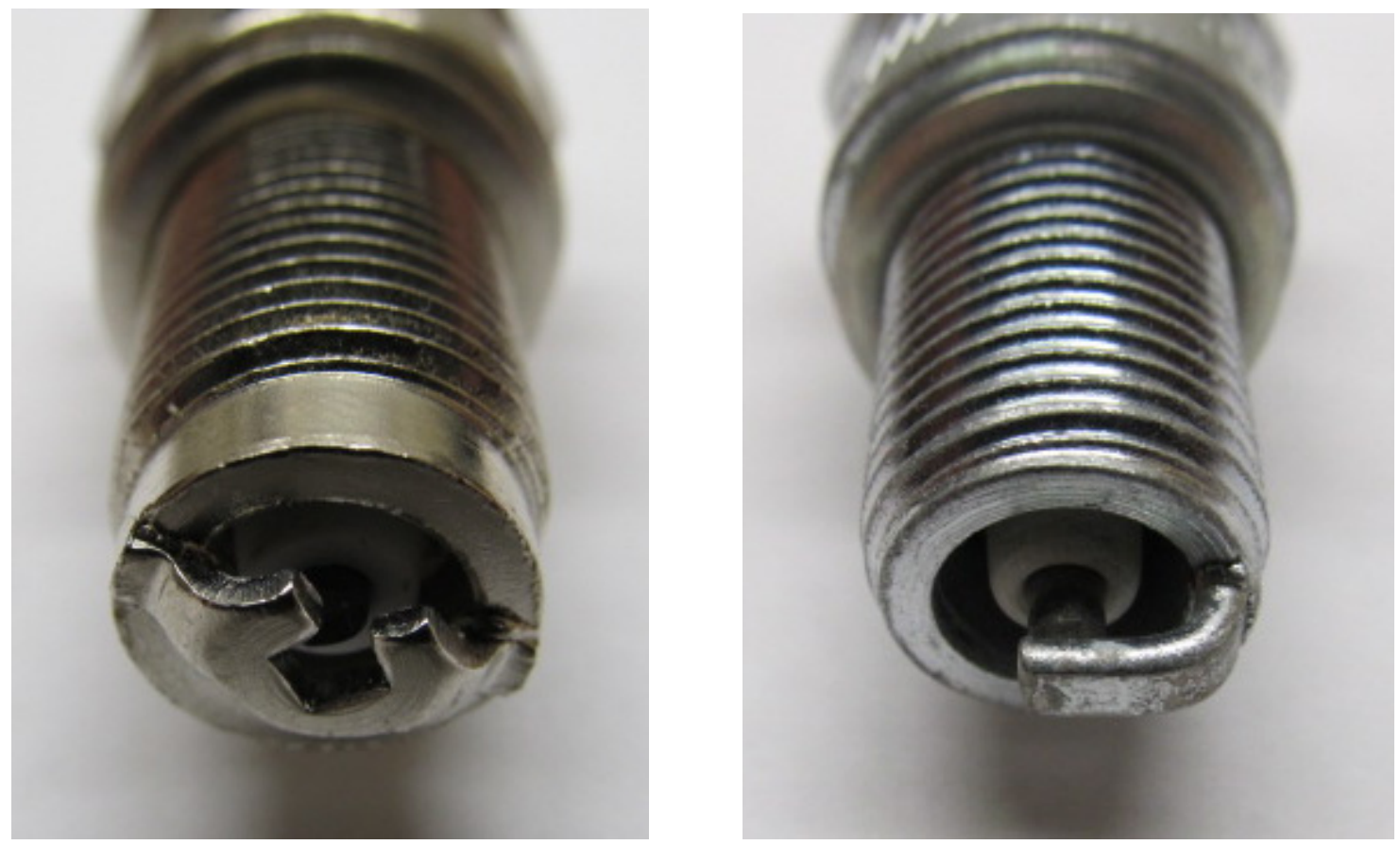

Figure 1.1: E3 (left) and stock (right) ground electrode difference

The fuel of interest was $15 \%$ ethanol (E15) and the aftermarket spark plug was a E3 manufactured unit. E10 and the stock spark plug were used to establish a baseline test condition. From the properties of the E3 spark plug, the combustion in the cylinder is expected to be improved along with advance in combustion timing due to reduced ignition delay. The E15 on the other hand is expected to decrease the performance due to its low calorific value and also reduce the $\mathrm{CO}$ and $\mathrm{HC}$ emissions due to more oxygen in the fuel. 


\section{Chapter 2 Background/Literature Review}

\subsection{Introduction of E15 (1)}

The concept of E15 fuel was started by a wavier submitted by a coalition of U.S. ethanol supporters called Growth Energy and 54 ethanol manufacturers. Their request was to increase the ethanol content in the gasoline from $10 \%$ to $15 \%$. Based on the test data available through the DOE from 2008, the EPA on October 13, 2010 partially granted Growth Energy's waiver request to use E15 fuel in MY2007 and newer lightduty motor vehicles but denied previous model year vehicles, heavy duty engines, motorcycles, and off-road engines. But after more extensive testing, the EPA approved the use of E15 in MY 2001 and newer light-duty motor vehicles with the same conditions on the other engines.

\subsection{Energy independence and security act of 2007 (2)}

The Energy Independence and Security Act (EISA) of 2007 is a bill by One Hundred Tenth Congress of the United State of America. As the name suggests the bill deals with the energy security of America in the future and ways to save energy. One of the sections of the act includes the increased use of renewable fuels in coming years. These biofuels for gasoline and diesel engines can be produced in the United States thereby decreasing the foreign oil imports into the country. The bill projects to use 20.5 billion gallons of biofuel or ethanol by 2015 and 36 billion gallons by 2022 .

\subsection{Effects of intermediate ethanol blends on legacy vehicles and small non road engines (3)}

The report was a study involving the testing of various engines using ethanol blends up to $20 \%$. The tests were conducted in two categories, one involving on-road vehicles that included popular selling cars in the United States and a second category of off-road engines. For the off-road engines, various engine sizes for different applications were included, but the results presented here focus on the results from the handheld 
power equipment. The two-stroke Weed Eater leaf blower tests are detailed as it represented an engine similar to the current test engine in this report. The second engine was a Stihl Line Trimmer which was a four-stroke engine but used fuel lubrication just like a two-stroke engine.

The two-stroke leaf blower was tested using two modes, mode 1 which was full power at wide open throttle (WOT) and mode 2 which was idle. The engine emissions where measured at a new engine condition (12 hours of run time) and at full-life where the engine was run a total of 20 hours. Durability testing of the engines using E15 and E20 fuels shows that the engine speed at mode 1 decreased by $500 \mathrm{rpm}$ after 35 hours of operation and the engine speed increased at idle when the concentration of ethanol was increased.

Table 2.1 details the emissions for the two-stroke engine using different ethanol blends. Eight engines were used in total for the two modes and E0, E10, E15 and E20 blends of fuel. The emissions show that the HC (Hydrocarbons) decrease with all the three blends of ethanol when compared with E0 fuel. The NOx emission increased due to the presence of more oxygen in the combustion chamber. The $\mathrm{CO}$ emissions also decreased consistently with the increase in ethanol content. 
Table 2.1: Emissions results for two-stroke leaf blower

\begin{tabular}{|c|c|c|c|c|}
\hline Equipment & \multicolumn{2}{|c|}{ New } & \multicolumn{2}{c|}{ Full life } \\
\hline & $\begin{array}{c}\text { New E0 } \\
\text { (g/kW-hr) }\end{array}$ & $\begin{array}{c}\text { Change } \\
\text { from E0 to } \\
\text { ethanol } \\
\text { blend }\end{array}$ & $\begin{array}{c}\text { Full life E0 } \\
(\mathrm{g} / \mathrm{kW}-\mathrm{hr})\end{array}$ & $\begin{array}{c}\text { Change } \\
\text { from E0 to } \\
\text { ethanol } \\
\text { blend }\end{array}$ \\
\hline \multicolumn{5}{|c|}{ HC emissions } \\
\hline Weed Eater B2 (E0 engine) & 47.6 & na & na & na \\
\hline Weed Eater B3 (E15 engine) & 42.4 & $-22 \%$ & na & na \\
\hline Weed Eater B5 (E10 engine) & 57.8 & $-20 \%$ & 48.1 & $-25 \%$ \\
\hline Weed Eater B7 (E15 engine) & 38.4 & $-19 \%$ & na & na \\
\hline \multicolumn{5}{|c|}{ NOx emissions } \\
\hline Weed Eater B2 (E0 engine) & 0.3 & na & na & na \\
\hline Weed Eater B3 (E15 engine) & 0.2 & $48 \%$ & na & na \\
\hline Weed Eater B5 (E10 engine) & 0.2 & $19 \%$ & 0.3 & $27 \%$ \\
\hline Weed Eater B7 (E15 engine) & 0.2 & $399 \%$ & na & na \\
\hline \multicolumn{7}{|c|}{ HC + NOx emissions } \\
\hline Weed Eater B2 (E0 engine) & 47.9 & na & na & na \\
\hline Weed Eater B3 (E15 engine) & 42.6 & $-21 \%$ & na & na \\
\hline Weed Eater B5 (E10 engine) & 58 & $-19 \%$ & 48.4 & $-25 \%$ \\
\hline Weed Eater B7 (E15 engine) & 38.6 & $-17 \%$ & na & na \\
\hline \multicolumn{7}{|c|}{ CO emissions } \\
\hline Weed Eater B2 (E0 engine) & 366 & na & na & na \\
\hline Weed Eater B3 (E15 engine) & 355 & $-42 \%$ & na & na \\
\hline Weed Eater B5 (E10 engine) & 448 & $-32 \%$ & 314 & $-46 \%$ \\
\hline Weed Eater B7 (E15 engine) & 239 & $-95 \%$ & na & na \\
\hline
\end{tabular}

The exhaust temperature was also recorded for all the tests and the temperature increased for increased ethanol content for new engine tests and the temperature decreased for the full life tests.

The Stihl line trimmer testing was performed using four different engines and the pilot study was performed without tampering with the factory settings. The idle speed increased on E15 and E20 fuels causing the clutch to engage and the full power mode (mode 1) was run at 10,000 rpm which was 2,000 rpm more than the rated speed. The emission trends of this engine follow the same pattern as the above engine with decreased 
$\mathrm{HC}$ and $\mathrm{CO}$ emissions and increased NOx emissions with increasing ethanol content.

Table 2.2 lists the emission results quantitatively.

Table 2.2: Emission results for Stihl line trimmer

\begin{tabular}{|c|c|c|c|c|}
\hline \multirow[t]{2}{*}{ Equipment } & \multicolumn{2}{|c|}{ New } & \multicolumn{2}{|c|}{ Full life } \\
\hline & $\begin{array}{l}\text { New E0 } \\
\text { (g/kW-hr) }\end{array}$ & $\begin{array}{l}\text { Change } \\
\text { from E0 to } \\
\text { ethanol } \\
\text { blend }\end{array}$ & $\begin{array}{l}\text { Full life E0 } \\
\text { (g/kW-hr) }\end{array}$ & $\begin{array}{l}\text { Change } \\
\text { from E0 to } \\
\text { ethanol } \\
\text { blend }\end{array}$ \\
\hline \multicolumn{5}{|c|}{ HC emissions } \\
\hline Stihl T1 (E0 engine) & 33.6 & na & 76.4 & na \\
\hline Stihl T2 (E10 engine) & 29.9 & $-11 \%$ & 65.6 & $-19 \%$ \\
\hline Stihl T3 (E15 engine) & 28.5 & $-37 \%$ & 68.8 & $-33 \%$ \\
\hline \multicolumn{5}{|c|}{ NOx emissions } \\
\hline Stihl T1 (E0 engine) & 3.3 & na & 3.7 & na \\
\hline Stihl T2 (E10 engine) & 4.1 & $11 \%$ & 4.8 & $39 \%$ \\
\hline Stihl T3 (E15 engine) & 3.2 & $116 \%$ & 2.5 & $184 \%$ \\
\hline \multicolumn{5}{|c|}{ HC + NOx emissions } \\
\hline Stihl T1 (E0 engine) & 36.9 & na & 80.1 & na \\
\hline Stihl T2 (E10 engine) & 33.9 & $-9 \%$ & 70.4 & $-15 \%$ \\
\hline Stihl T3 (E15 engine) & 31.7 & $-14 \%$ & 73.7 & $-10 \%$ \\
\hline \multicolumn{5}{|c|}{ CO emissions } \\
\hline Stihl T1 (E0 engine) & 347 & na & 591 & na \\
\hline Stihl T2 (E10 engine) & 285 & $-7 \%$ & 461 & $-20 \%$ \\
\hline Stihl T3 (E15 engine) & 408 & $-39 \%$ & 712 & $-40 \%$ \\
\hline
\end{tabular}

The exhaust temperatures increased for both the new engine tests and the full-life tests as ethanol content increased. Note that the $\%$ increase in temperature for the full-life test was substantially lower than the new engine tests. This was attributed to the $30 \%$ decrease in the brake specific power during full-life dynamometer tests when compared to new engine tests.

\subsection{High ethanol fuel endurance (4):}

The report consists of test results of four Mercury Marine engines tested on E0 and E15 fuel for 300 hours of endurance testing and wide open throttle conditions. The 
engines selected are three types of four-stroke engines and one type of two-stroke engine. The results from the two-stoke are discussed in detail in this literature review. The test procedure followed prior to the actual test was to break-in the engines for approximately 2.5 hours followed by a power run with E0 on all engines and E15 fuel for engines that will run on E15. The emissions were referenced using the EPA Tier II emissions reference grade fuel (E0 gasoline) also named EEE fuel and three different tests were performed to check repeatability. The durability tests were concluded with a visual inspection and cylinder integrity checks.

The two-stroke test engine was 2.51 liters in displacement, produced $200 \mathrm{hp}$, operated using an open loop electronic fuel injection system with oil injection. The E15 fuel had the following properties: $14.1 \%$ ethanol, RON of $95.7, \mathrm{MON}$ of $84.7,[\mathrm{R}+\mathrm{M}] / 2$ of 90.2 and Reid vapor pressure of 8.5.

The engine did not complete the durability test due to the failure of a big end connecting rod bearing on cylinder 3. The engine ran for total of 283 hours in which 256 hours was endurance time at wide open throttle. The HC + NOx emissions were low for the E0 engine but as the run time increased the emissions also increased and were higher than the E15 engine. At 150 hours of operation, the $\mathrm{HC}+\mathrm{NOx}$ emissions for E0 were approximately $124 \mathrm{~g} / \mathrm{kW}-\mathrm{hr}$ while the E15 engine produced $115 \mathrm{~g} / \mathrm{kW}-\mathrm{hr}$. The CO emissions for E0 were $360 \mathrm{~g} / \mathrm{kW}$-hr which was $80 \mathrm{~g} / \mathrm{kW}$-hr greater than the E15 engine at 150 hours of operation.

The $\mathrm{HC}$ and $\mathrm{CO}$ emissions were lower for the E15 engine due to the leaner airfuel mixture and the NOx emissions increased for the same reason. "There was more variability in the $\mathrm{HC}+\mathrm{NOx}$ emissions for $\mathrm{E} 0$ than the change in emissions for the E15 engine" (4). According to the authors, $15-20^{\circ} \mathrm{C}$ of temperature increment was observed in the exhaust gases with E15 fuel due to leaner operation. 


\section{Chapter 3 Experimental Setup}

\subsection{Test Product}

The engine used for the study was a naturally aspirated two-stroke power tool engine from Yard Machine used in a String Trimmer shown in Figure 3.1. The engine was a single cylinder, air-cooled, carbureted, 31cc two-stroke with direct throttle control and fuel-oil mixture for lubrication. The engine performance on E15 (15 volume \% ethanol, 85 volume \% gasoline) was compared with E10 (10 volume \% ethanol, 90 volume $\%$ gasoline) with both the standard spark plug from the engine manufacture and an aftermarket spark plug from E3 Spark Plugs. The engine parameters that were compared are the engine speed, cylinder head temperature, exhaust gas temperature and tail pipe emissions including $\mathrm{CO} 2, \mathrm{CO}, \mathrm{NO}$, and $\mathrm{HC}$.

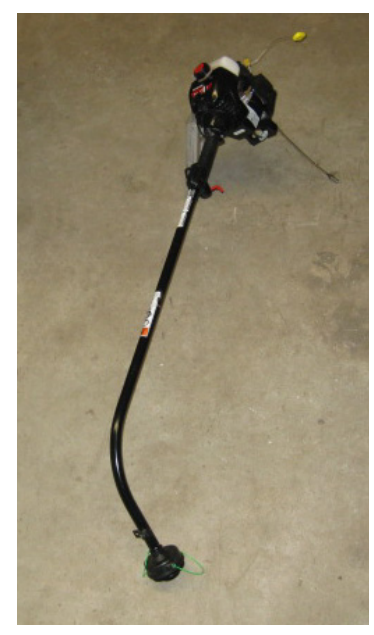

Figure 3.1: 3100M string trimmer

\subsection{Test Setup}

The string trimmer was used in stock form to replicate the load of an actual machine when in use. The engine was instrumented to collect the data required for the performance analysis and was recorded using National Instruments (NI) cDAQ modules and Labview software was used to program the acquisition. Matlab was used to postprocess the data and generate plots. 


\subsubsection{Engine speed measurement}

The spark event of the engine was used to measure the speed of the engine. The wire leading from the ignition coil to the spark plug was tapped using a current probe. The current probe used was a Fluke 80i-110s AC/DC and the output was a sine wave which had peaks at every spark event. The current clamp was placed over the wire with filler as shown in Figure 3.2 to prevent the clamp from bouncing around on the wire which originally occurred and caused a high level of noise in the RPM signal. The current clamp was powered using a DC power supply with a constant voltage of 9VDC and the output from the clamp was connected to a cDAQ NI 9234.

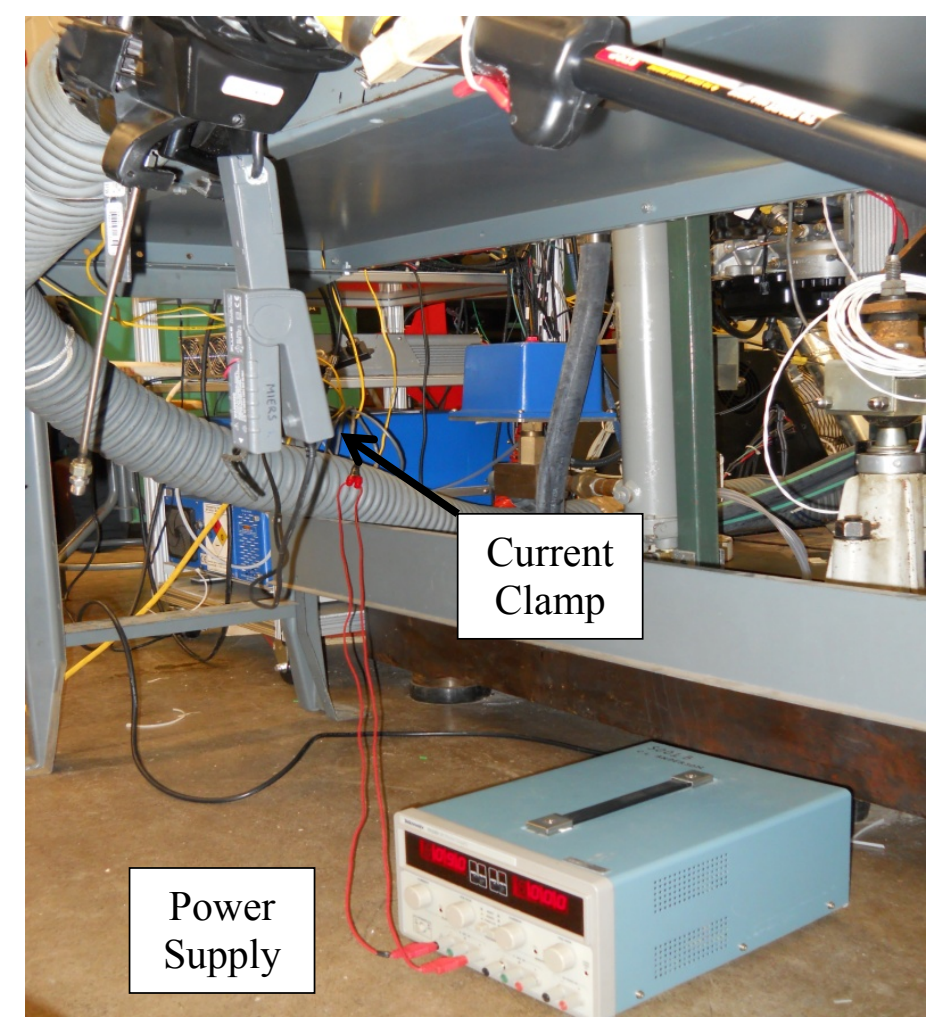

Figure 3.2: Current clamp placed on the spark plug wire with power supply unit

\subsubsection{Cylinder head temperature}

The cylinder head temperature of the engine was measured using a 0.03125 " diameter, k-type thermocouple. The thermocouple was placed closest to the spark plug so that the temperature in the cylinder was recorded with reduced time lag. A hole was 
drilled into a boss in the cylinder head and the thermocouple was secure to the cylinder head using high temperature epoxy. The thermocouple reading was recorded using a cDAQ NI 9211 module. Figure 3.3 shows the thermocouple mounting on the engine.

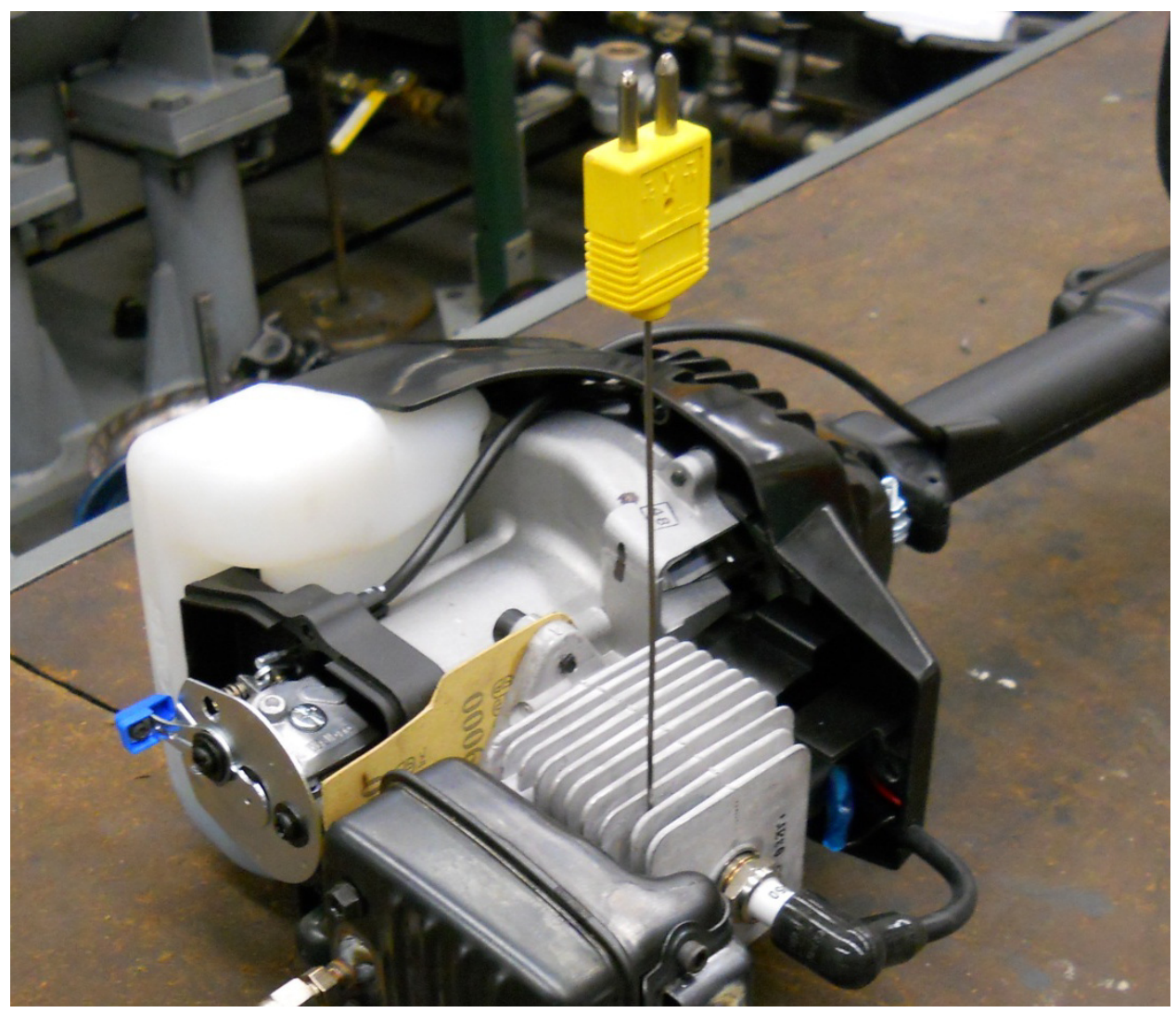

\section{Figure 3.3: Cylinder head thermocouple installation}

\subsubsection{Exhaust gas temperature}

The exhaust gas temperature was measured using a 0.125 " diameter, k-type thermocouple. The thermocouple was placed close to the exhaust port and the tip of the thermocouple was placed such that it was perpendicular to the flow of the gases and at the center of the passage for the most consistent recording of the exhaust temperature. The installation of the exhaust thermocouple is shown in Figure 3.4. The thermocouple output was connected to a cDAQ NI 9211 module. 


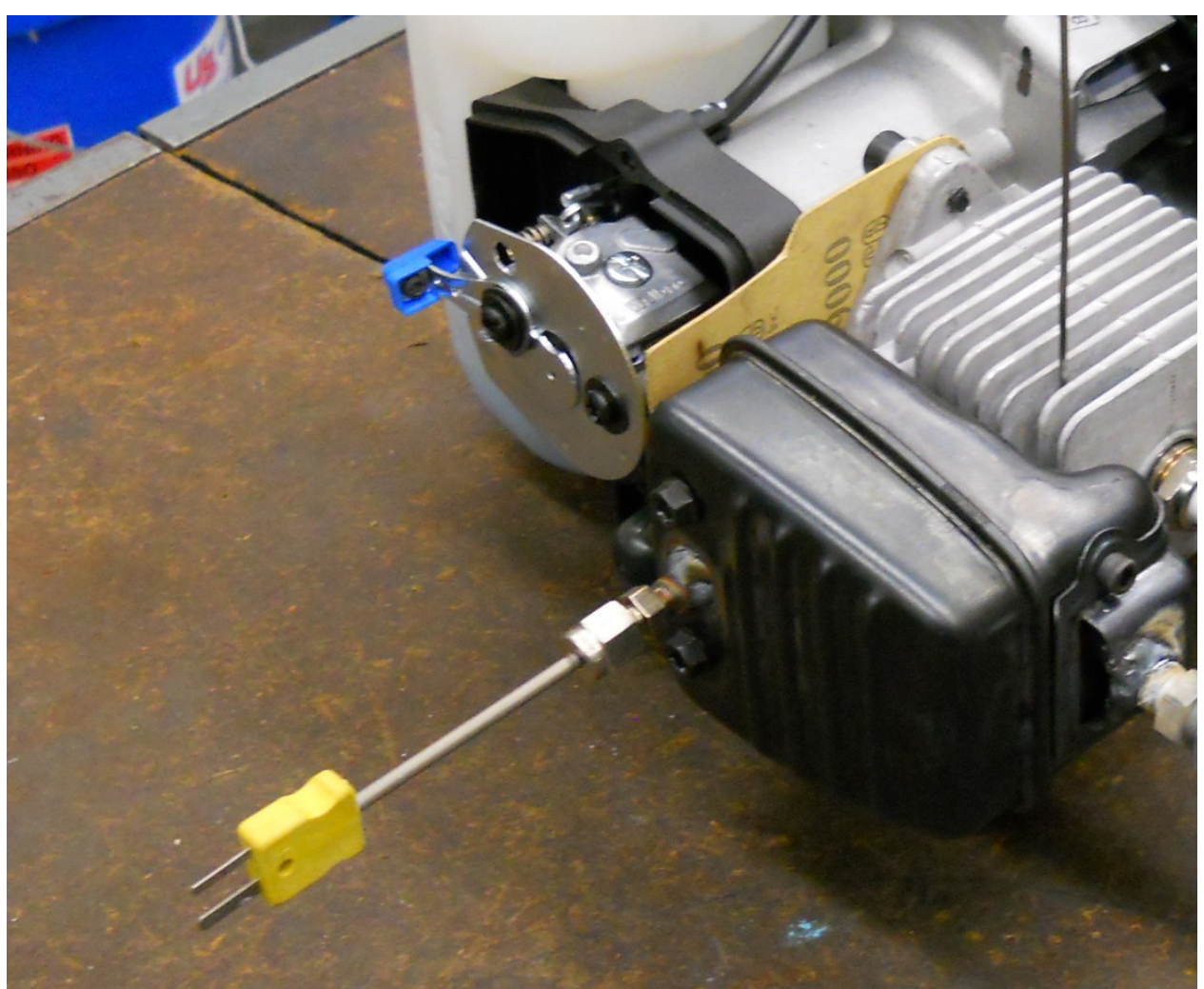

\section{Figure 3.4: Exhaust gas thermocouple installation}

\subsubsection{Exhaust sampling port}

In order to measure the exhaust emissions from the string trimmer, a hole was drilled into the exit of the muffler so an emissions probe could be installed. Figure 3.5 shows the exhaust manifold where the sample probe was inserted and Figure 3.6 shows the attached sampling probe. 


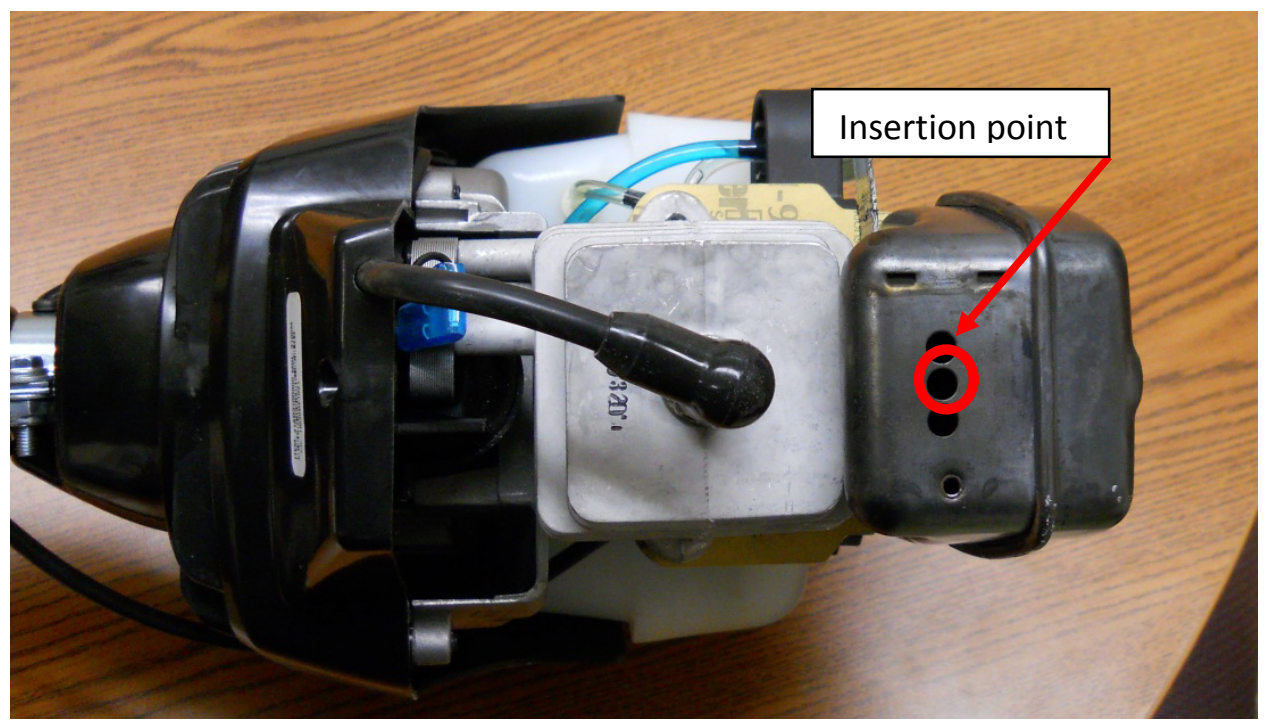

Figure 3.5: Emissions sample probe installation location

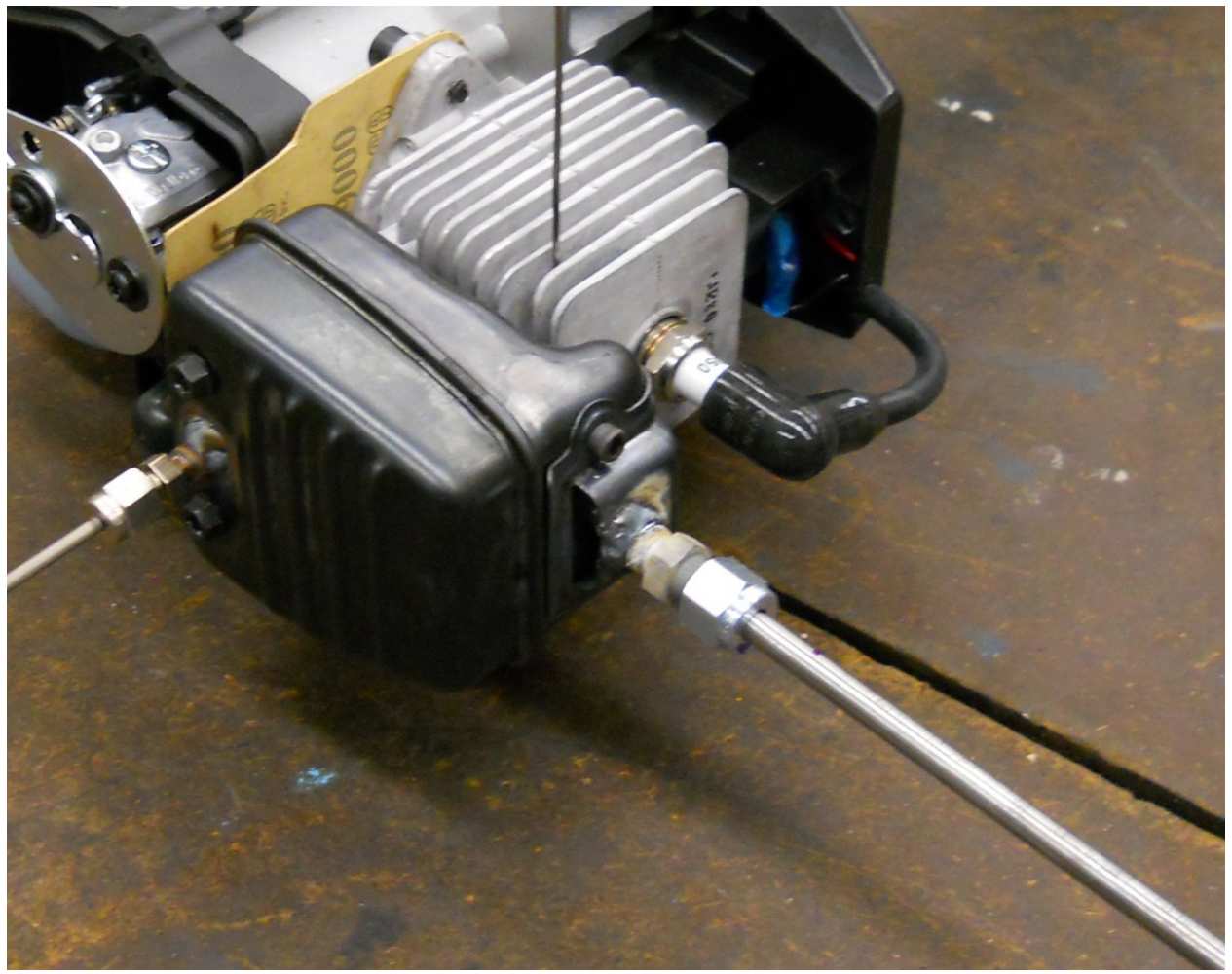

Figure 3.6: Installed exhaust sampling probe 


\subsection{Data Acquisition and Processing}

\subsubsection{National Instruments system}

The cDAQ system from National Instruments was used to acquire data using Labview Signal Express. The raw data files from Signal Express were saved as acsii files for post-processing and analysis in Matlab. The data was collected using a Dell XP laptop with Intel i7 processer and Windows 7 operating system. The NI 9211 and NI 9234 modules were used to collect the data from the thermocouples and current probe respectively. Both the modules were placed in an NI 9172 eight slot chassis which was connected to the computer using a USB 2.0 wire. Figure 3.7 shows the NI 9172 chassis with the NI 9211 and NI 9234 modules installed.

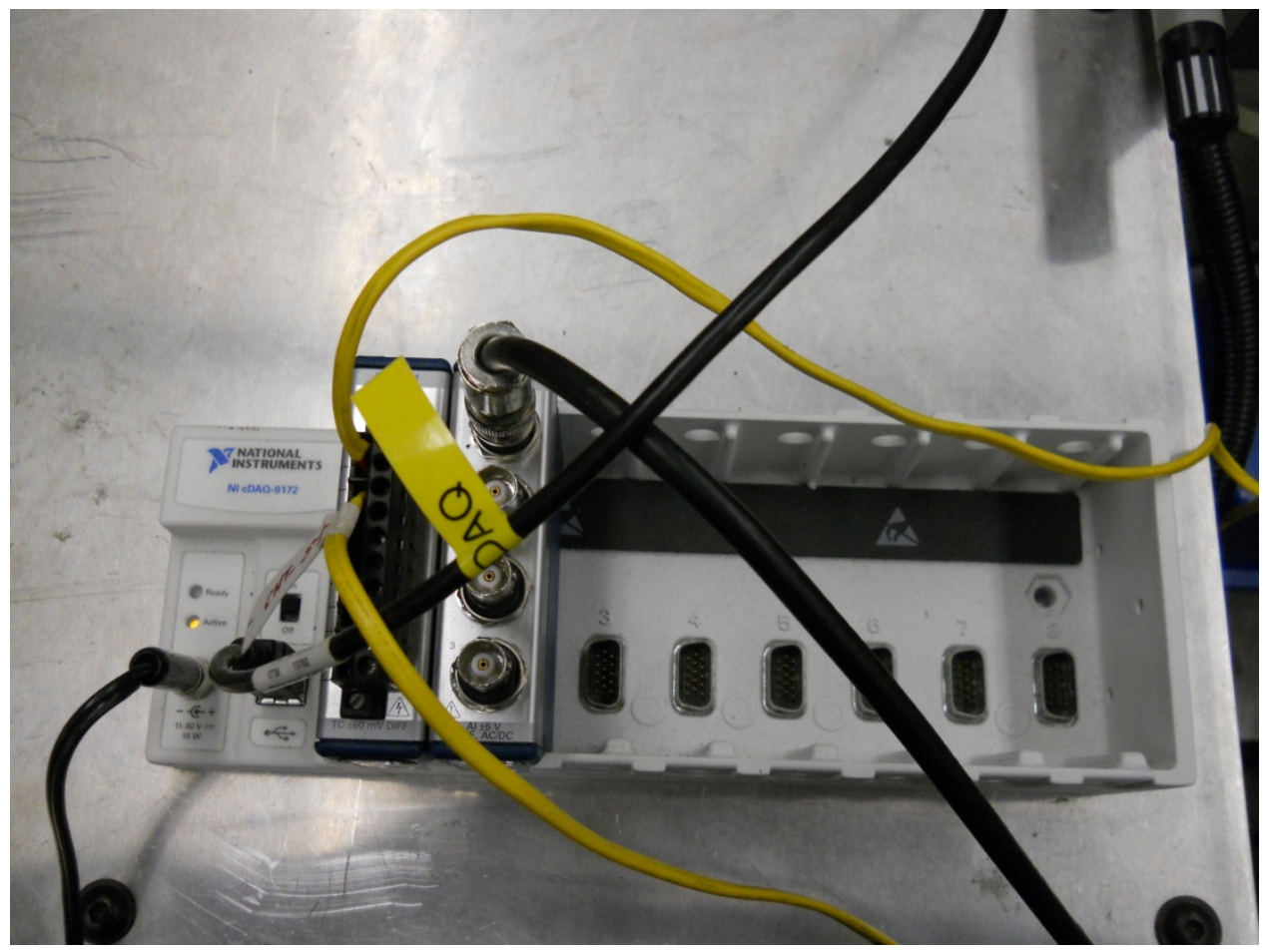

Figure 3.7: NI cDAQ chassis used for recording engine speed and temperatures

\subsubsection{Emission analyzer}

A Semtech-DS raw gas emissions analyzer was used to analyze the exhaust gases from the string trimmer. The analyzer was used to measure concentrations of carbon 
dioxide $(\mathrm{CO} 2)$, carbon monoxide $(\mathrm{CO})$, nitrogen oxide $(\mathrm{NO})$, total hydrocarbons $(\mathrm{HC})$, and oxygen $(\mathrm{O} 2)$. From this data and knowing the fuel chemistry $(\mathrm{C} / \mathrm{H} / \mathrm{O})$ the air fuel ratio was calculated. The software converted the dry emissions concentrations to wet using ambient air data. To ensure measurement accuracy, span gases were used to test the $\mathrm{CO} 2, \mathrm{CO}, \mathrm{NO}$ and $\mathrm{HC}$ analyzers. A pre-test and post-test zero and span of the analyzer was performed each time the spark plug or fuel was changed. The data was output in comma separated variable (csv) format which was post-processed in Excel. Raw gas measurement range, accuracy and resolution are shown in Table 3.1for the Semtech analyzer.

Table 3.1: Semtech analyzer measurement range, accuracy, and resolution

\begin{tabular}{|c|c|c|c|}
\hline & $\begin{array}{c}\text { Range of } \\
\text { Measurement }\end{array}$ & Accuracy & Resolution \\
\hline $\mathrm{CO} 2$ & $0-20 \%$ & $\pm 3 \%$ of reading or $\pm 0.1 \%$, whichever is greater & $0.01 \%$ \\
\hline $\mathrm{CO}$ & $0-8 \%$ & $\begin{array}{c} \pm 3 \% \text { of reading or } 50 \mathrm{ppm}, \text { whichever is } \\
\text { greater }\end{array}$ & $10 \mathrm{ppm}$ \\
\hline $\mathrm{NO}$ & $0-3,000 \mathrm{ppm}$ & $\pm 2 \%$ of meas. or $\pm 2 \%$ of $\mathrm{pt} 4$ & $0.1 \mathrm{ppm}$ \\
\hline $\mathrm{HC}$ & $0-40,000 \mathrm{ppmC} 1$ & $\begin{array}{c} \pm 2.0 \% \text { of reading or } \pm 100 \mathrm{ppmC} \text { whichever is } \\
\text { greater }\end{array}$ & $10 \mathrm{ppmC} 1$ \\
\hline
\end{tabular}

\subsubsection{Data Processing}

The data from the experiments collected by the NI system was processed using Matlab where the signals from the current probe were used for determining the engine speed and thermocouple data for temperatures. The code for finding the engine speed from the current signal data is provided in Appendix A.

\subsection{Test Plan}

The testing consisted of recording the engine performance and emissions for each of the two fuels (E10 and E15) with each of two spark plugs (stock spark plug and E3 spark plug). The test points were chosen based on the throttle position and the length of 
the string. By changing the length of the string on the trimmer, it effectively changed the load on the engine, which simulated cutting grass, yet was far more repeatable.

At the beginning of a test sequence, the engine was operated for 10 minutes to ensure a fully warmed up condition. The emissions and performance data were sampled after the engine was operated at a steady state test point for a predetermined time so as to maintain the cylinder head temperature at a stable value. The stability time for E10 fuel was three minutes and the sampling time was two minutes which resulted in a total test duration of five minutes. It took longer for the cylinder head temperature to stabilize when running on E15 fuel and hence an additional minute was added to the stability time. A summary of the test points is shown in Table 3.2.

Three different throttle positions were used in the test matrix and different loads were applied by changing the length of the string. The standard length of the string was 6.5 inches and different loads were applied by selecting three different string lengths summarized in Table 3.2. The throttle position settings included $0 \%$ (idle condition), 50\% and $100 \%$. For the $0 \%$ throttle position, only the stock string length of 6.5 inches was tested. Each combination was performed three times to ensure repeatability of the test results. 
Table 3.2: String trimmer test matrix

\begin{tabular}{|c|c|c|c|c|c|}
\hline Fuel & $\begin{array}{c}\text { Load } \\
\text { designation }\end{array}$ & $\begin{array}{l}\text { String length } \\
\text { (inches) }\end{array}$ & $\begin{array}{c}\text { Throttle } \\
\text { setting } \\
(\%) \\
\end{array}$ & $\begin{array}{c}\text { Stability } \\
\text { time } \\
\text { (minutes) }\end{array}$ & $\begin{array}{c}\text { Measurement } \\
\text { time (minutes) }\end{array}$ \\
\hline \multirow{4}{*}{$\begin{array}{c}\text { E10/Stock } \\
\text { plug }\end{array}$} & $0 \mathrm{~L}$ & 6.5 & $0 / 50 / 100$ & 3 & 2 \\
\hline & $1 \mathrm{~L}$ & 7.5 & $50 / 100$ & 3 & 2 \\
\hline & $2 \mathrm{~L}$ & 8.5 & $50 / 100$ & 3 & 2 \\
\hline & $3 \mathrm{~L}$ & 9.5 & $50 / 100$ & 3 & 2 \\
\hline \multirow{4}{*}{$\begin{array}{c}\text { E15/Stock } \\
\text { plug }\end{array}$} & $0 \mathrm{~L}$ & 6.5 & $0 / 50 / 100$ & 4 & 2 \\
\hline & $1 \mathrm{~L}$ & 7.5 & $50 / 100$ & 4 & 2 \\
\hline & $2 \mathrm{~L}$ & 8.5 & $50 / 100$ & 4 & 2 \\
\hline & $3 \mathrm{~L}$ & 9.5 & $50 / 100$ & 4 & 2 \\
\hline \multirow{4}{*}{$\begin{array}{c}\text { E10/E3 } \\
\text { plug }\end{array}$} & $0 \mathrm{~L}$ & 6.5 & $0 / 50 / 100$ & 3 & 2 \\
\hline & $1 \mathrm{~L}$ & 7.5 & $50 / 100$ & 3 & 2 \\
\hline & $2 \mathrm{~L}$ & 8.5 & $50 / 100$ & 3 & 2 \\
\hline & $3 \mathrm{~L}$ & 9.5 & $50 / 100$ & 3 & 2 \\
\hline \multirow{4}{*}{$\begin{array}{c}\text { E15/E3 } \\
\text { plug }\end{array}$} & $0 \mathrm{~L}$ & 6.5 & $0 / 50 / 100$ & 4 & 2 \\
\hline & $1 \mathrm{~L}$ & 7.5 & $50 / 100$ & 4 & 2 \\
\hline & $2 \mathrm{~L}$ & 8.5 & $50 / 100$ & 4 & 2 \\
\hline & $3 \mathrm{~L}$ & 9.5 & $50 / 100$ & 4 & 2 \\
\hline
\end{tabular}




\section{Chapter 4 Results}

The data from the experiments was processed as discussed in the previous section and the results are summarized in the present chapter. Each combination of the two ethanol blends of gasoline and the two types of spark plugs was conducted three times and the three tests for each combination was averaged as a single test denoted by the fuel and spark plug type, as shown in Table 4.1.

\section{Table 4.1: Notation of the different test combinations}

\begin{tabular}{|c|c|c|}
\hline Type of fuel & Type of plug & Notation \\
\hline E10 & Stock Plug (SP) & E10/SP \\
\hline E10 & E3 Plug (E3) & E10/E3 \\
\hline E15 & Stock Plug (SP) & E15/SP \\
\hline E15 & E3 plug (E3) & E15/E3 \\
\hline
\end{tabular}

The test series are summarized in four different sets based on the string length of the unit. In each of the sets the performance data and exhaust gas emissions for different throttle positions is summarized. The first test is performed with the string length at its standard length and three throttle positions $0 \%$ throttle, $50 \%$ throttle and $100 \%$ throttle opening. The remaining three test sets are were conducted with the string length setting of $1 \mathrm{~L}, 2 \mathrm{~L}$ and $3 \mathrm{~L}$ where only $50 \%$ and $100 \%$ throttle positions were used.

\section{$4.10 \%$ Throttle (Idle) Results}

This test was conducted by setting the string length of the string trimmer at its standard length of 6.5 inches. The test was conducted with $0 \%$ throttle opening or idle condition.

Because the string trimmer has a two-stroke, spark-ignition engine, the $0 \%$ throttle tests are grouped separately for better data analysis from an emissions stand point. Despite the poor combustion quality during idle there were differences in the engine speeds with the change in fuels, as observed previously from other researchers. Using the stock spark plug, the engine had a higher idle speed on E15 compared to E10, as shown in Figure 4.1. A slight increase in idle speed was noted for the E3 spark plug on 
E10, but the variability in engine speed increased measurably as well. The reduction in idle speed for the E15/E3 combination was a more difficult and unexpected result to explain.

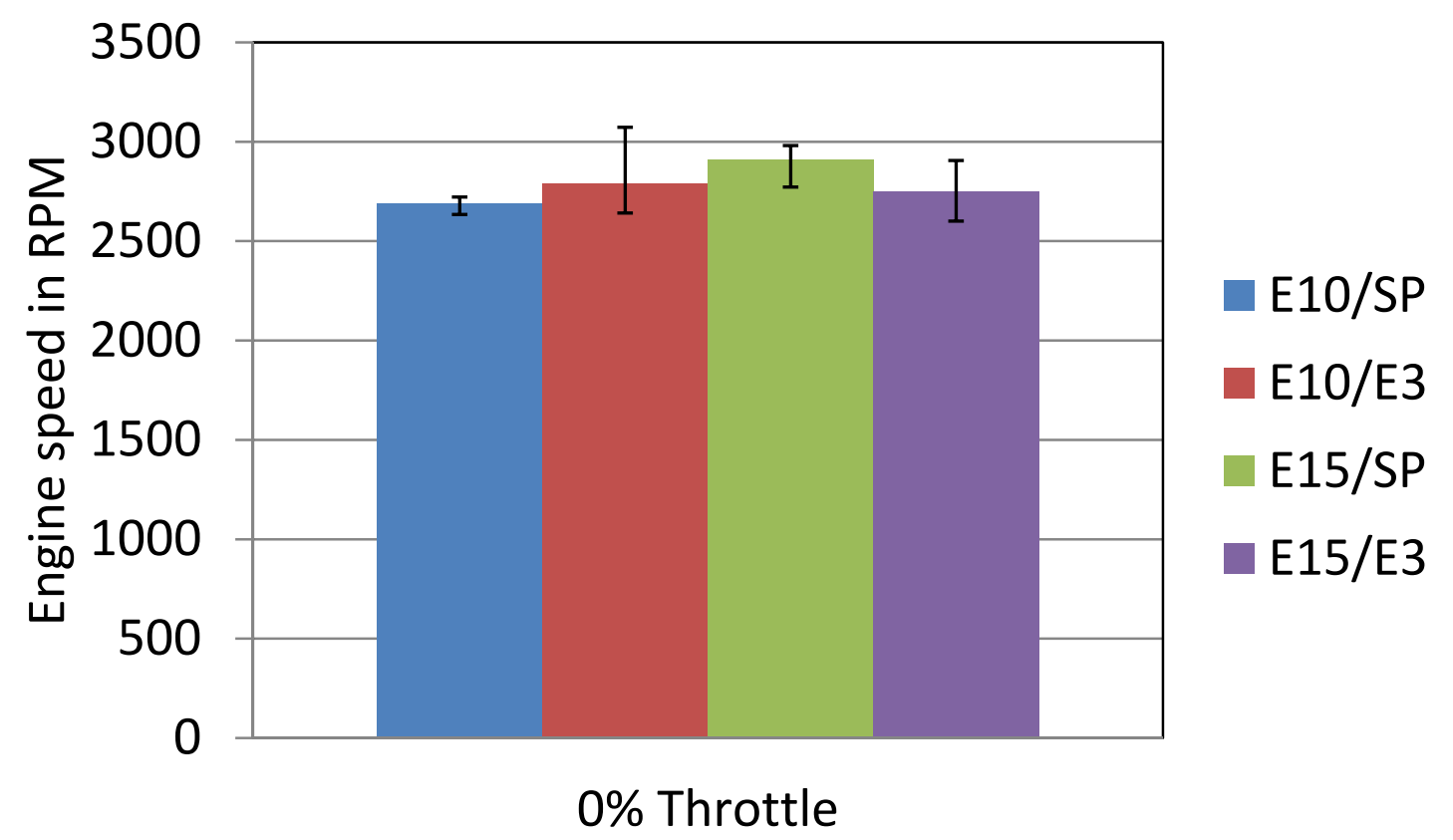

Figure 4.1: Engine speed for OL load with $0 \%$ throttle

The cylinder head temperature for E15/E3 configuration, Figure 4.2 showed the highest values of all four combinations. This information combined with the fact that the engine speed was low leads to the hypothesis that the combination of E15 and E3 spark plug may have changed the combustion timing to the extent that increased negative work on the piston results, raising the in-cylinder temperatures and slowing the engine speed. 


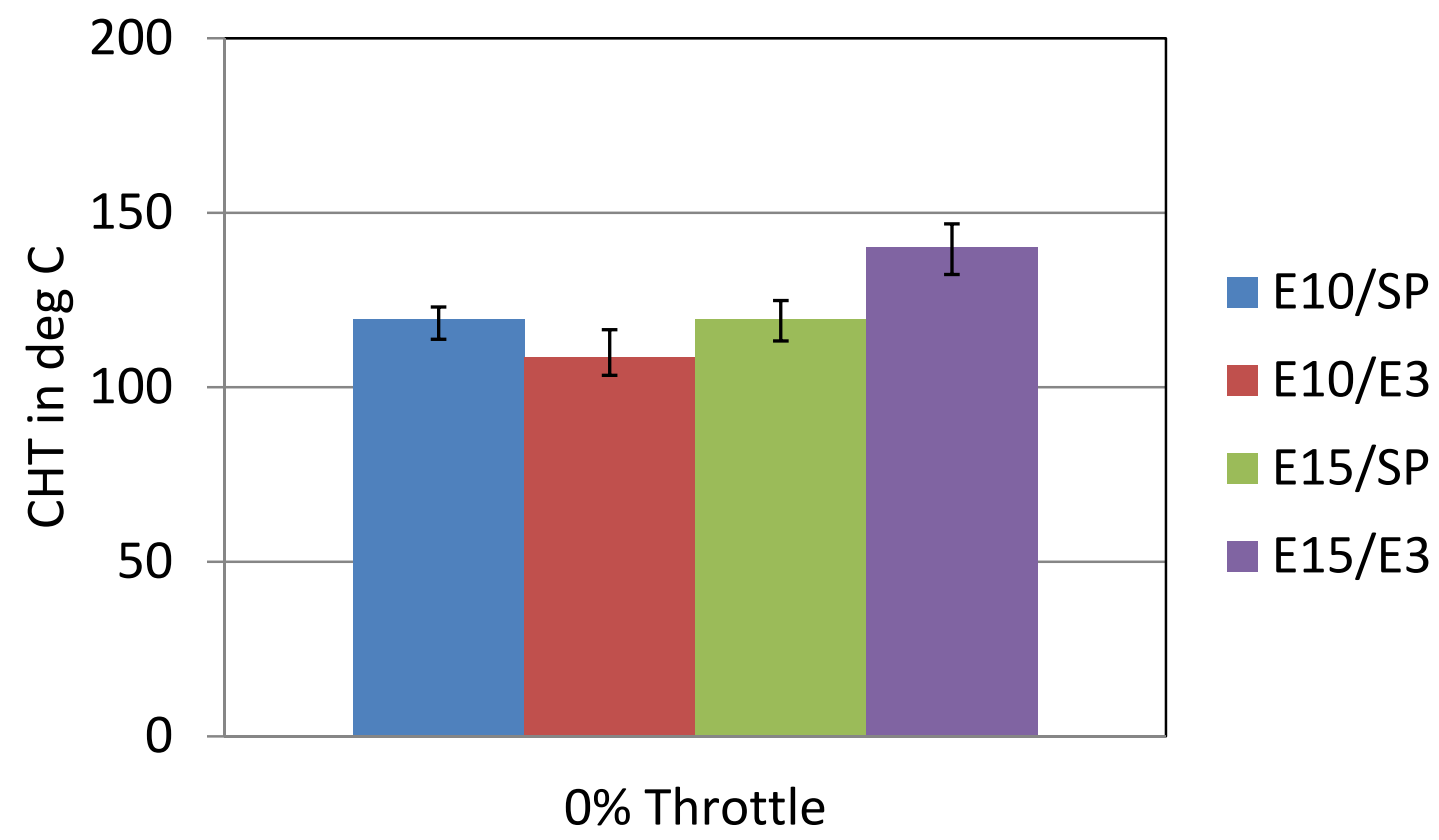

Figure 4.2: Cylinder head temperature for 0L load with $0 \%$ throttle

As shown in Figure 4.3, the exhaust gas temperatures for the different combinations changed very little, except for the E15/E3 combination.

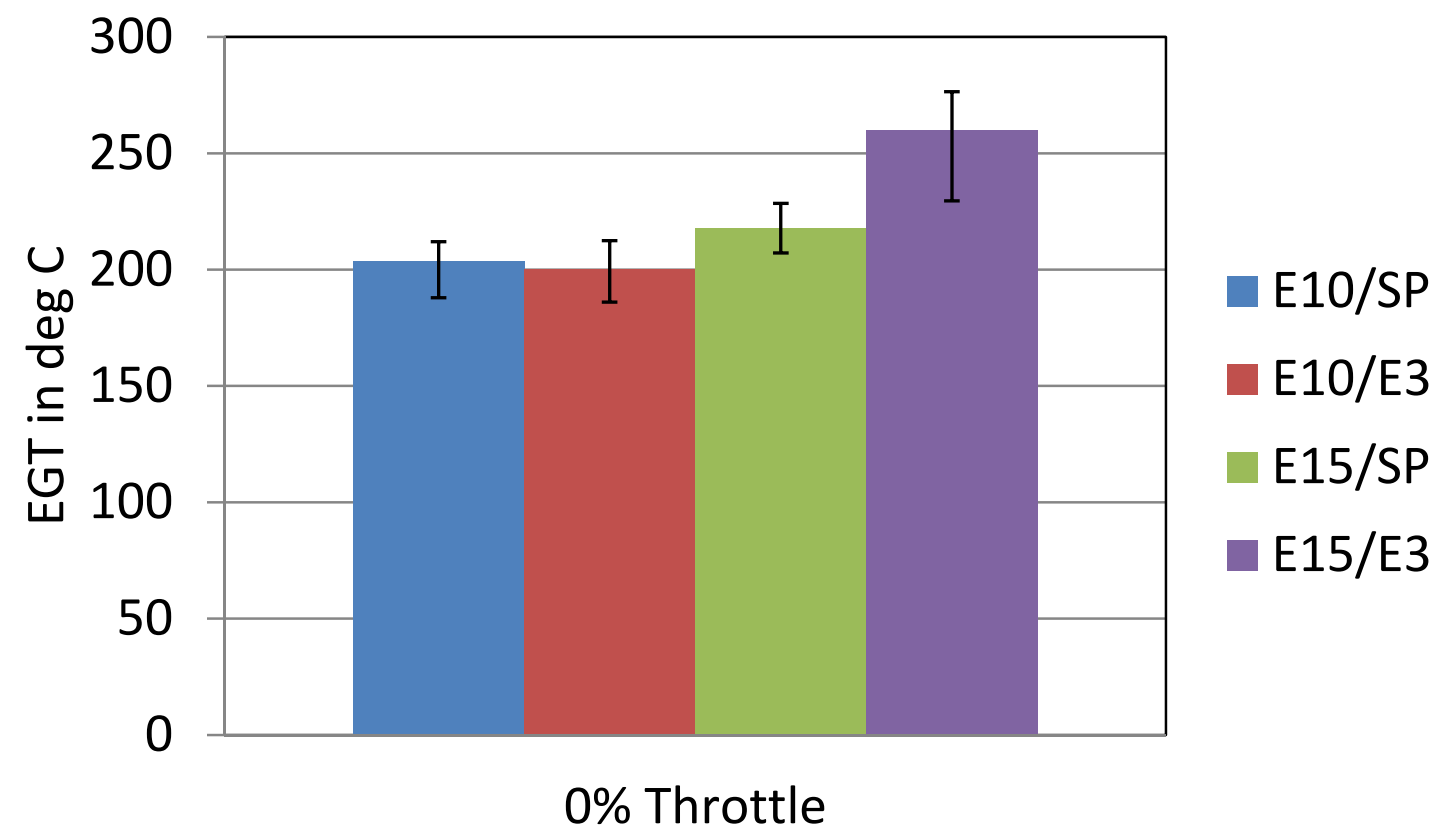

Figure 4.3: Exhaust gas temperature for $0 \mathrm{~L}$ load with $0 \%$ throttle 
One of the results of poor combustion at idle was the hydrocarbon levels exceeded the measurement range of the analyzer. Typically the emissions results are reported on a mass basis, but with the $\mathrm{HC}$ emissions range exceeded at idle, raw concentrations are presented for $\mathrm{CO} 2, \mathrm{CO}$, and $\mathrm{NO}$. The $\mathrm{CO} 2$ emissions are very low for a spark-ignition engine as a result of high levels of unburned fuel (HC). $\mathrm{CO} 2$ emissions are shown in Figure 4.4, where a consistent trend of increased variability was noted for E3 spark plugs. An especially high level of variability was noted for the E15/E3 combination.

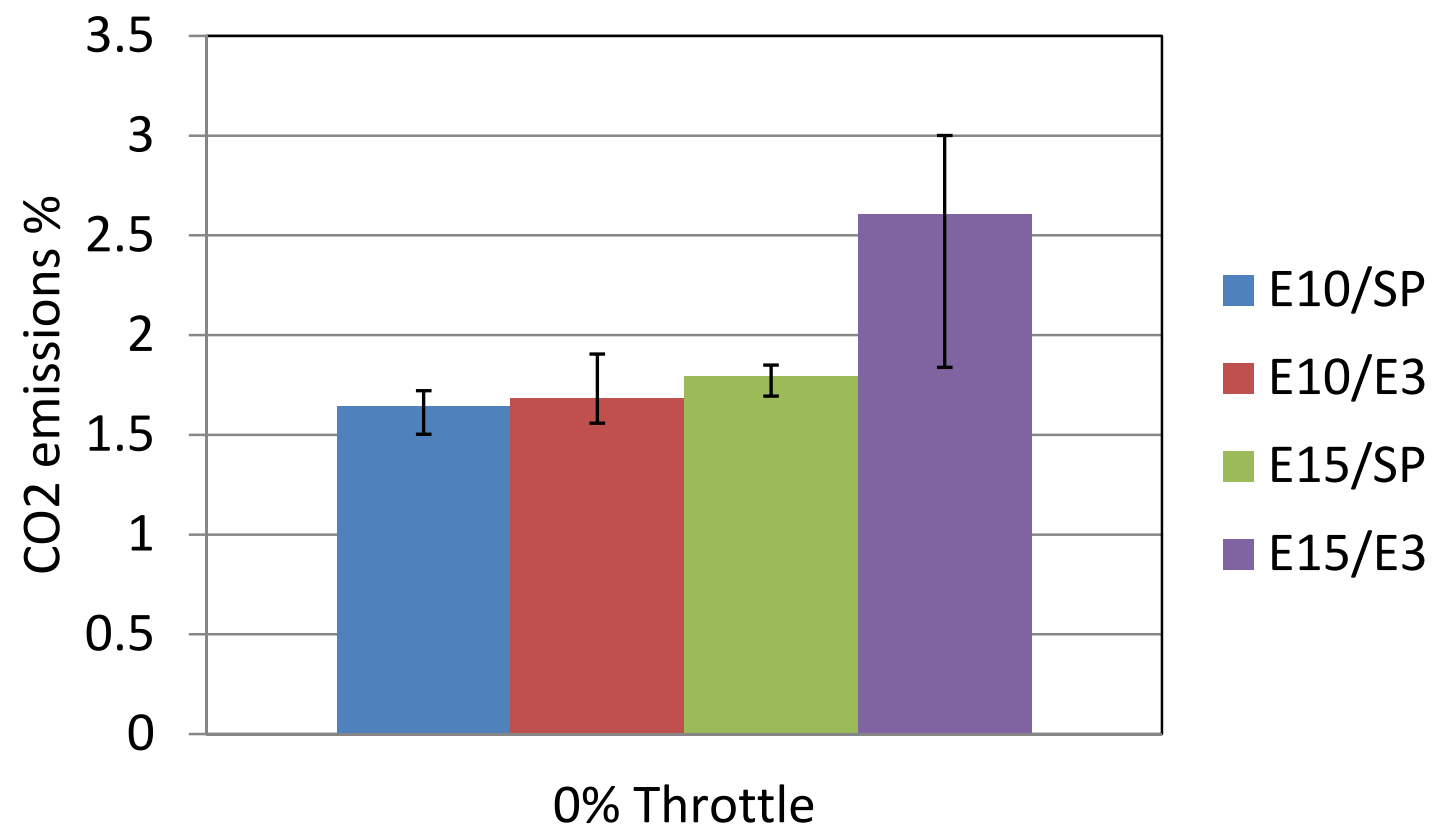

Figure 4.4: CO2 emissions for 0L load with $0 \%$ throttle

The $\mathrm{CO}$ emissions, shown in Figure 4.5, are quite high as expected, due to the poor combustion at this throttle setting. Again, a large range of emissions values were recorded for the E15/E3 combination. 


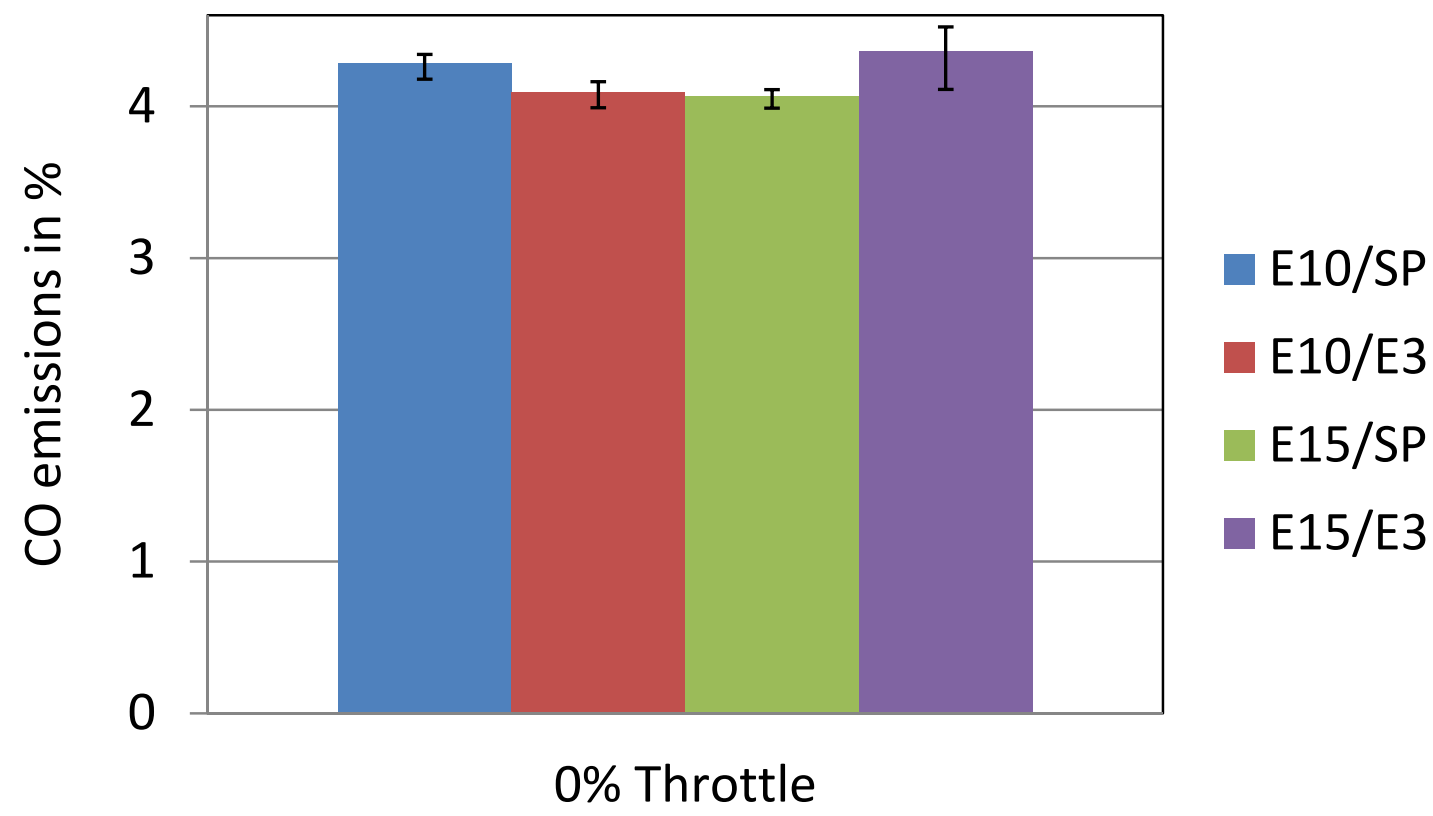

Figure 4.5: CO emissions for $0 \mathrm{~L}$ load with $0 \%$ throttle

The NO formation during idle was very low as the combustion temperatures were low at idle. Figure 4.6 shows the NO emissions in ppm which were very close to zero and E15 fuel with stock plug recorded no formation of NO. 


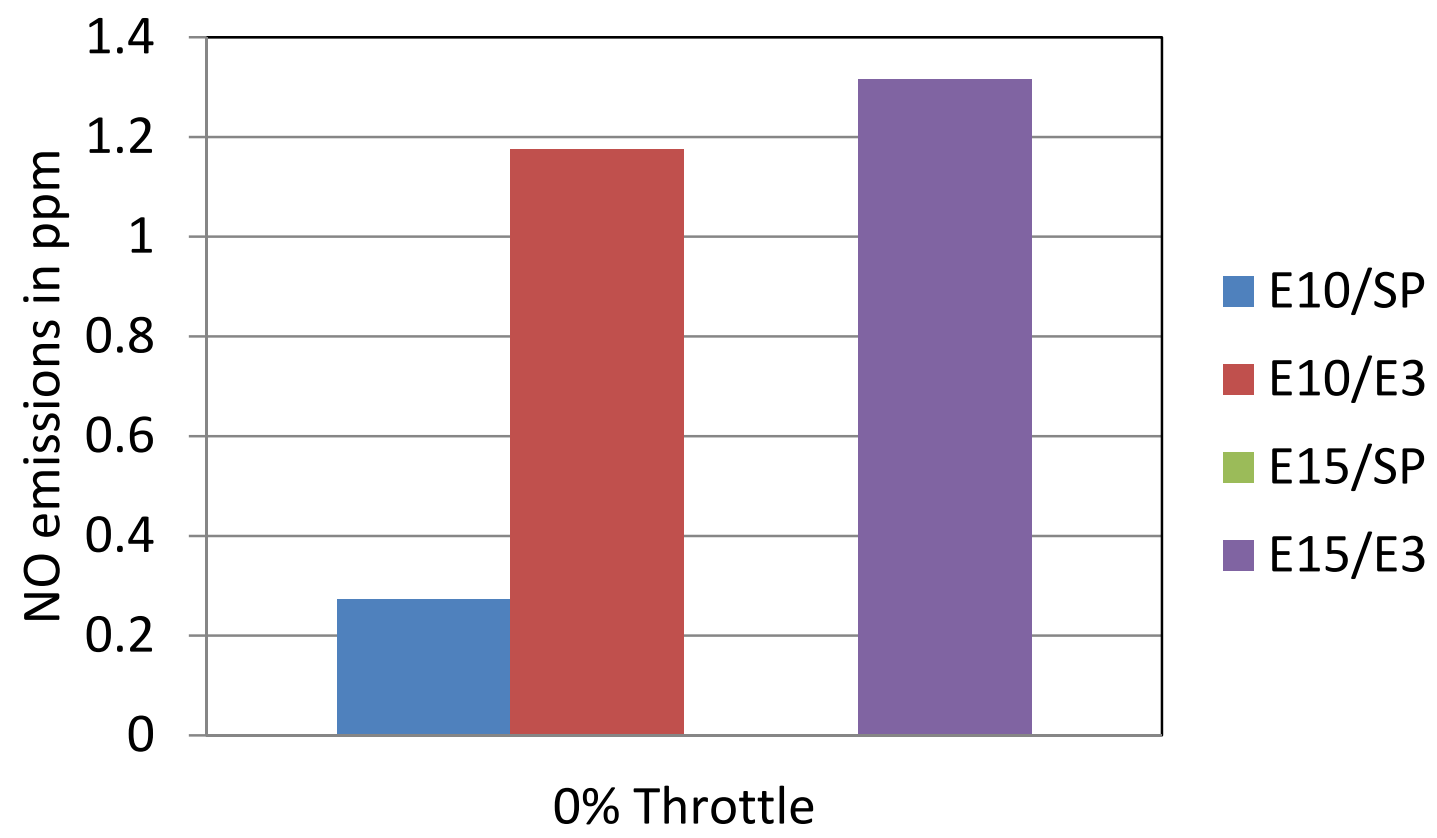

Figure 4.6: NO emissions for $0 \mathrm{~L}$ load with $0 \%$ throttle

\section{$4.250 \%$ Throttle Results}

The $50 \%$ throttle setting was used to check the engine performance at partial throttle. Figure 4.7 shows the speeds of the engine at $50 \%$ and $100 \%$ throttle in order to compare both the throttle settings. The results indicate very little or no deviation in the engine speed between the two throttle settings. 


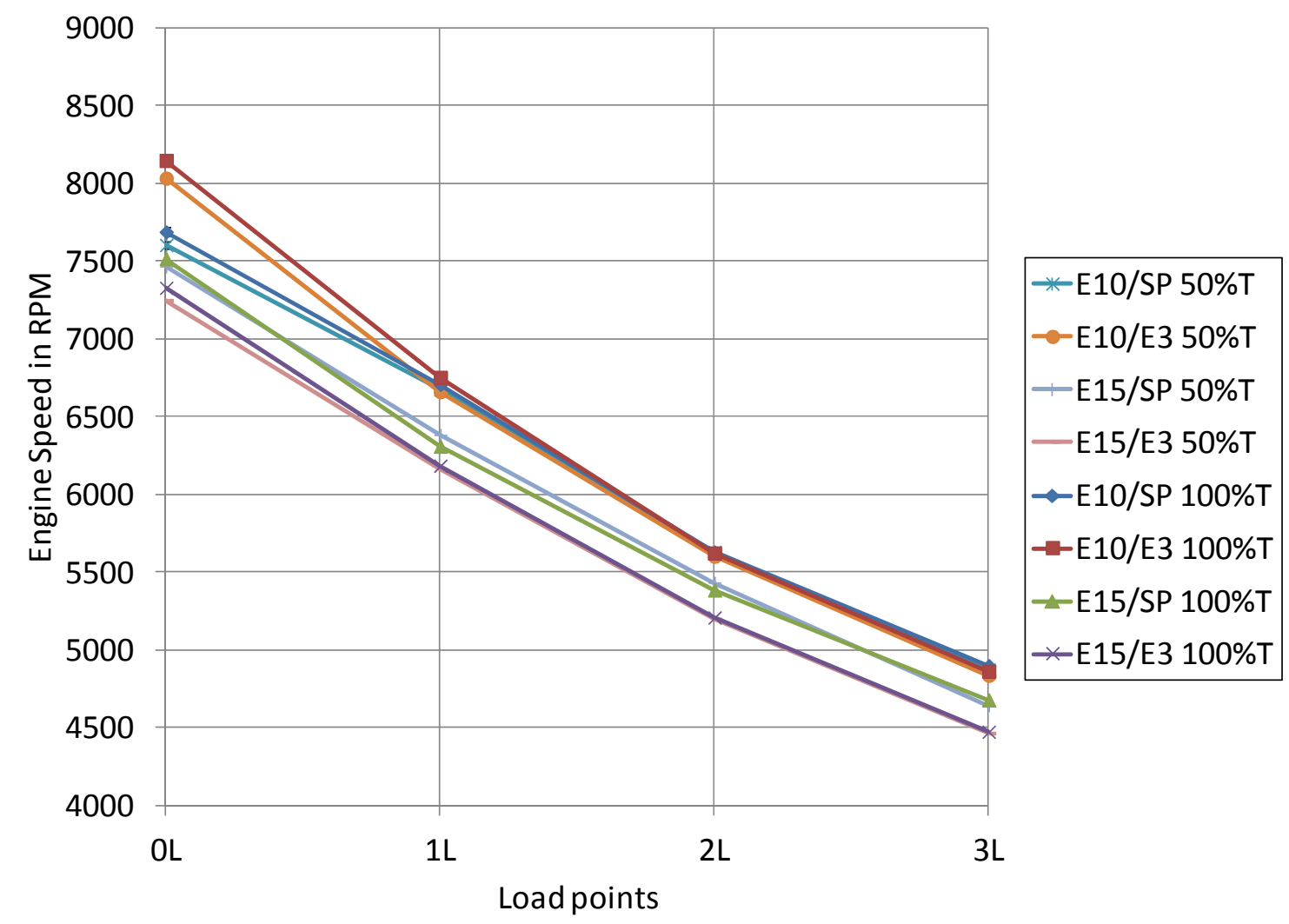

Figure 4.7: Comparison of engine speed for $50 \%$ and $100 \%$ throttle setting

The elimination of the $50 \%$ throttle position for the analysis was statistically determined with the help of Minitab. Results from Minitab are shown in Figure 4.8. The results show the change in engine speed when the test conditions are varied. The engine speed does not vary statistically between the $50 \%$ and $100 \%$ throttle positions. The variation in the speed was statistically significant between the E10 and E15 fuel and also between the different load points which was expected. 


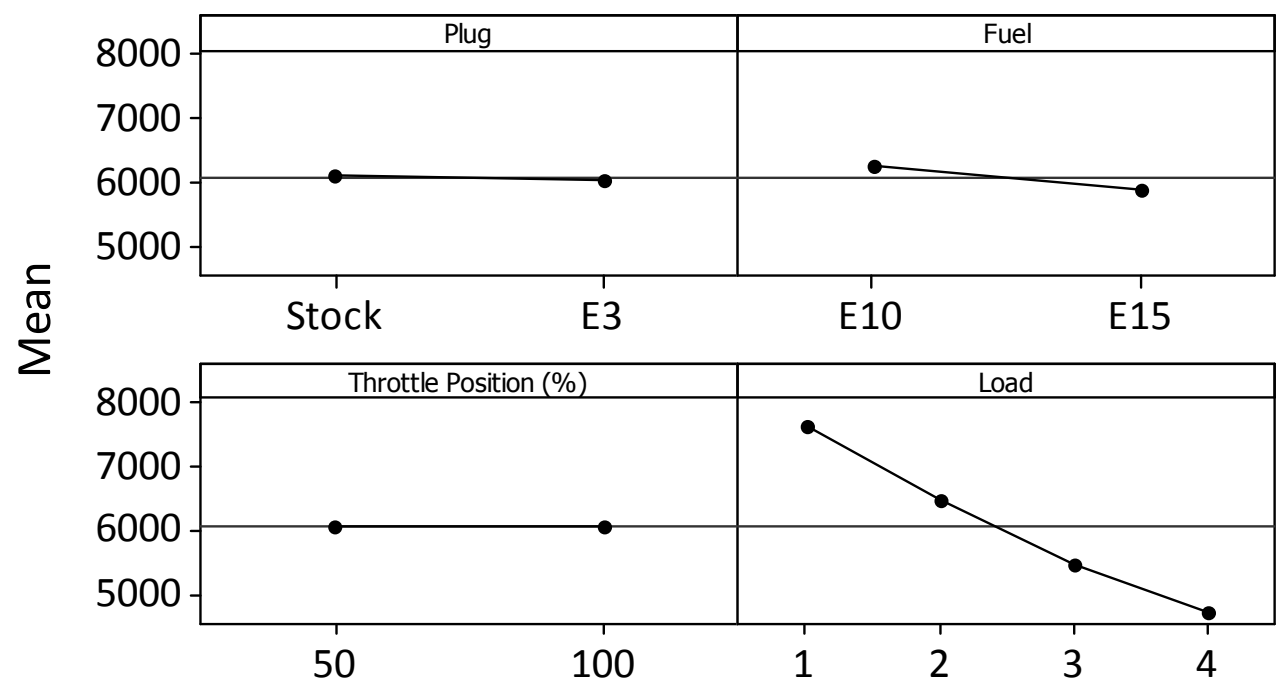

Figure 4.8: Data means for engine speed for different test variables

Additional parameters such as CHT and EGT were also investigated in Minitab, and no significant difference between $50 \%$ and $100 \%$ throttle was noted. Since little variance between the $50 \%$ and $100 \%$ throttle positions was identified, the following report concentrates on the results for the $100 \%$ throttle setting. The data for the $50 \%$ throttle and additional statistical analysis results are included in Appendix A.2 for reference.

\section{$4.3100 \%$ Throttle Results}

A summary of the engine speed results are shown in Figure 4.9. As string length (load) was increased, engine speed steadily decreased. For the 0L load case, the E10/E3 combination had the highest engine speed and the E15/E3 combination had the lowest engine speed. The difference was approximately 820 RPM. The E3 spark plug increased engine speed with E10 fuel and decreased engine speed with E15 fuel. The engine speed was lower with E15 fuel, regardless of the spark plug compared to E10 due to the reduced lower heating value of E15. 


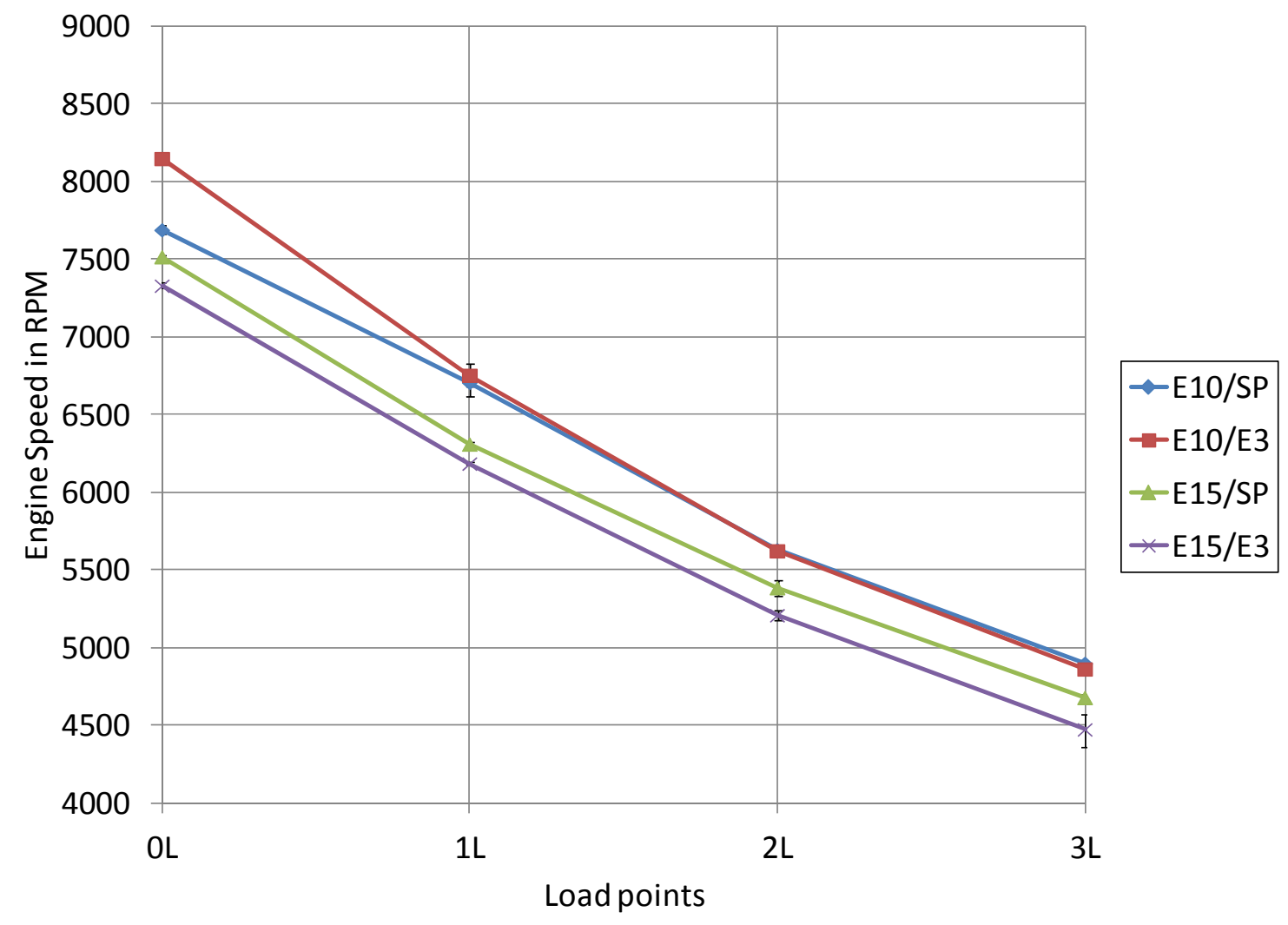

Figure 4.9: Engine speed for $100 \%$ throttle

The cylinder head temperature results are shown Figure 4.10. The CHT for the E15/E3 combination was the highest for all string lengths. The lowest CHT was recorded for the E15/SP combination for all throttle positions. The E3 spark plugs had higher CHT's regardless of the fuel used. The reduction in temperature when switching from E10 to E15 with the stock spark plug is expected, due to the reduced lower heat value of the fuel. However, the consistent increase in temperature for the E3 spark plug shows that this spark plug alters the characteristics of the combustion in the engine. 


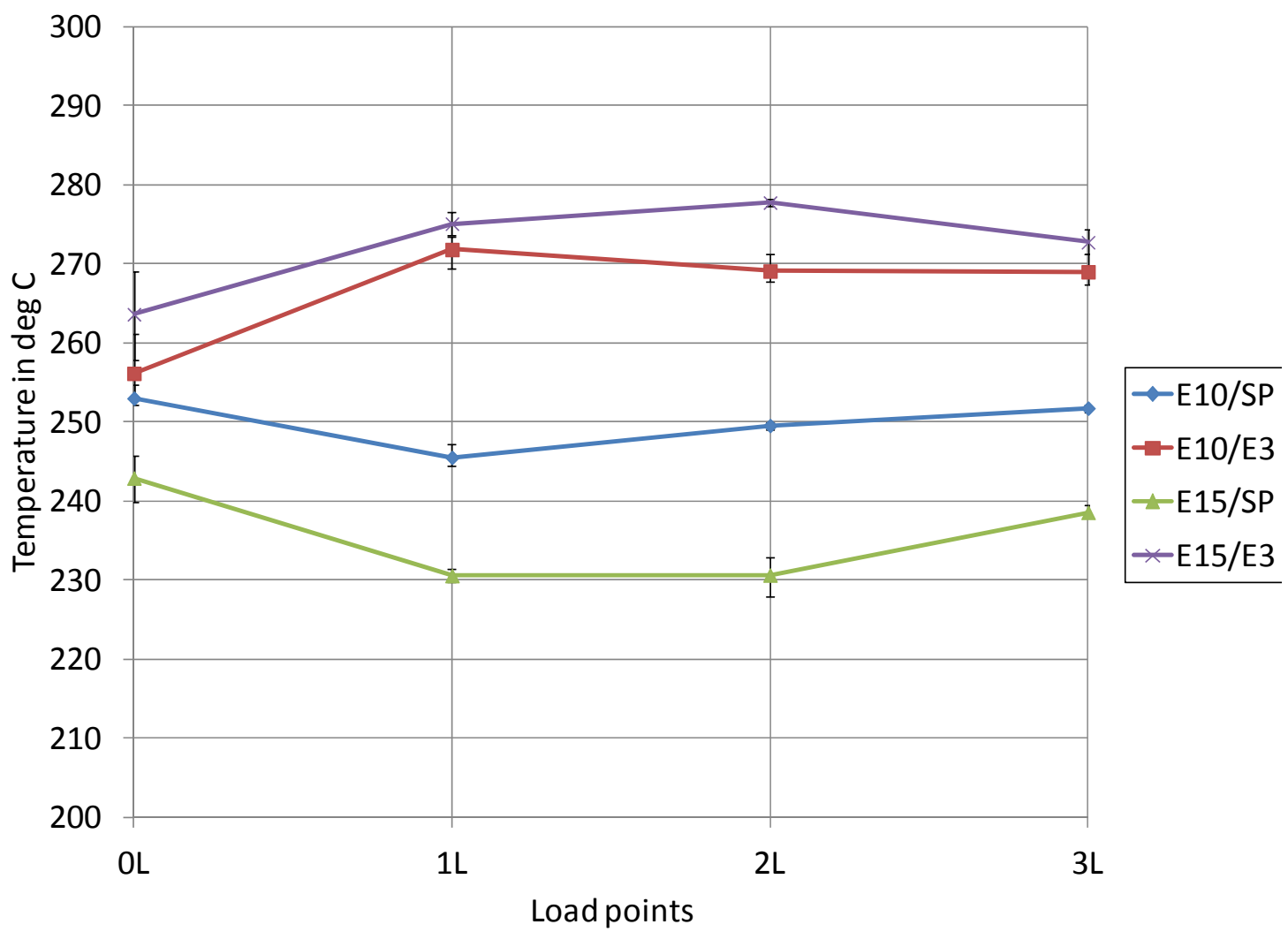

Figure 4.10: Cylinder head temperature for $100 \%$ throttle

The exhaust gas temperature results are summarized in Figure 4.11. A consistent reduction in EGT with increasing load (string length) is observed. As load increases, the engine speed decreases, which reduces the draw through the carburetor and thus less fuel is inducted into the engine. The E15/E3 combination had the lowest exhaust gas temperature, but the highest cylinder head temperature. E10/SP showed the highest exhaust gas temperature yet the second lowest cylinder head temperature. When comparing between different spark plugs, the E3 plugs lowered the exhaust temperature for both fuels, regardless of string length. 


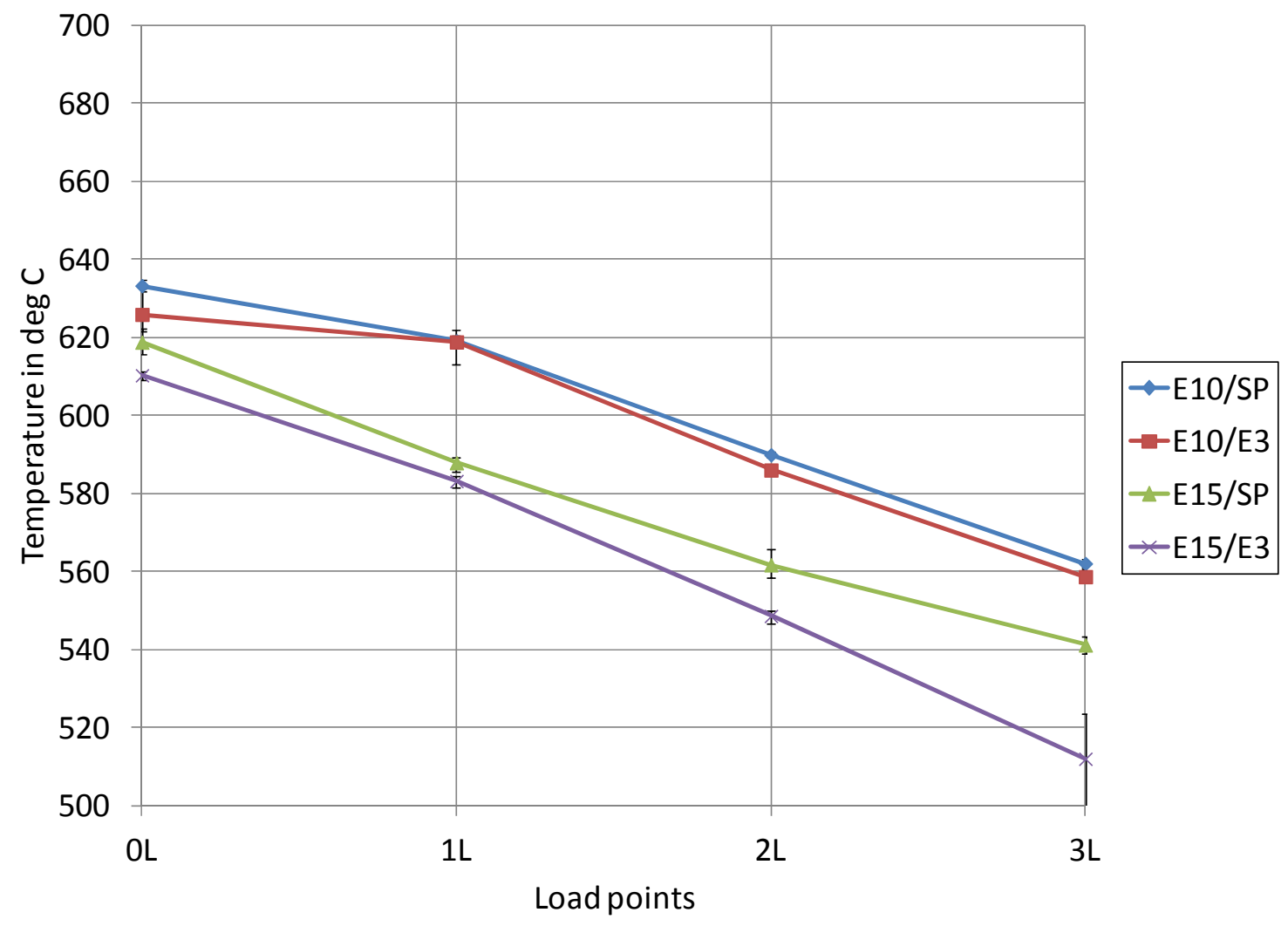

Figure 4.11: Exhaust gas temperature for $100 \%$ throttle

$\mathrm{CO} 2$ emissions are shown in Figure 4.12. The formation of $\mathrm{CO} 2$ was much higher than CO indicating significantly increased combustion efficiency but also increased fuel consumption compared to the emissions at idle. 


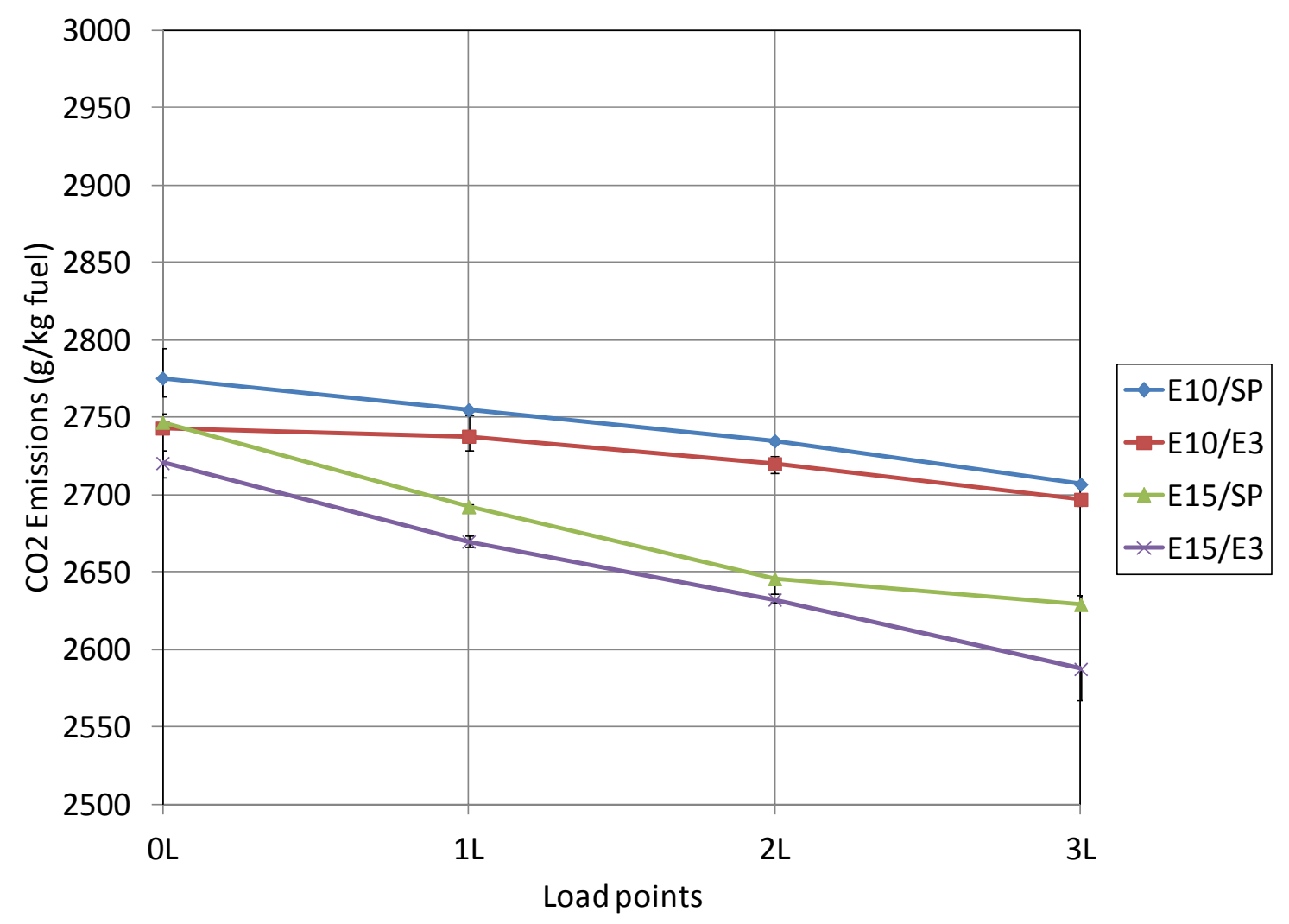

Figure 4.12: CO2 emissions for $100 \%$ throttle

The CO formation decreased significantly from idle, as shown in Figure 4.13. This is common for SI engines where the $\mathrm{CO}$ formation is accelerated at idle due to the rich mixture and poor combustion quality which can be confirmed by the presence of the high amount of $\mathrm{HC}$ at idle. A significant increase in $\mathrm{CO}$ was measured for the E10/E3 combination, perhaps due to reduced combustion quality. A consistent reduction in $\mathrm{CO}$ emissions with E15 fuel, regardless of spark plug, was identified. This is consistent with previously published results related to E15 positive impacts on emissions. The CO formation was directly impacted by the amount of oxygen in the cylinder, and oxygenated fuels provide immediate oxygen for the combustion event. 


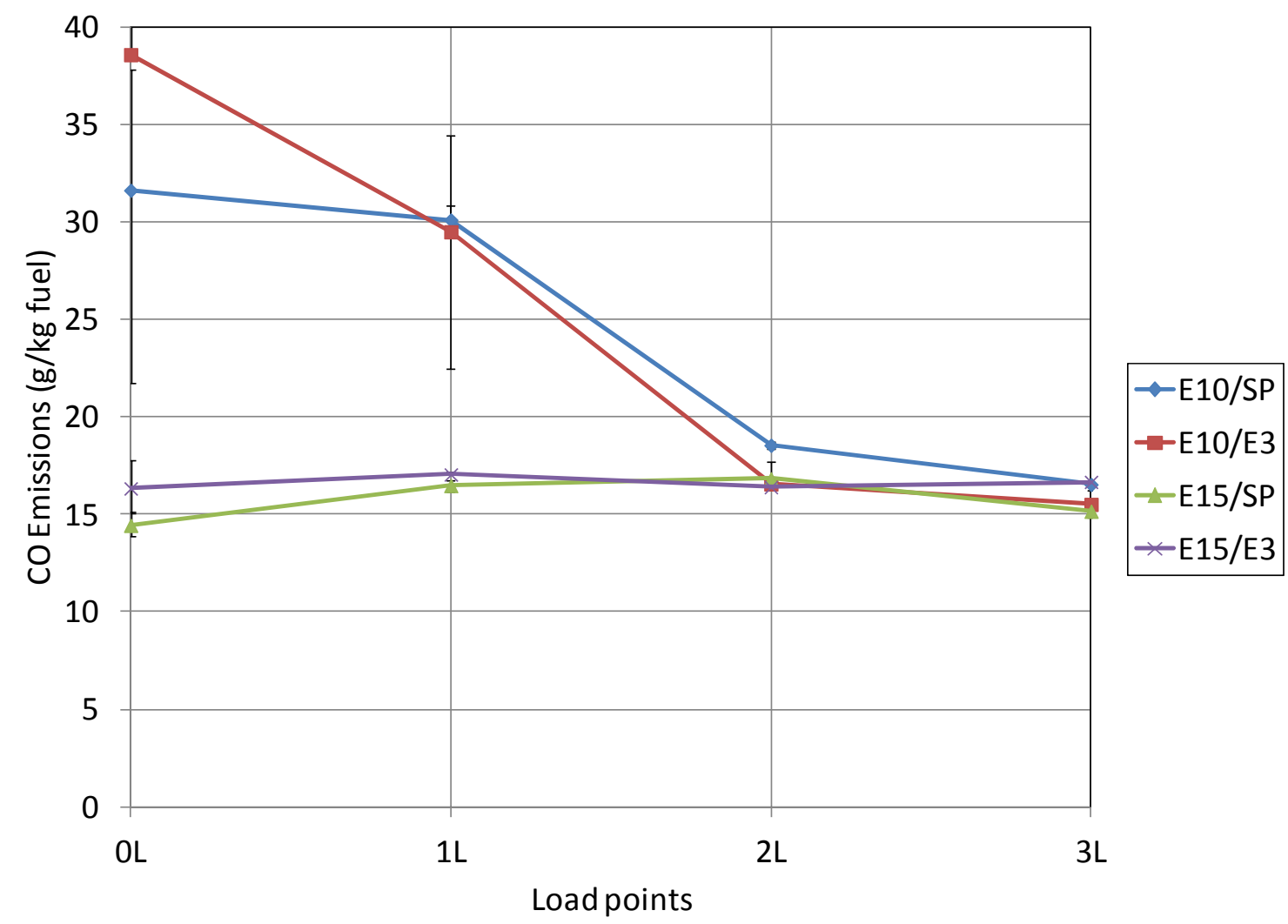

Figure 4.13: CO emissions for $100 \%$ throttle

NO emissions for the four combinations are shown in Figure 4.14. The NO formation increased as the throttle was opened due to a rise in the combustion temperatures. While the E3 spark plugs reduced the NO emissions with E10 fuel, it tended to increase NO emissions with E15 fuel. Note the significant increase in NO variability with the E3 spark plug, regardless of load setting. 


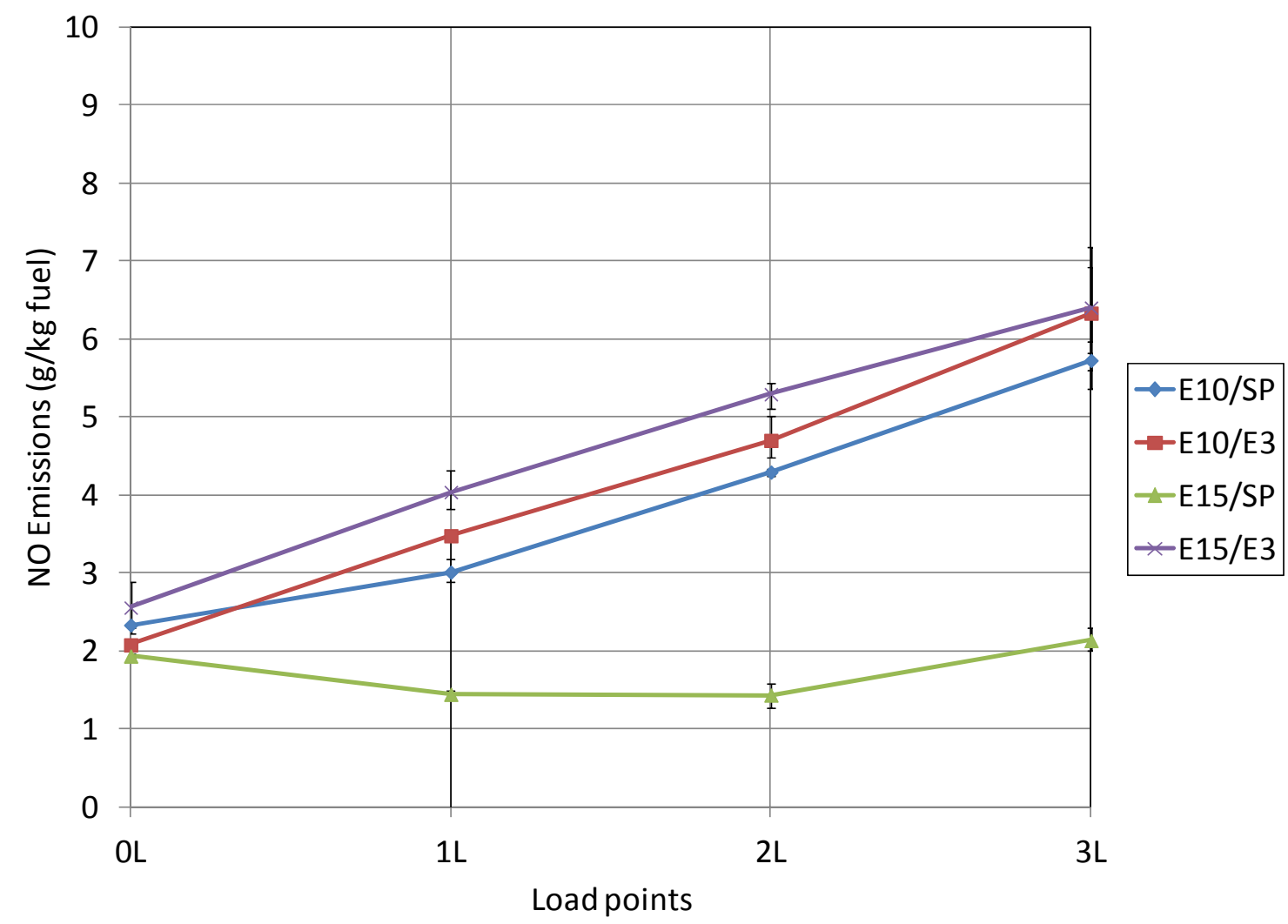

Figure 4.14: NO emissions for $100 \%$ throttle

The $\mathrm{HC}$ emissions gives the amount of un-burnt fuel that gets out through the exhaust port and since the string trimmer uses a two stroke engine, the HC emissions consists of the lubrication oil that was mixed with the gasoline. The HC significantly decreased at when compared to the $0 \%$ throttle position and E15/E3 had highest values of through all the load positions and E10/SP showed the least HC emissions. Figure 4.14 shows the trends in the formation of $\mathrm{HC}$ and the E15/E3 combination is seen as statistically higher than the rest of the combinations. 


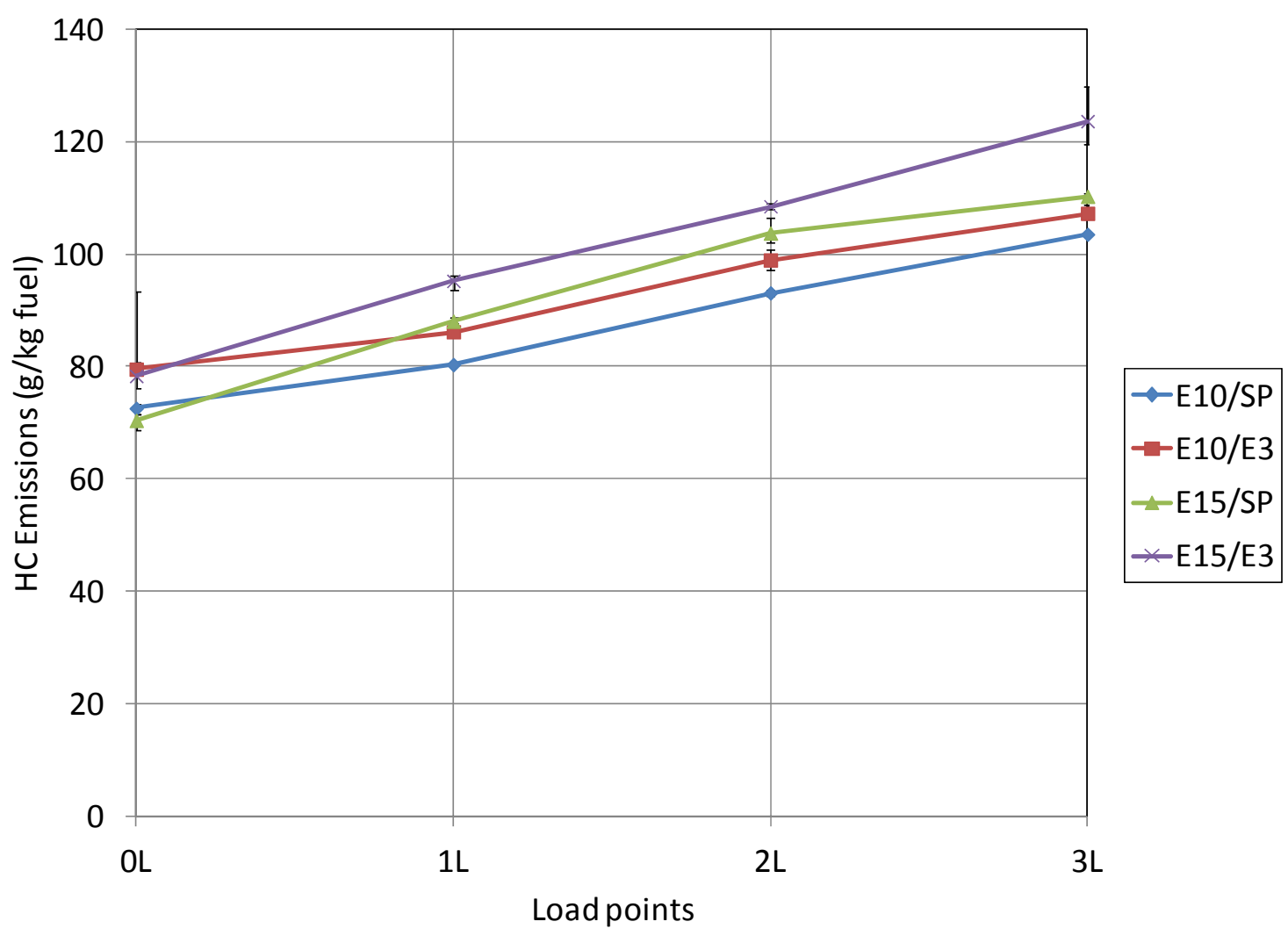

Figure 4.15: $\mathrm{HC}$ emissions for $100 \%$ throttle

\subsection{Summary}

The two-stroke engine was tested for three different throttle positions namely, $0 \%, 50 \%$, and $100 \%$. It was noted that the $50 \%$ throttle position results did not vary significantly from the $100 \%$ throttle position. The load on the engine was applied by increasing the length of the cutting string to three lengths beyond the stock length. The engine performance for each of the string lengths was evaluated at $0 \%$ and $100 \%$ throttle positions. The $0 \%$ throttle was applied only for the stock string length and $50 \%$ and $100 \%$ throttle position was applied for all the string lengths. Each of these test combinations were performed three times. The $50 \%$ test condition was removed from the analysis as it was found to be statistically insignificant with $100 \%$ throttle position.

The idle condition was the least consistent of all the tests and on multiple occasions, the engine stopped running before the end of the test. The combustion was 
very poor at idle and was represented in the emissions data which made it difficult to draw definite trends about the impact of E15 or E3 spark plugs.

The speed of the engine for the E3 spark plug, while running on E10 fuel, was higher than the stock spark plug at lighter loads but decreased at higher loads. The engine speed for the E3 spark plug running on E15 fuel was lower than the stock spark plug for all the test cases.

The cylinder head temperature was notably higher and the exhaust gas temperature was lower for the E3 spark plug with either fuel, compared to the stock spark plug.

The $\mathrm{CO} 2$ emissions for the E15/E3 combination were the same as the E10/SP for light loads and decreased for high loads. CO emissions were low at light loads and increased with E10/SP at the highest load. The NO and HC emissions for E15/E3 were higher than E10/SP for all load points.

The trend of the E3 spark plug having the higher CHT, lower EGT than stock plug and yet running at a lower speed could be due to the advance in combustion timing caused by the diamond shaped ground electrode. The energy released from the E3 spark plug may have been more widely distributed in the combustion chamber, igniting more of the air-fuel mixture and causing a high heat release rate early in the combustion cycle. This could be further validated with cylinder pressure analysis. 


\section{Chapter 5 Conclusions and Future Work}

\subsection{Conclusions}

After testing the string trimmer for different test cycles which included combinations of E10 versus E15 fuel and stock versus E3 spark plug and running each test point for three times, the following can be concluded about the performance of the E3 spark plug.

The E3 plug caused the engine to run slower than the stock plug which resulted in less fuel consumption. It caused high cylinder head temperatures which has the possibility of reducing the engine life and high NVH (high NVH was noticed during testing but there is no scientific data to support this observation). The emissions were higher with the E3 spark plug which could be the result of possible combustion advance.

Mid-level ethanol fuel had an effect on the performance and emissions of the two stroke engine. E15 fuel caused the engine to run slower irrespective of the spark plug used. E15 fuel reduced the $\mathrm{CO} 2$ and $\mathrm{CO}$ emissions while increasing hydrocarbons emissions. The cylinder head temperature was not influenced by the ethanol content but exhaust gas temperature decreased with E15.

E3 spark plug when running on E15 fuel had the lowest engine speed and exhaust gas temperature, while the cylinder head temperature was the highest for all load points. Carbon emissions ( $\mathrm{CO} 2$ and $\mathrm{CO}$ ) where low for this combination while having the highest $\mathrm{NO}$ and $\mathrm{HC}$ emissions. The high cylinder head temperature combined with the low exhaust gas temperature and engine speed suggests advancement in combustion timing. This was expected due to the reduced ignition delay and potentially larger flame kernel from the E3 spark plugs. These conclusions show that the E3 spark plugs did not improve the performance or the emissions for the string trimmer that was tested using E15 as the fuel. 


\subsection{Future Work}

Need combustion analysis of the engine to determine if the theory of advanced combustion is valid and to investigate why the cylinder head temperatures are high and low exhaust gas temperature and engine speed for E3 plug.

Test on a dynamometer with instantaneous fuel consumption to determine the emission in $\mathrm{g} / \mathrm{kW}$-hr so to compare with EPA emission norms.

Testing the equipment for the noise and vibration for the different combinations of fuels and spark plugs can provide insight if the higher cylinder head temperatures caused by E3 plugs is a potential problem for the structural integrity for the string trimmer. 


\section{Bibliography}

1. http://www.epa.gov/otaq/regs/fuels/additive/e15/index.htm

2. H.R. $6\left(100^{\text {th }}\right)$ : Energy Independence and Security Act of $2007,110^{\text {th }}$ Congress, 20072009.

3. "Effects of Intermediate Ethanol Blends on Legacy Vehicles and Small Non-Road Engines, Report 1", Bran West, Keith Knoll, Wendy Clark, Ronald Graves, John Orban, Steve Przesmitzki, and Timothy Theiss, NREL/TP-540-43543.

4. "High Ethanol Fuel Endurance: A Study of the Effects of Running Gasoline with 15\% Ethanol Concentration in Current Production Outboard Four-Stroke Engines and Conventional Two-Stroke Outboard Marine Engines", David Hilbert, NREL/SR-540052909

5. http://www.e3sparkplugs.com 


\section{Appendix A}

\section{A.1 Matlab code for engine speed calculation}

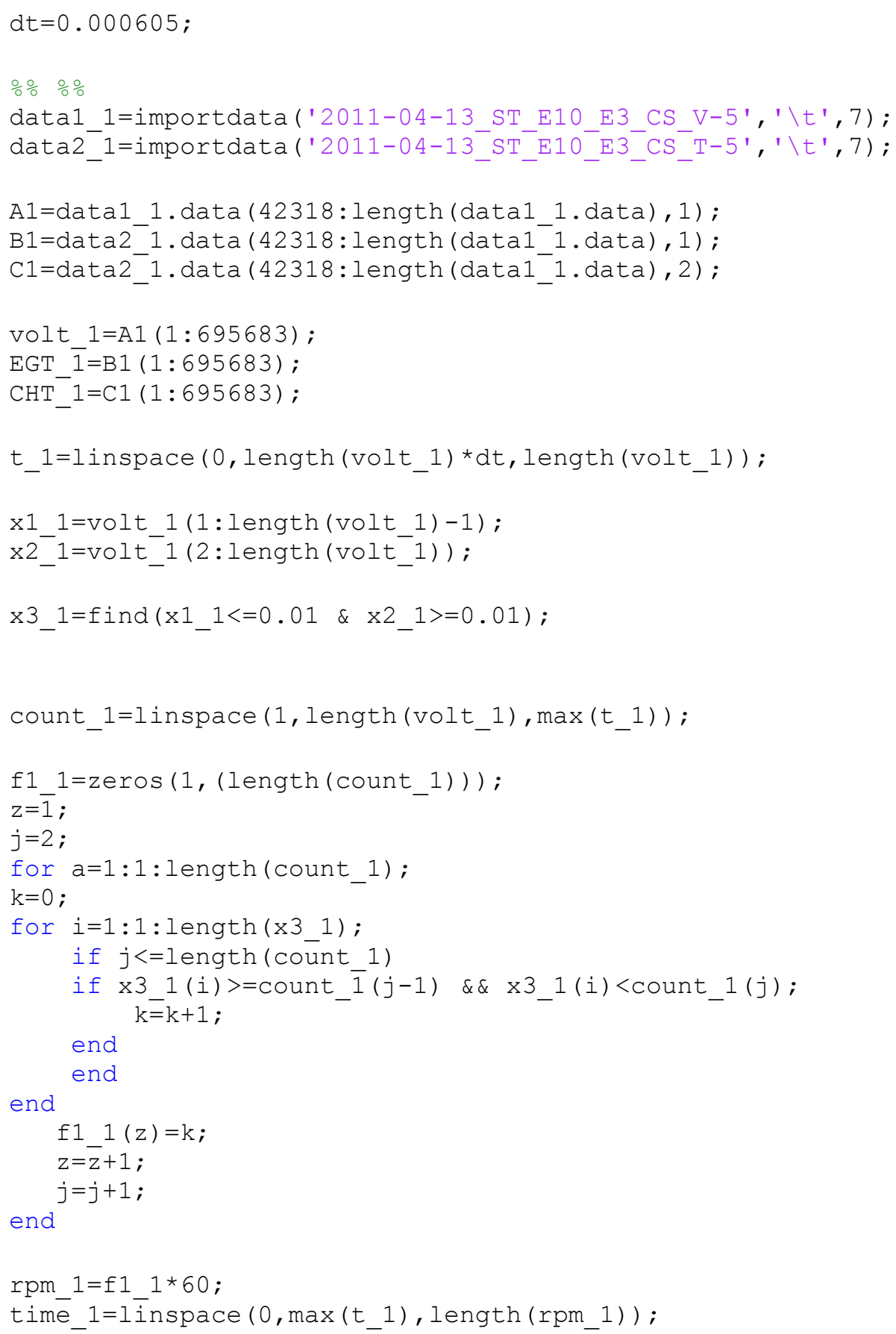




\section{A.2 Additional plots for reference}

A.2.1 OL load

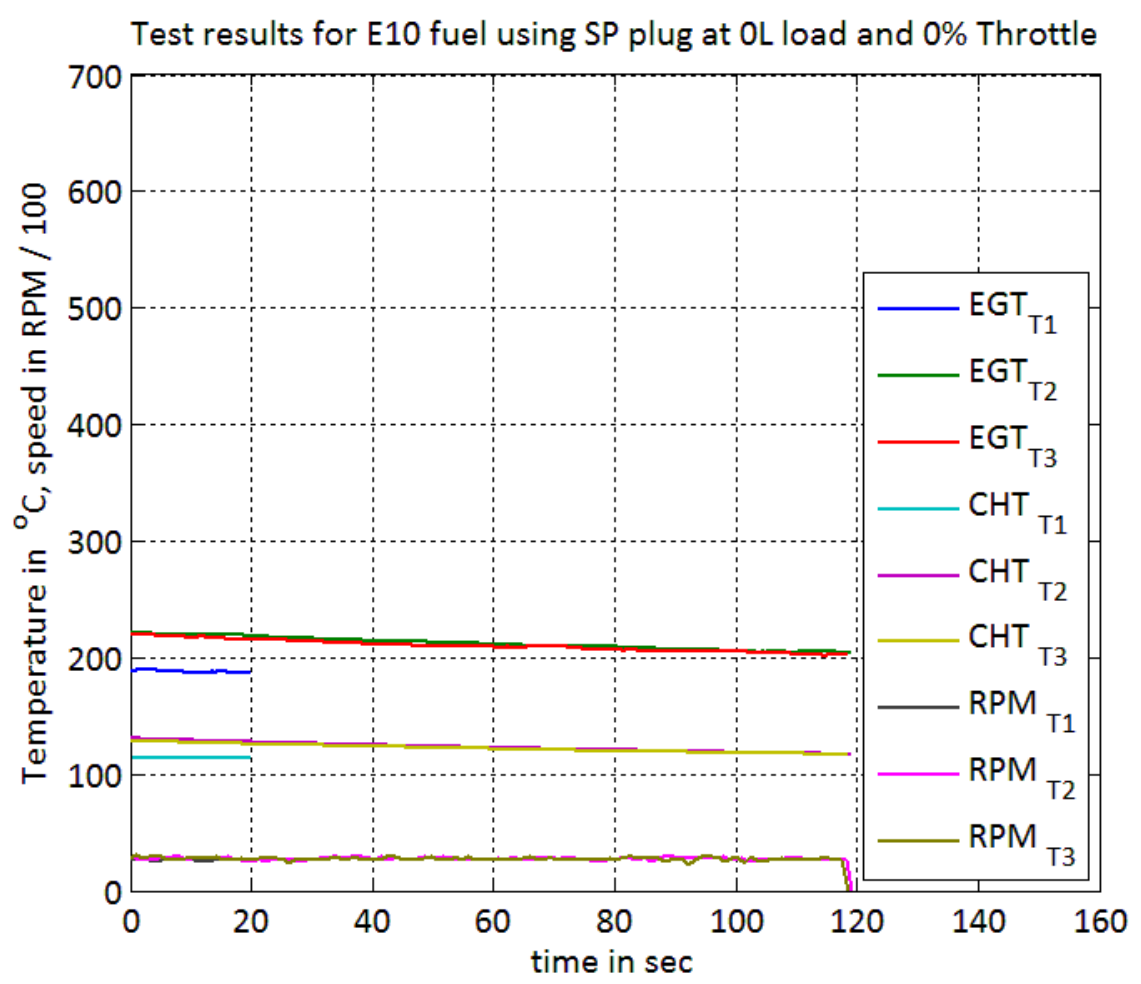

Figure A.1 


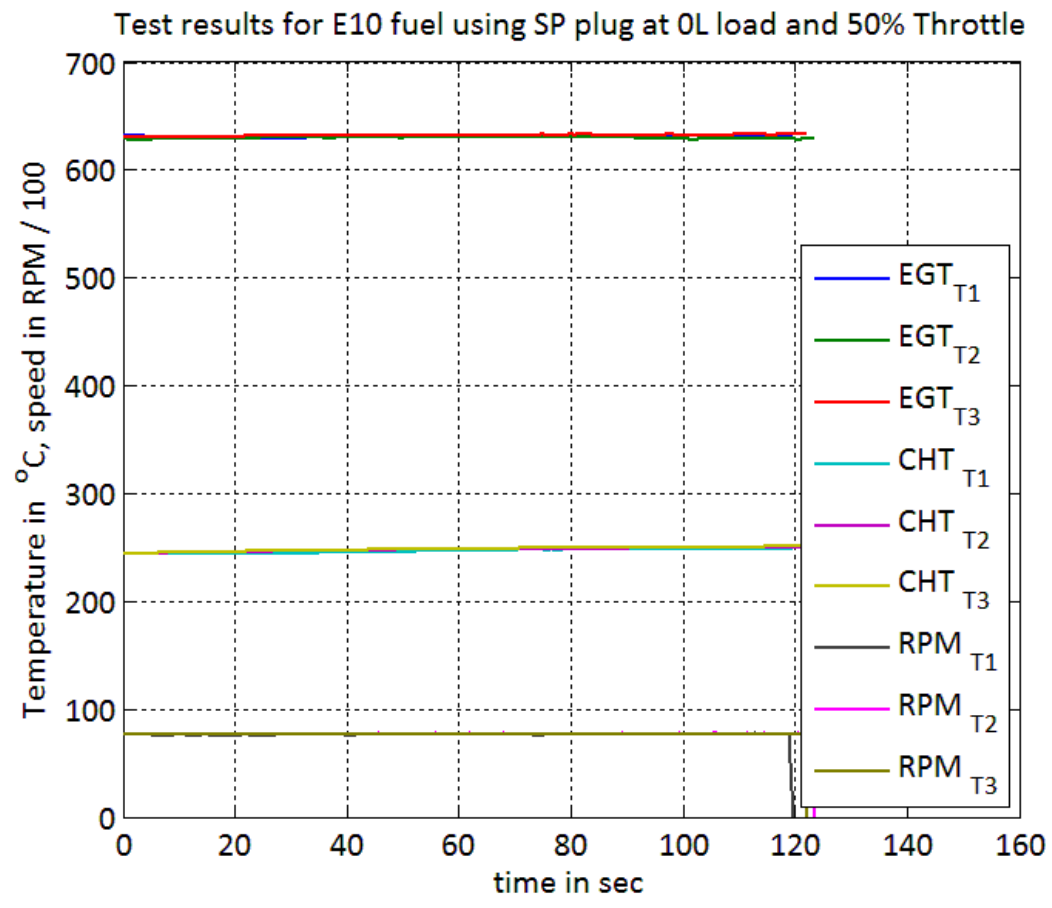

Figure A.2

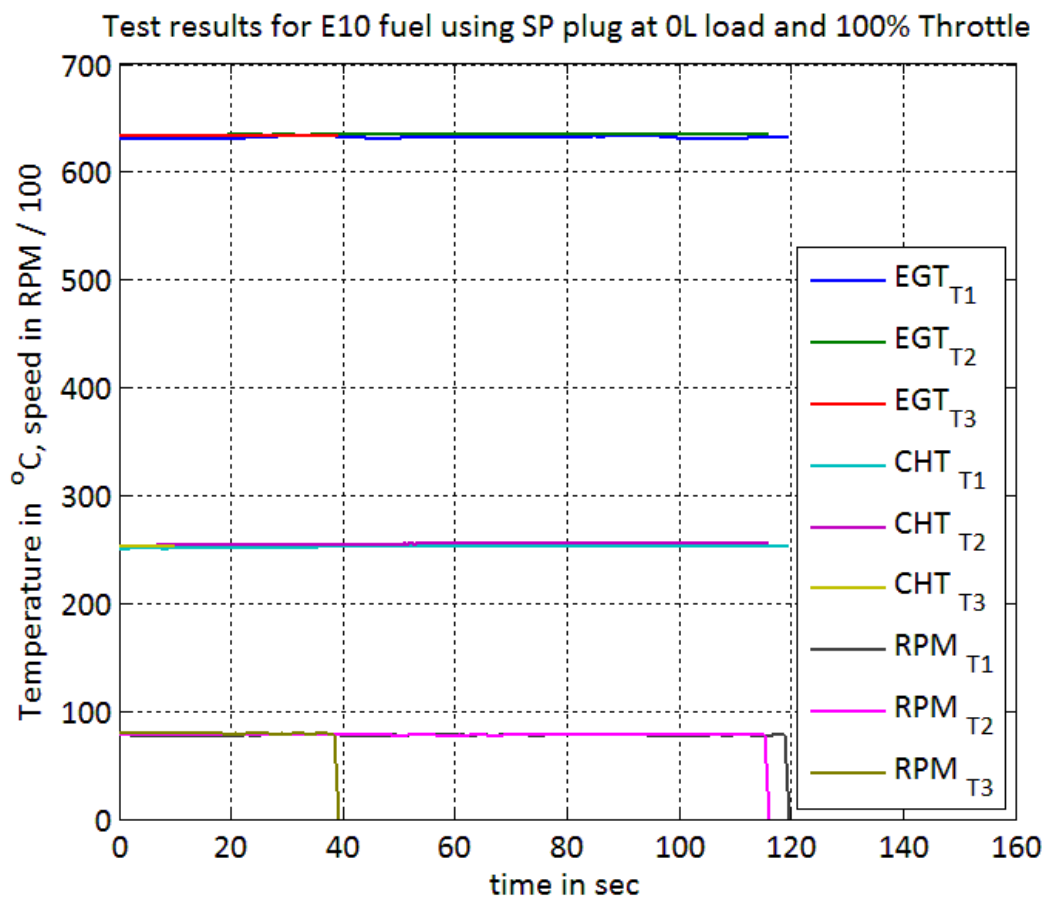

Figure A.3 


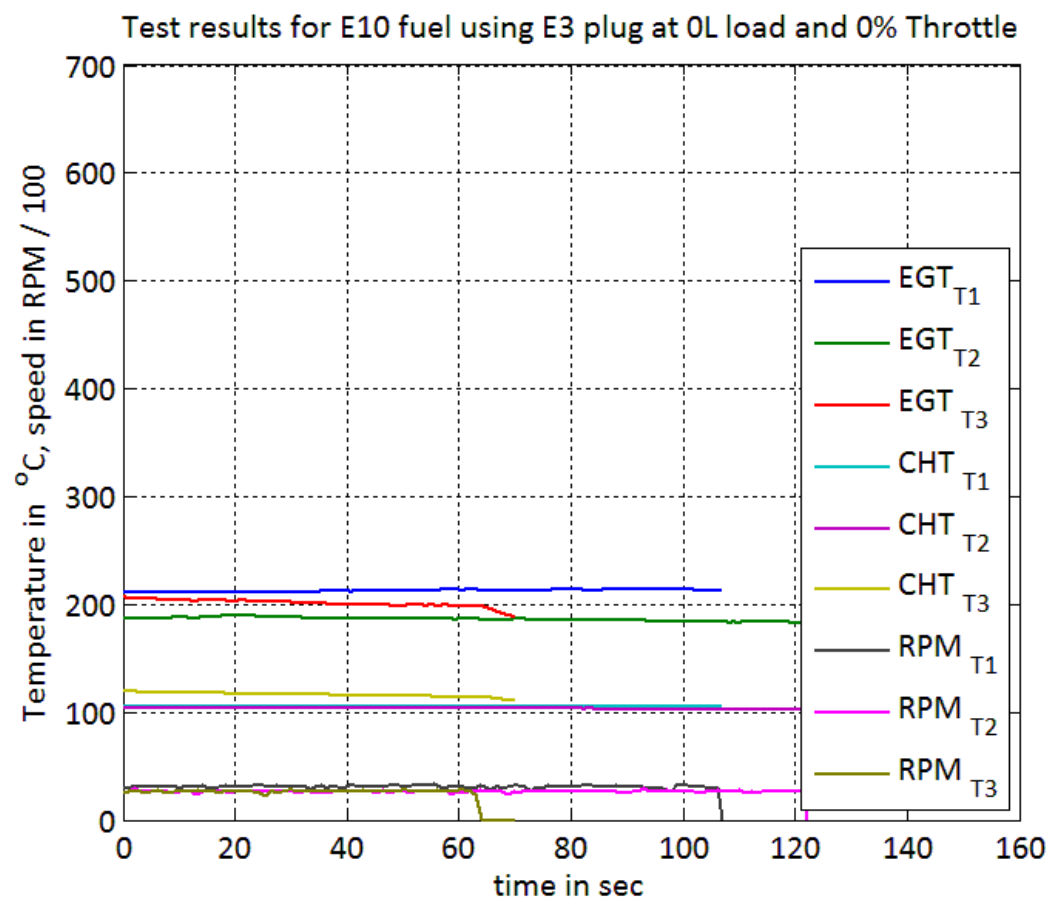

Figure A.4

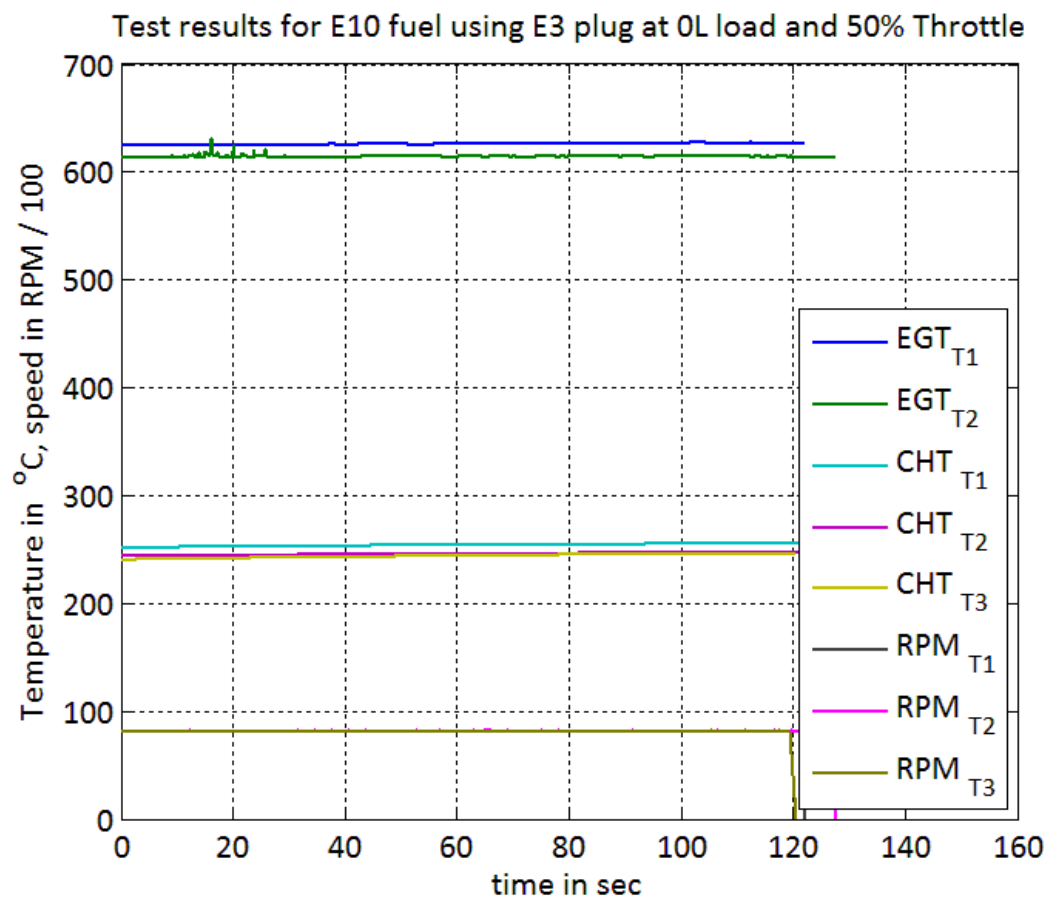

Figure A.5 


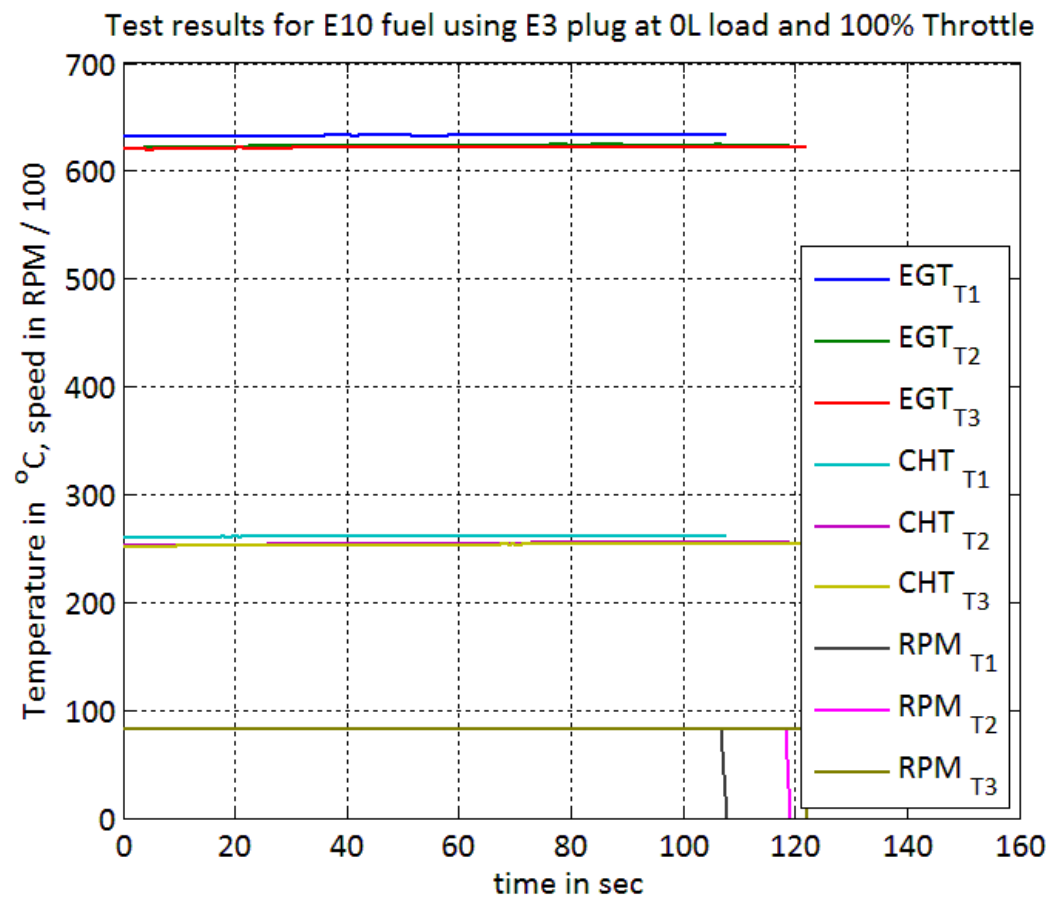

Figure A.6

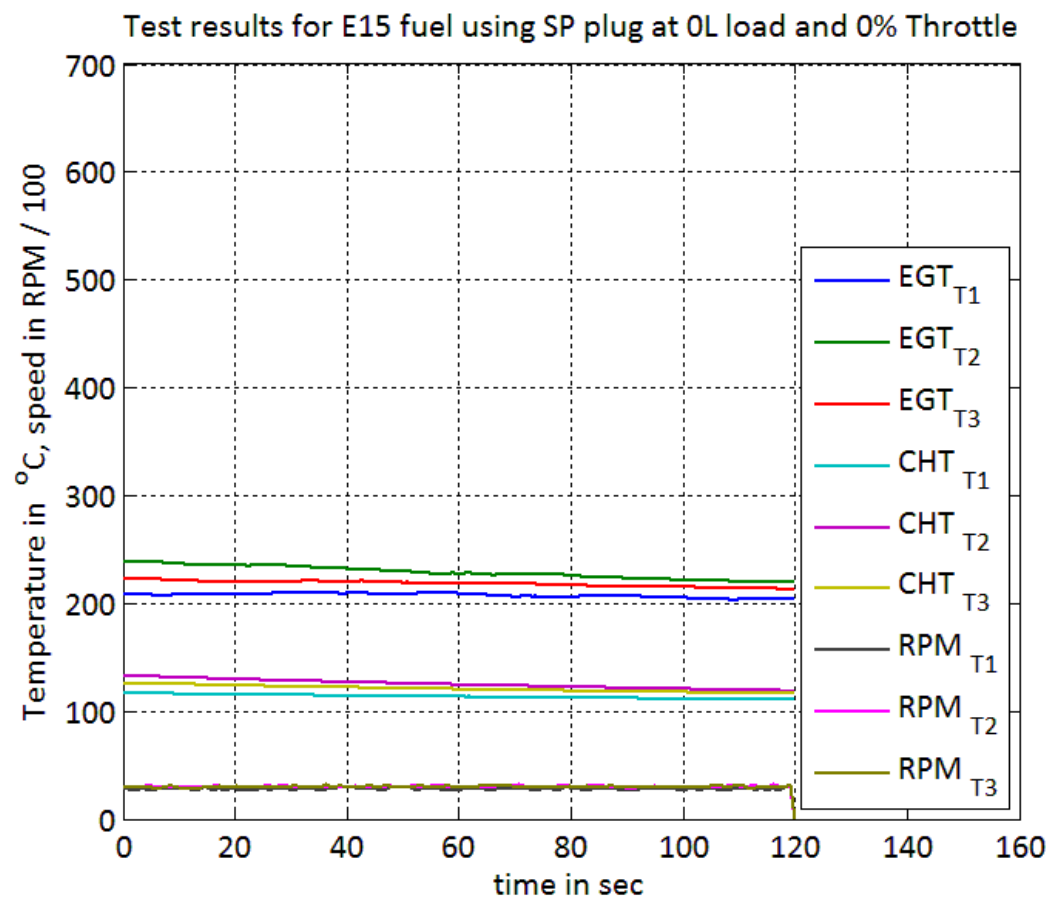

Figure A.7 


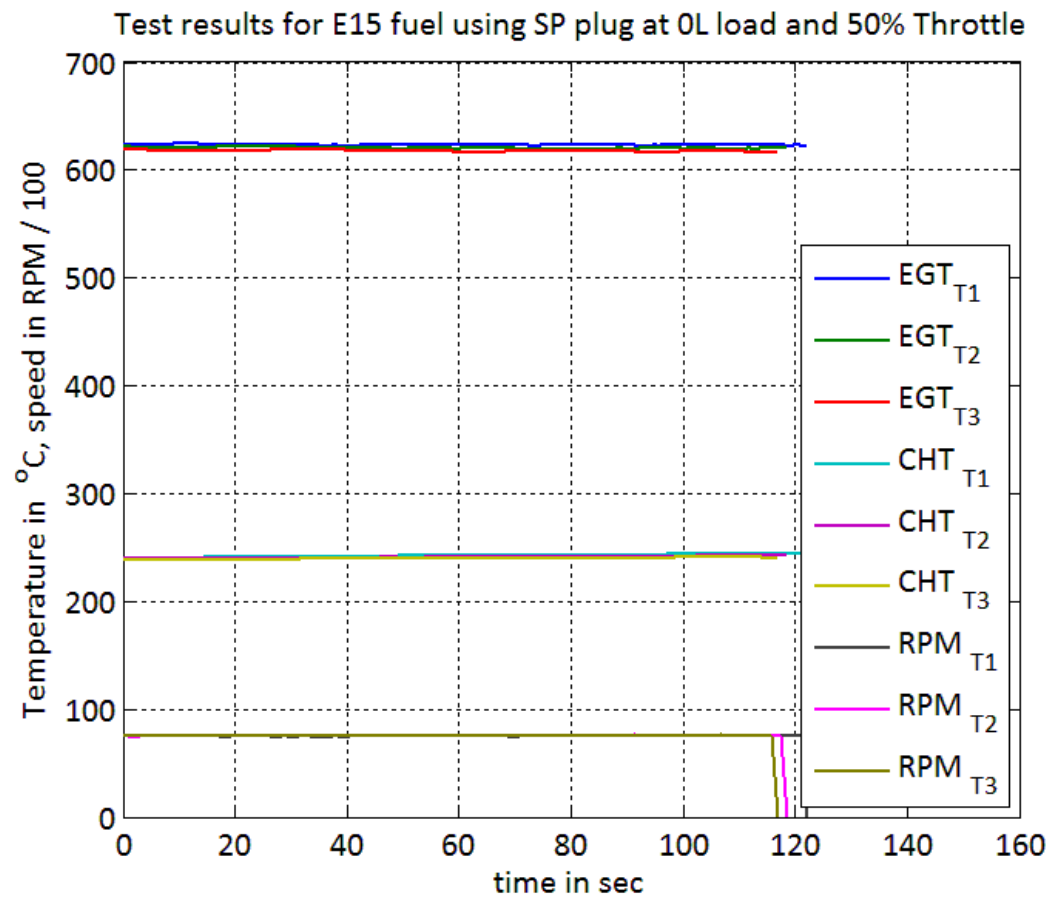

Figure A.8

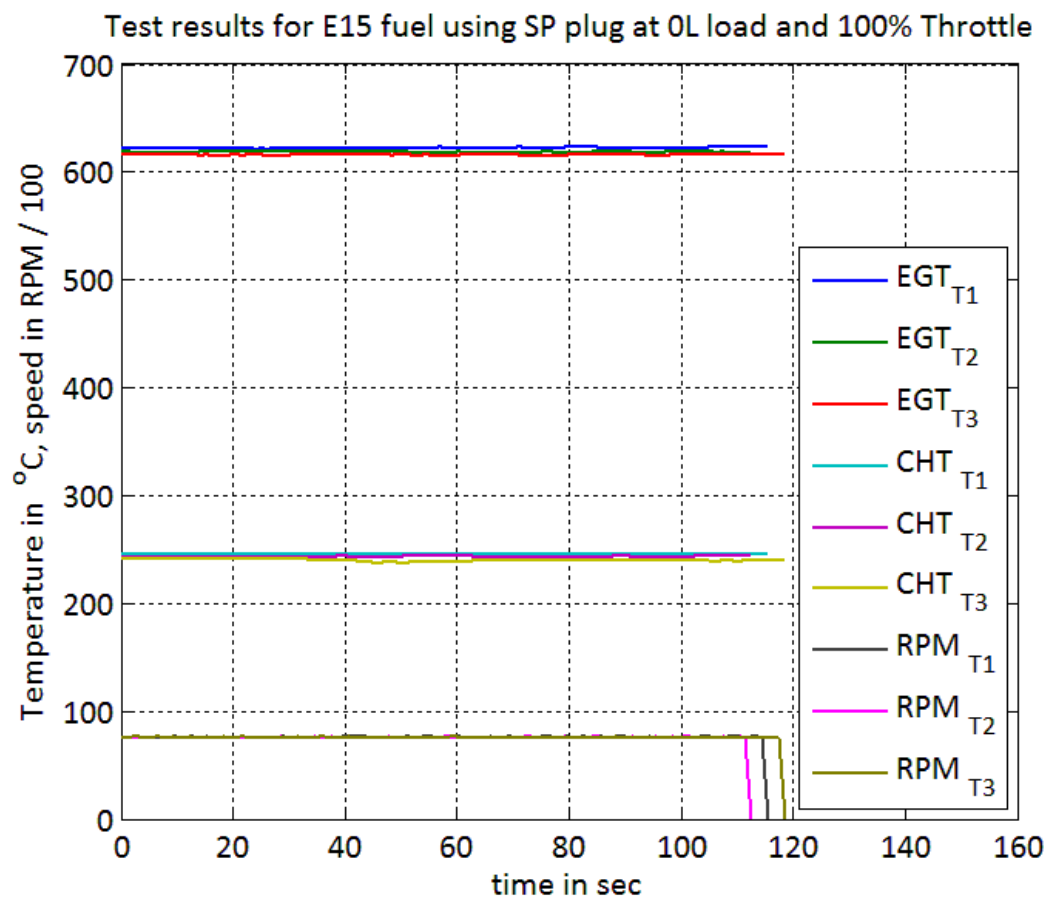

Figure A.9 


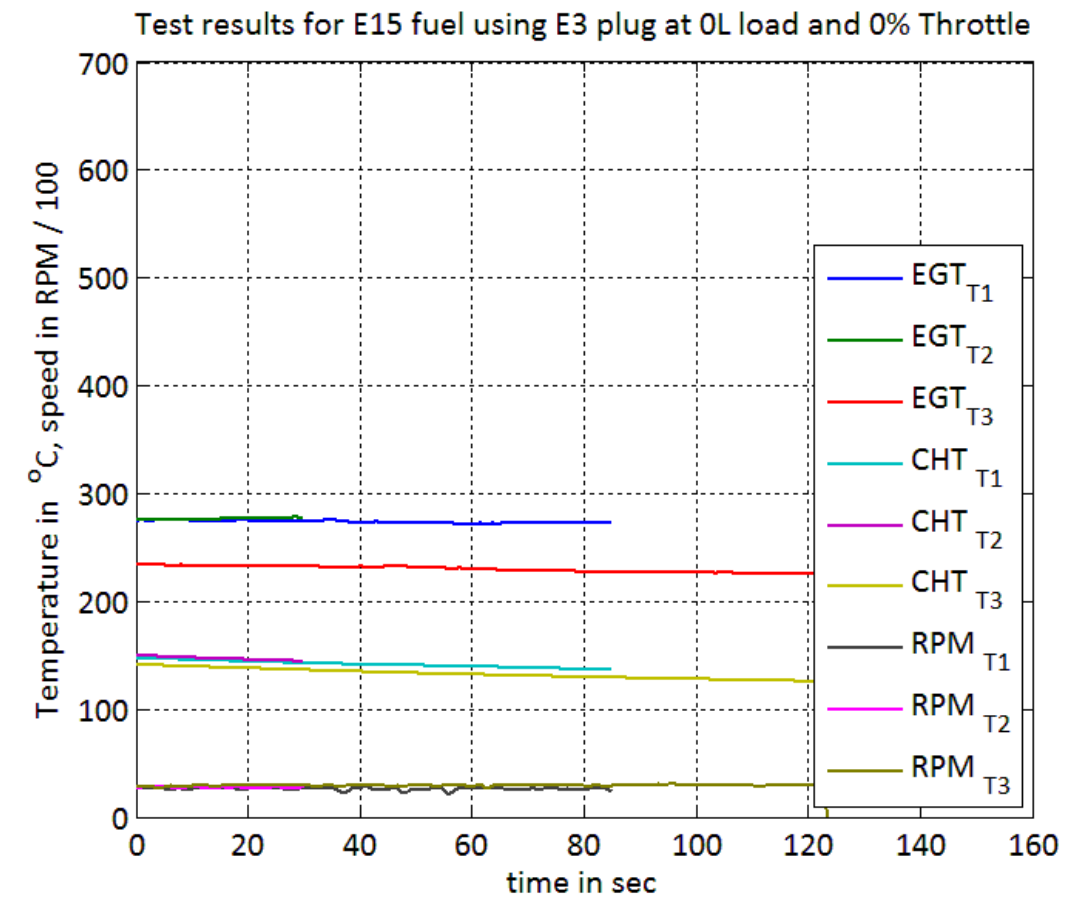

Figure A.10

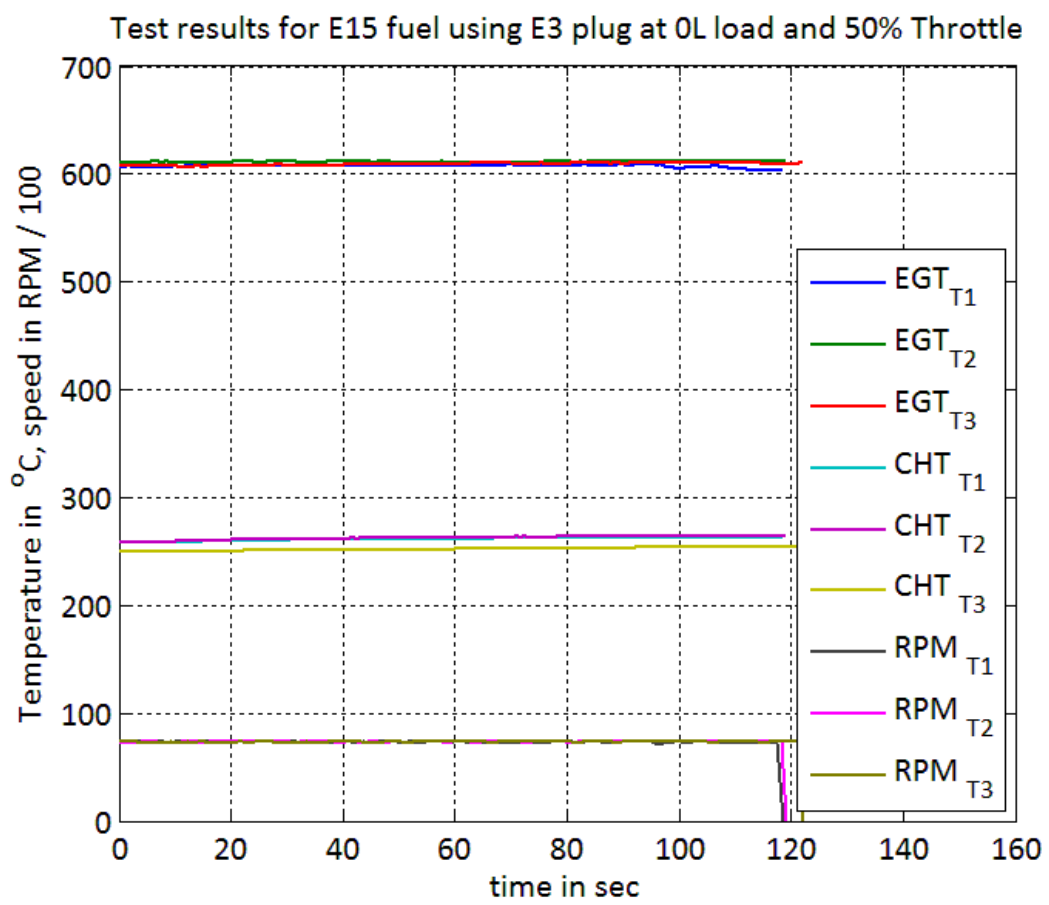

Figure A.11 


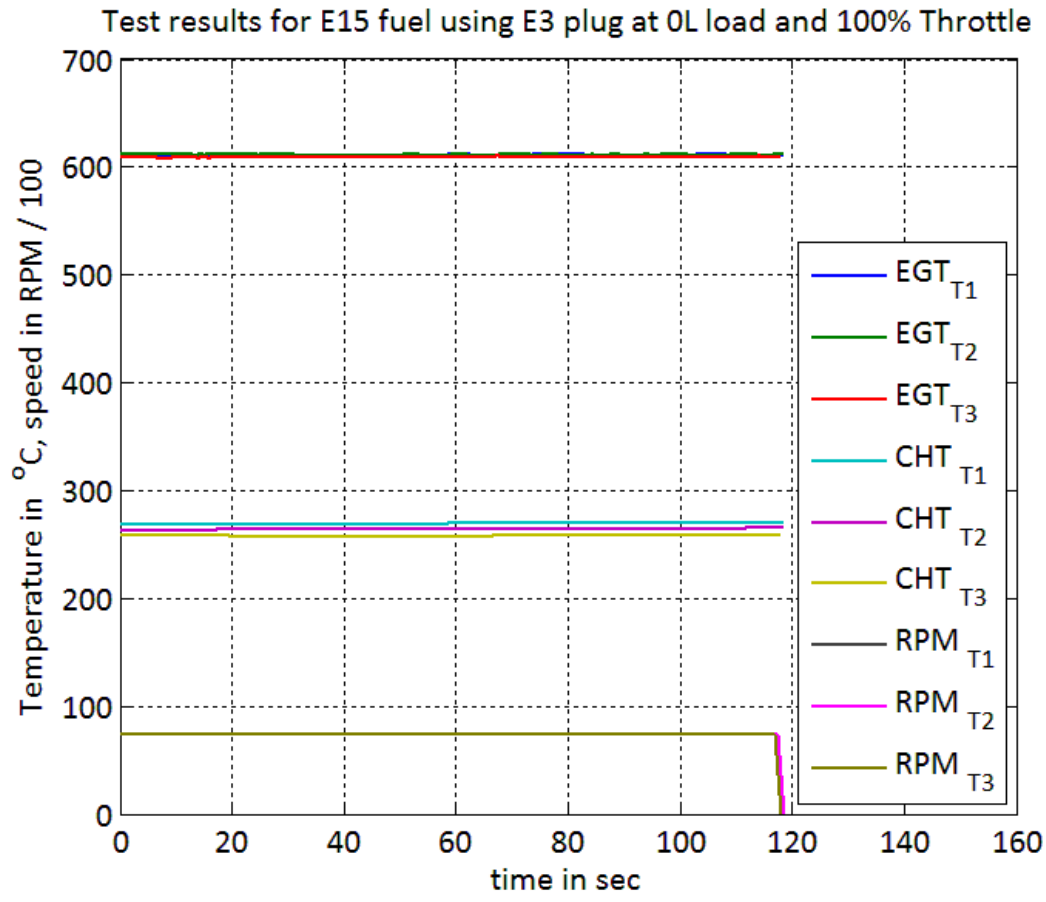

Figure A.12 


\section{A.2.2 IL load}

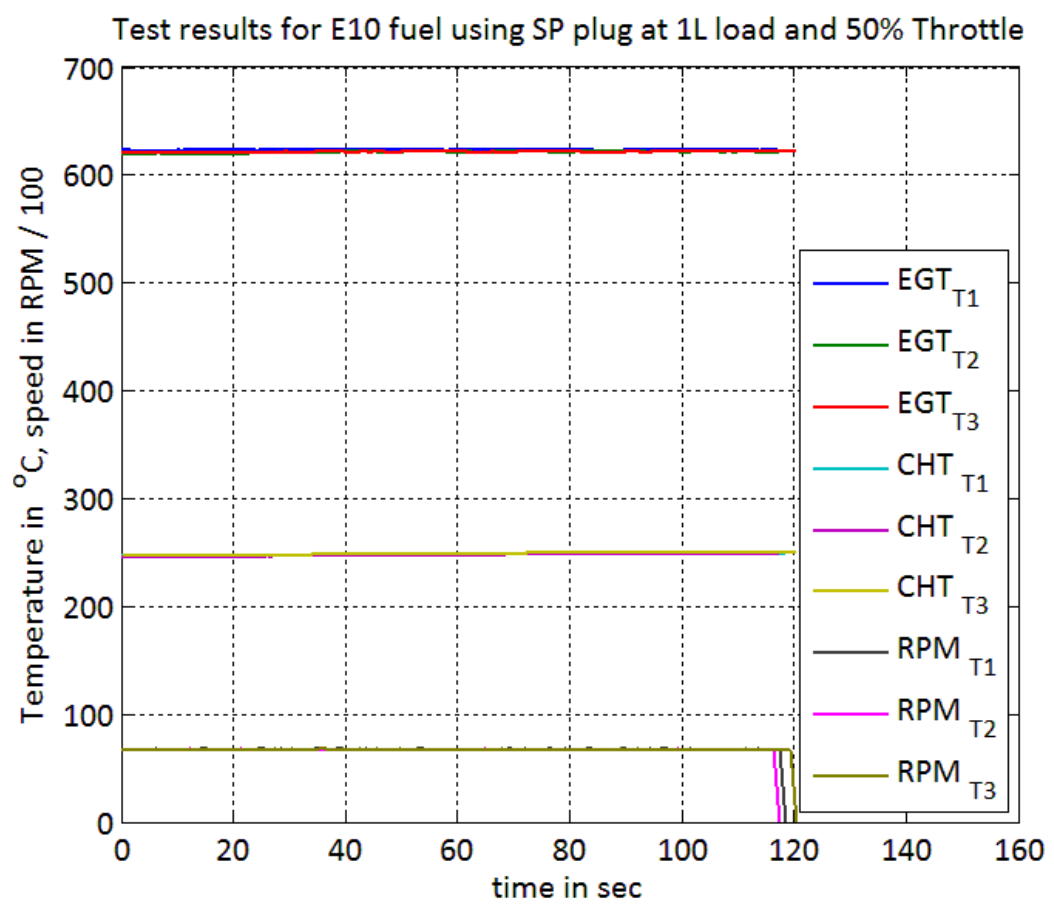

Figure A.13 


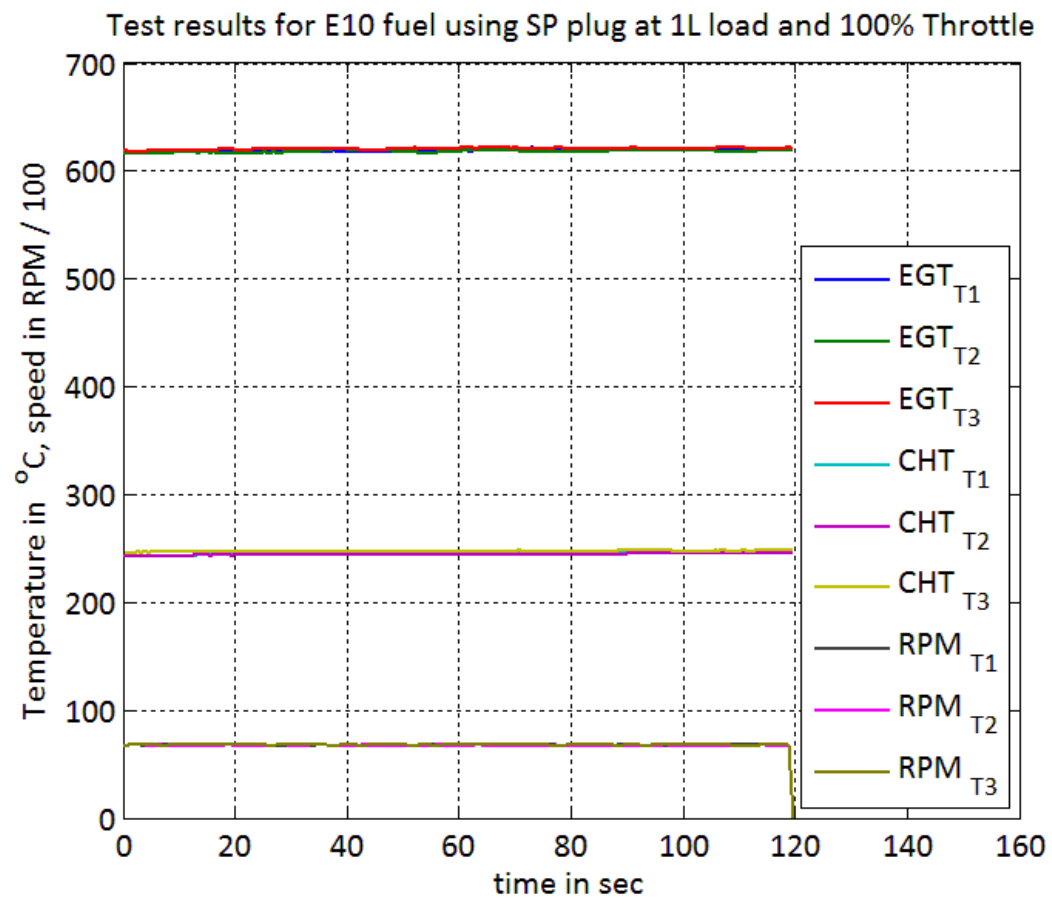

Figure A.14

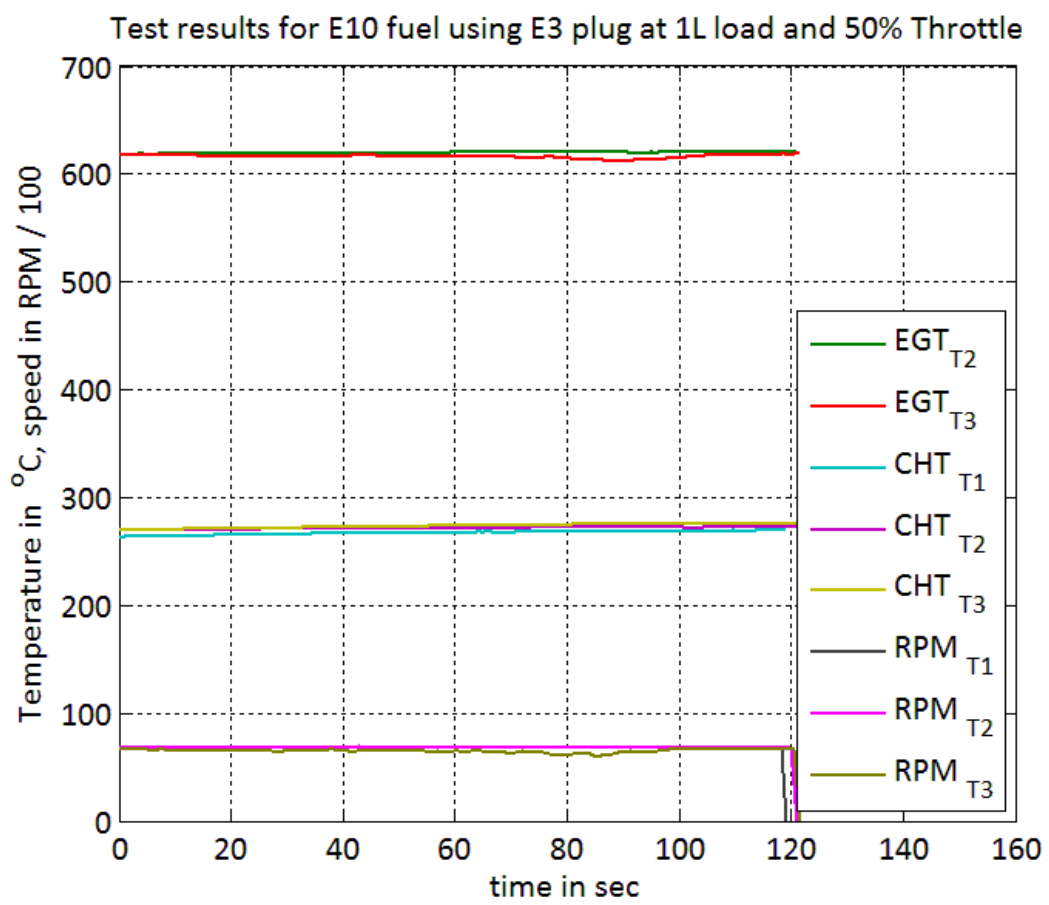

Figure A.15 


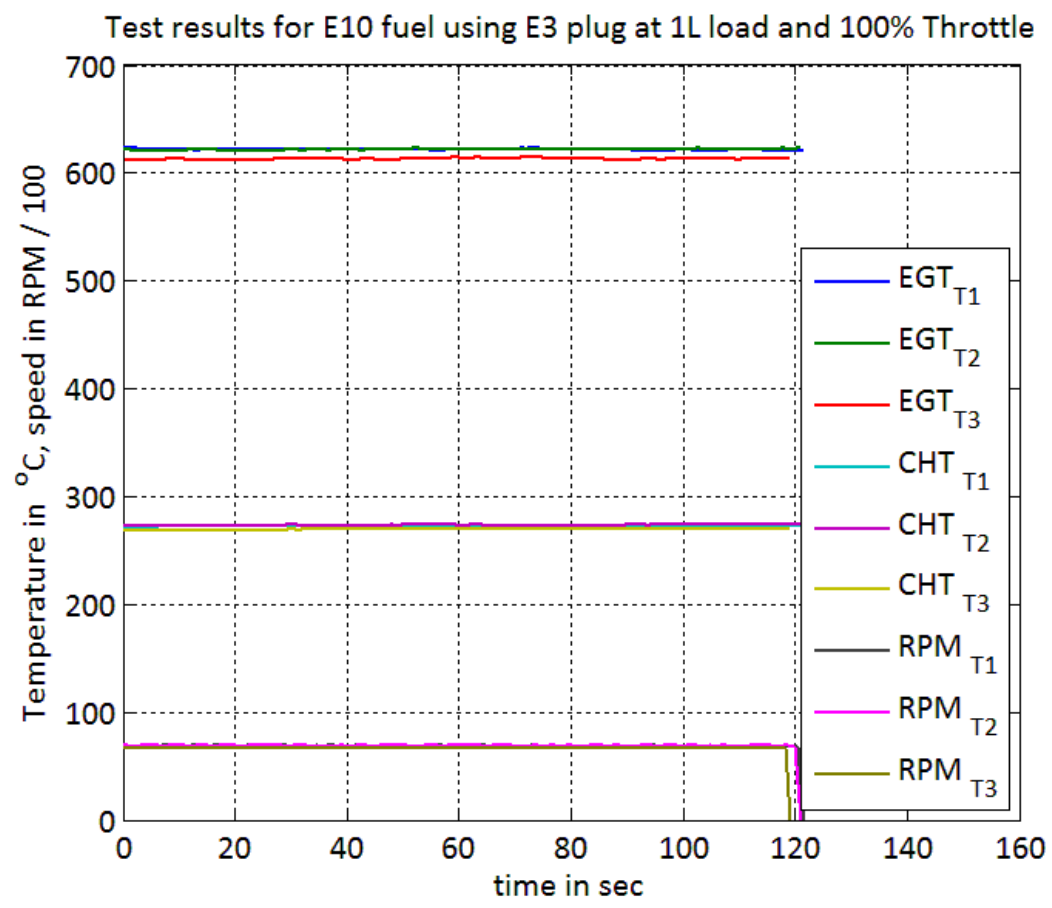

Figure A.16

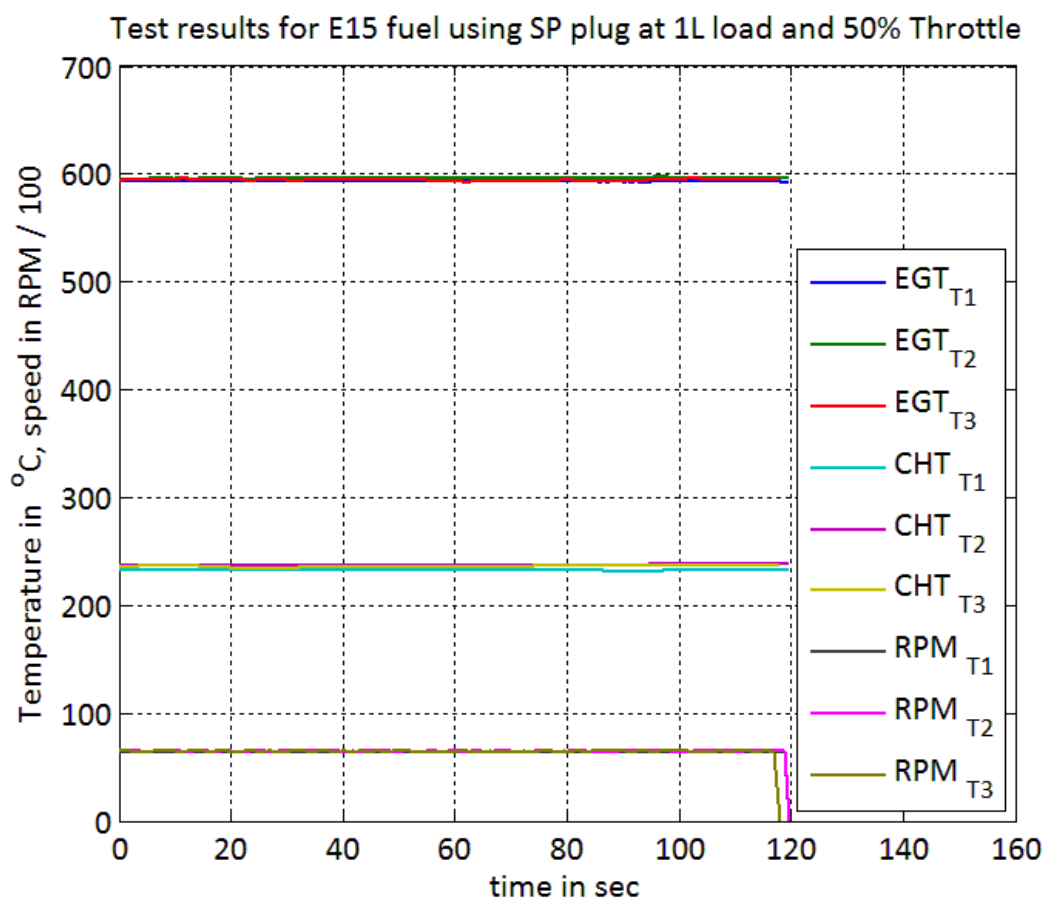

Figure A.17 


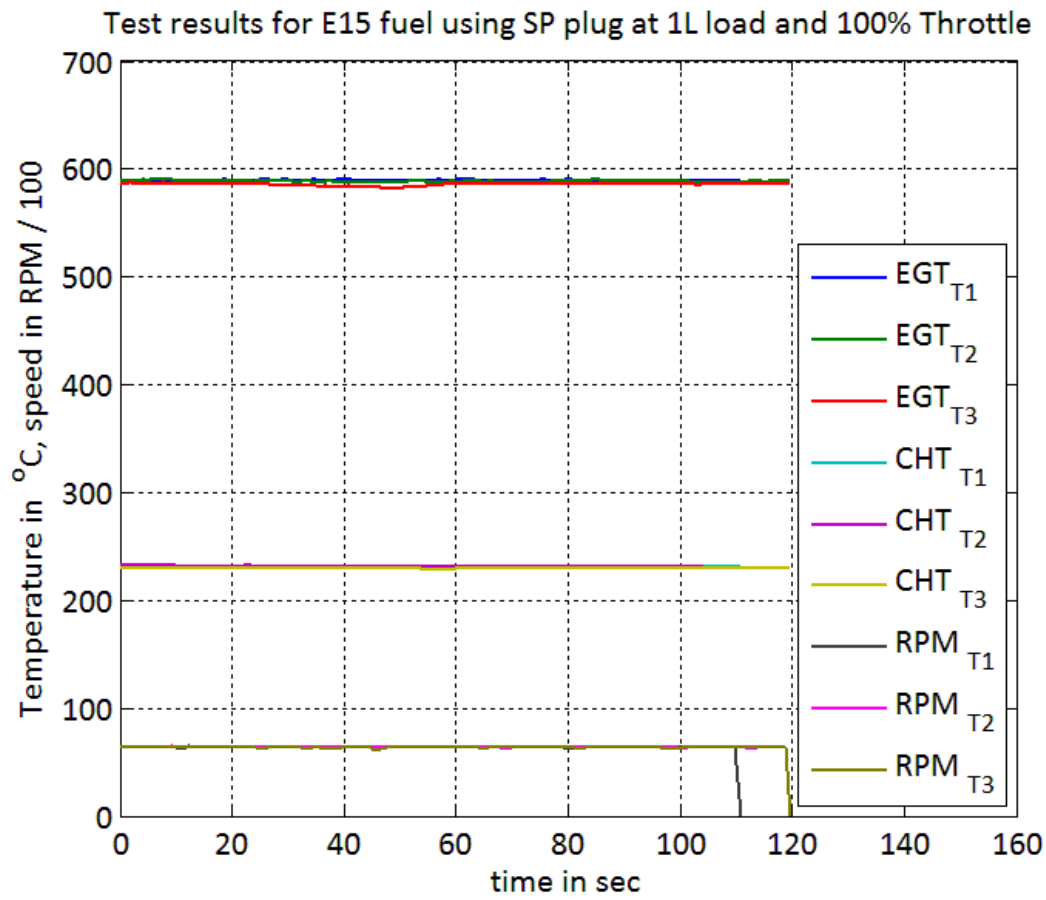

Figure A.18

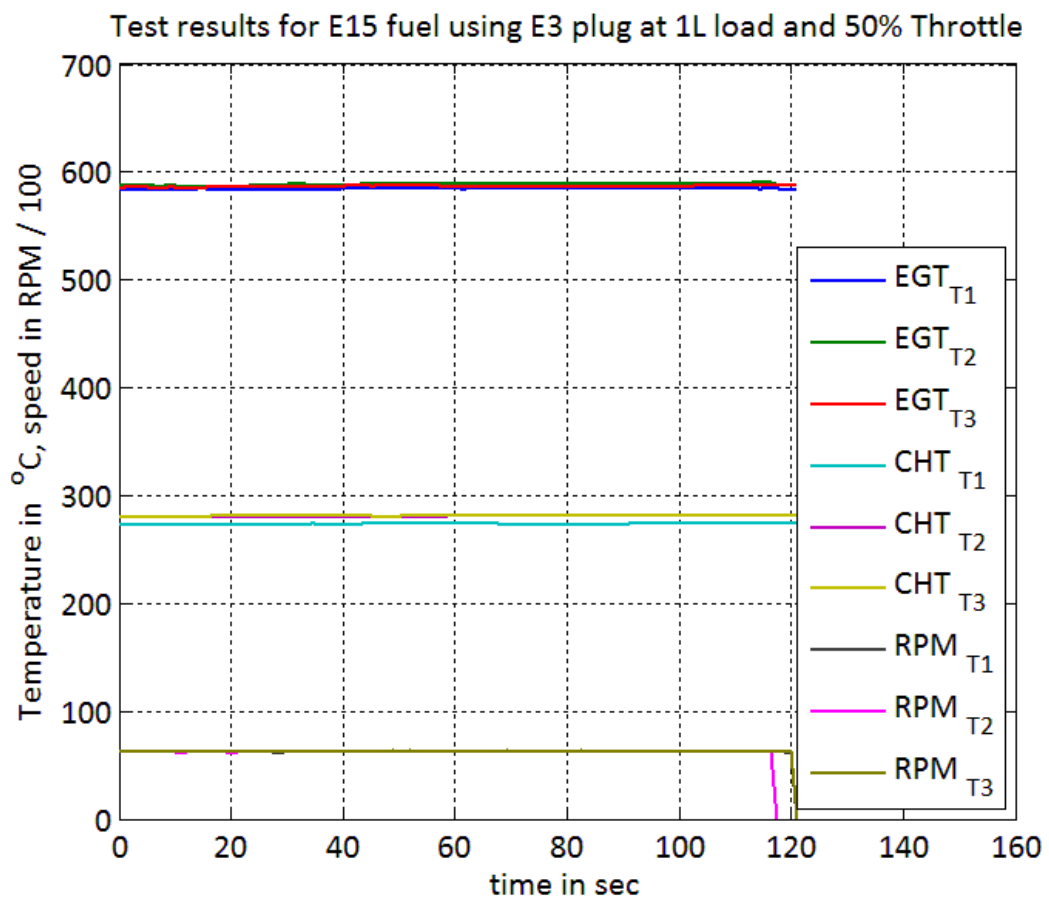

Figure A.19 


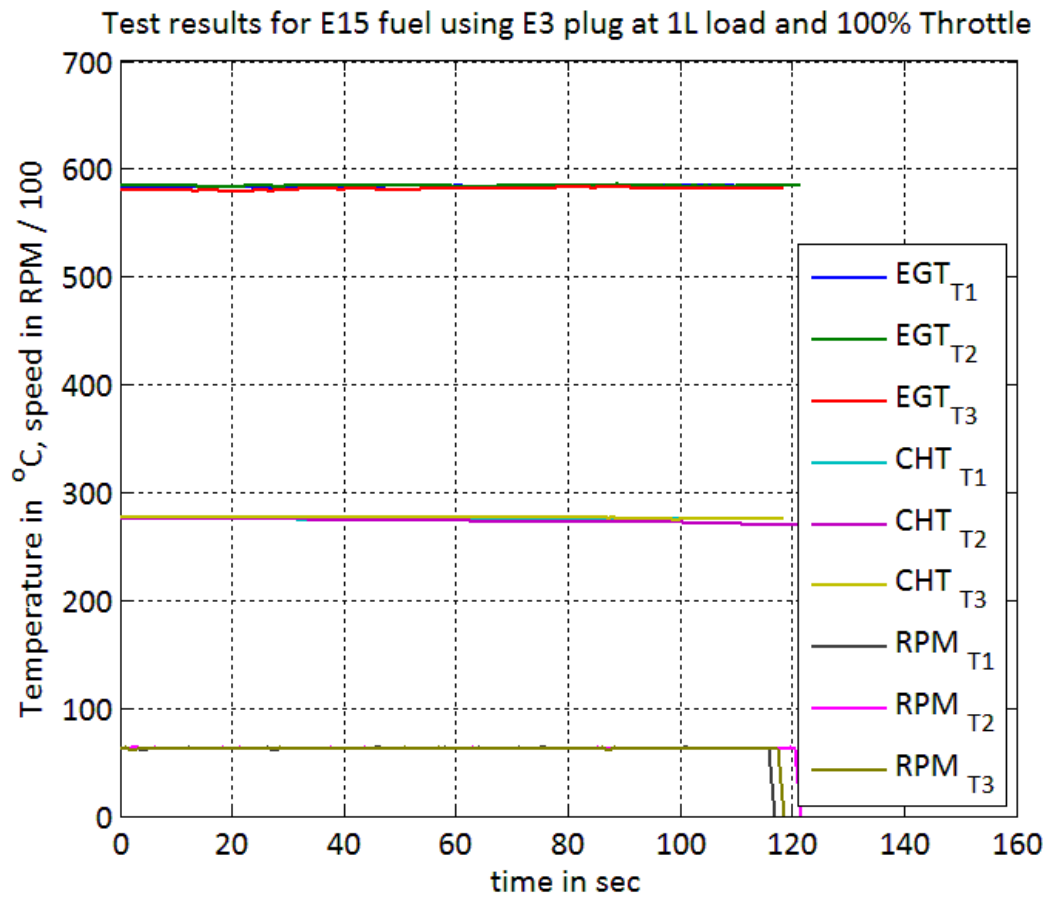

Figure A.20 


\section{A.2.3 2L load}

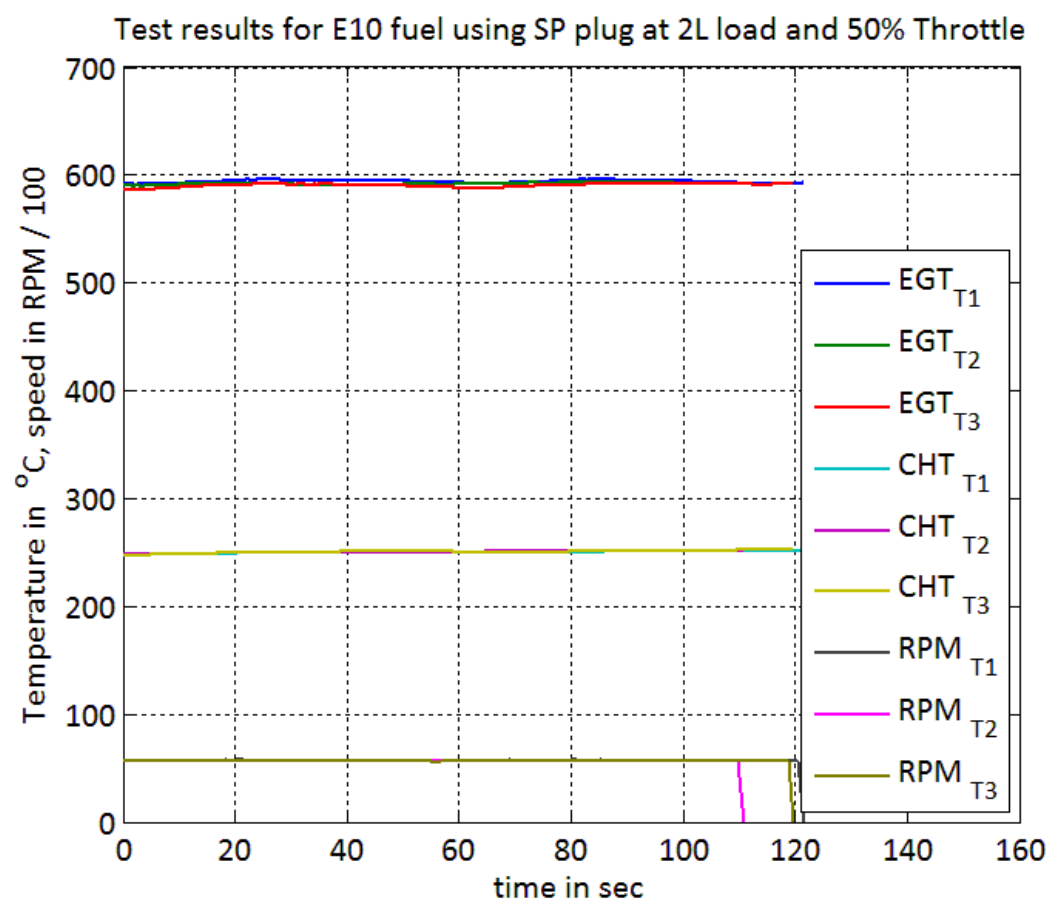

Figure A.21 


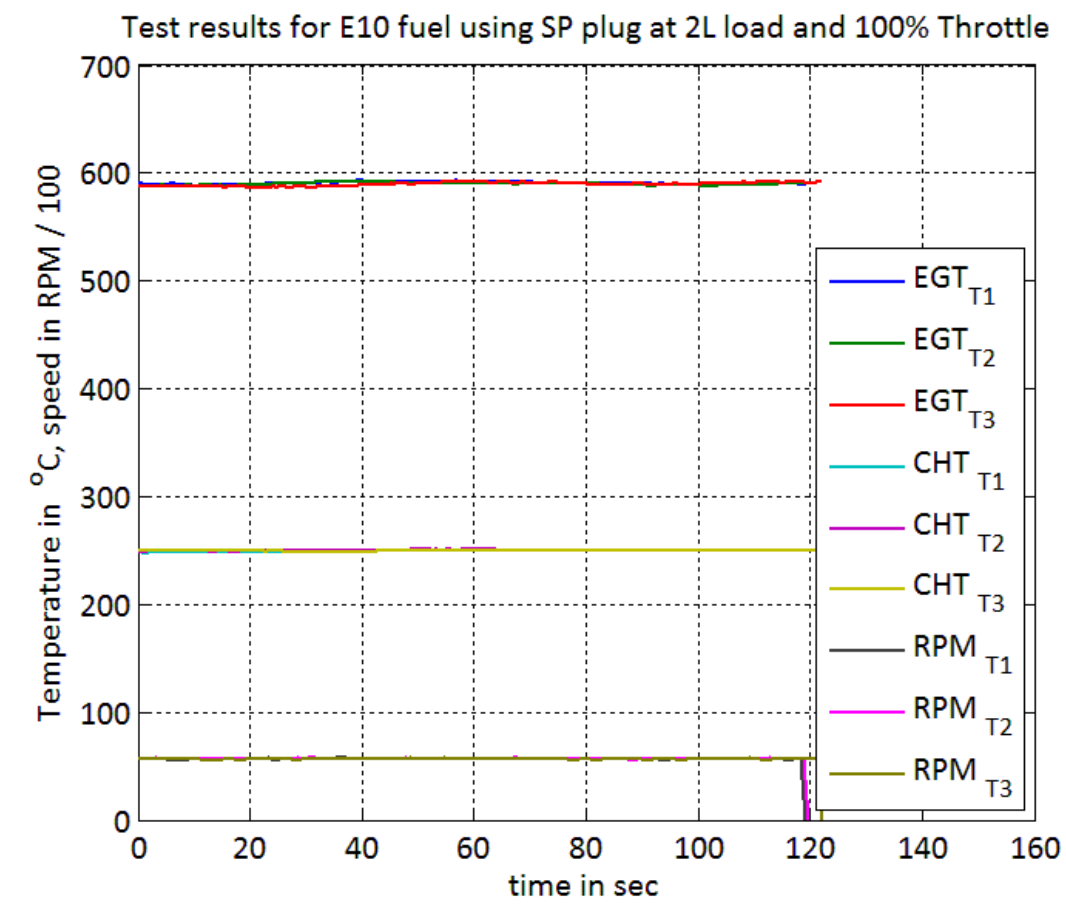

Figure A.22

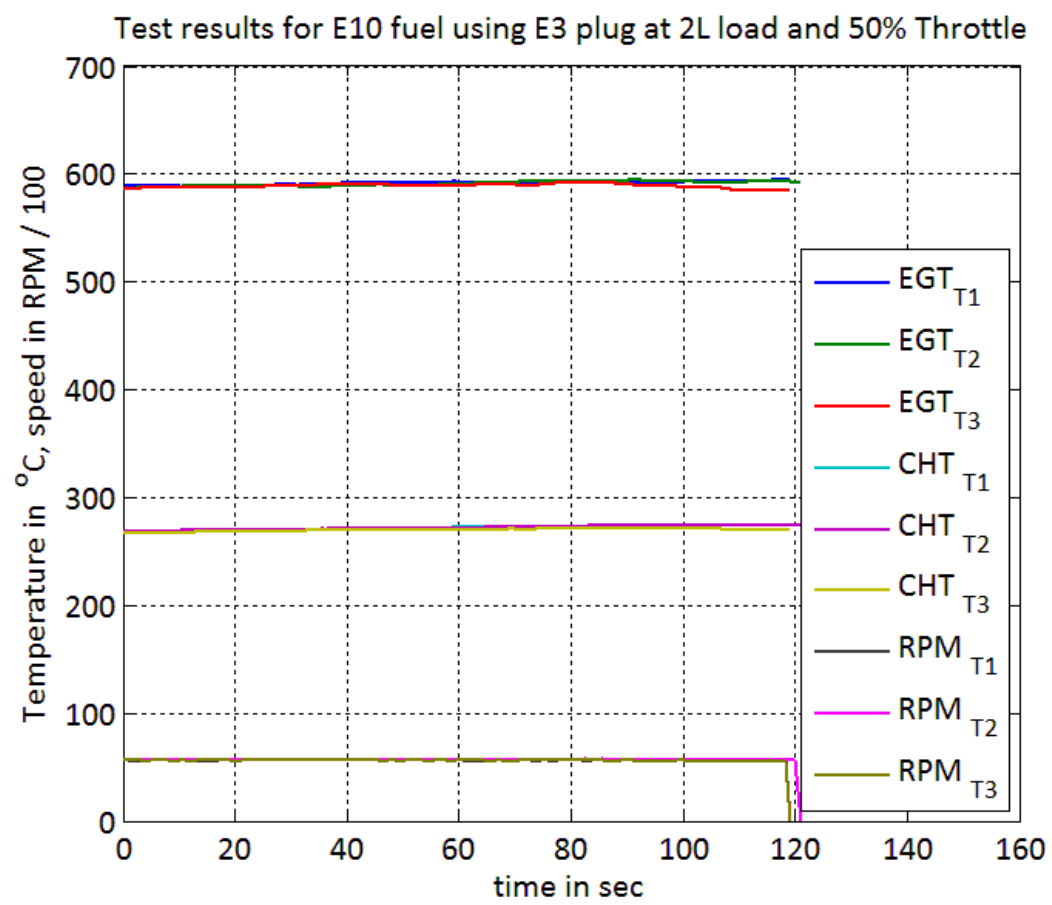

Figure A.23 


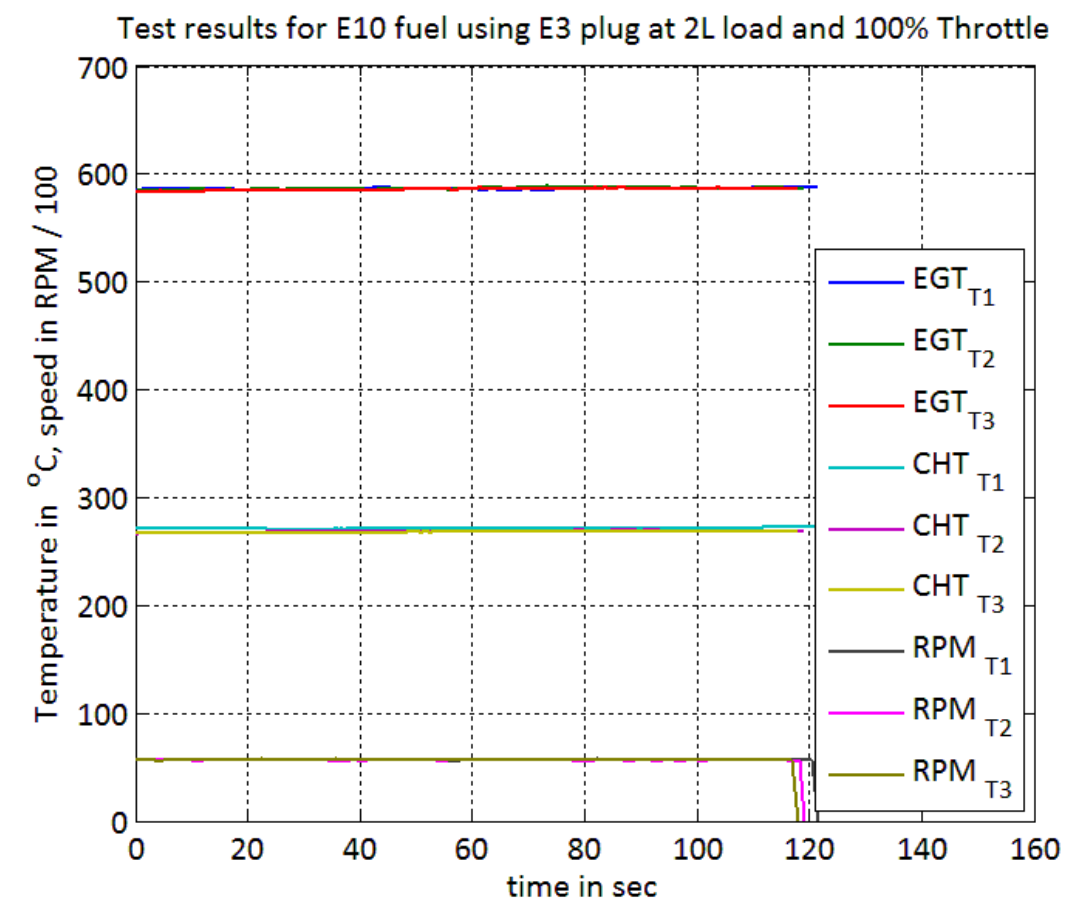

Figure A.24

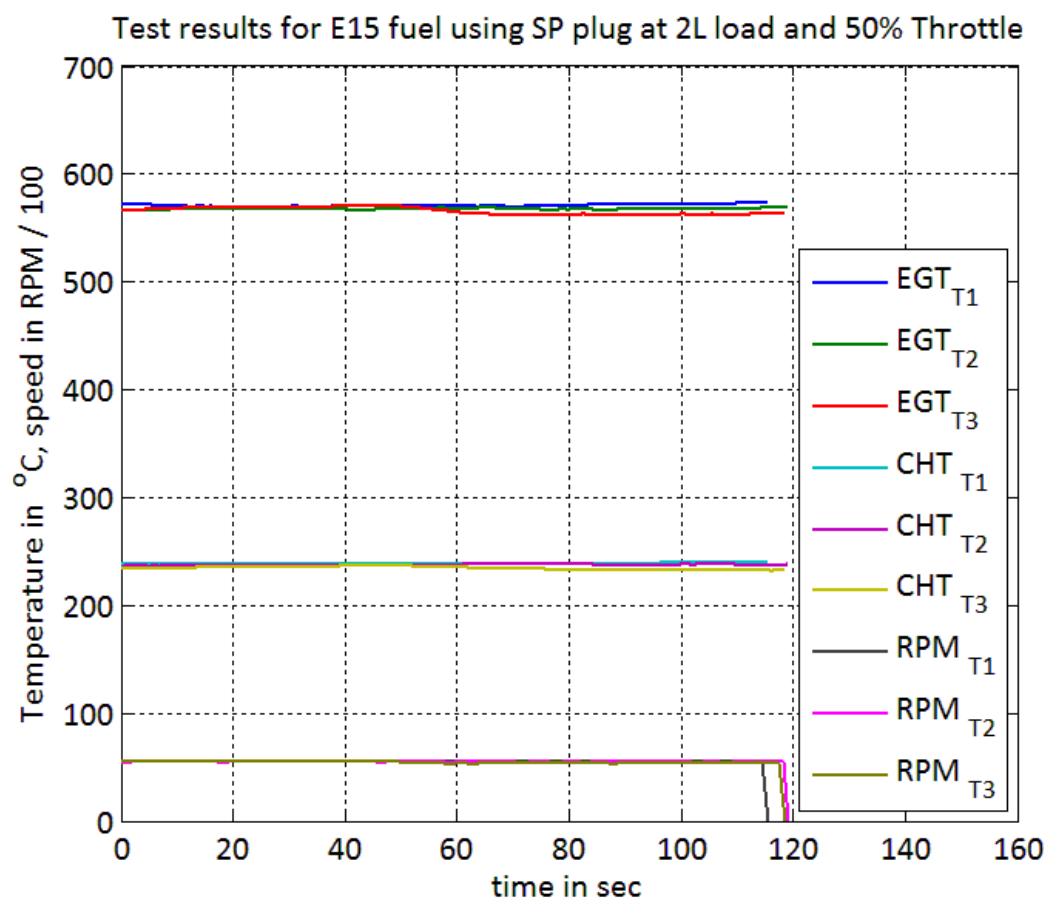

Figure A.25 


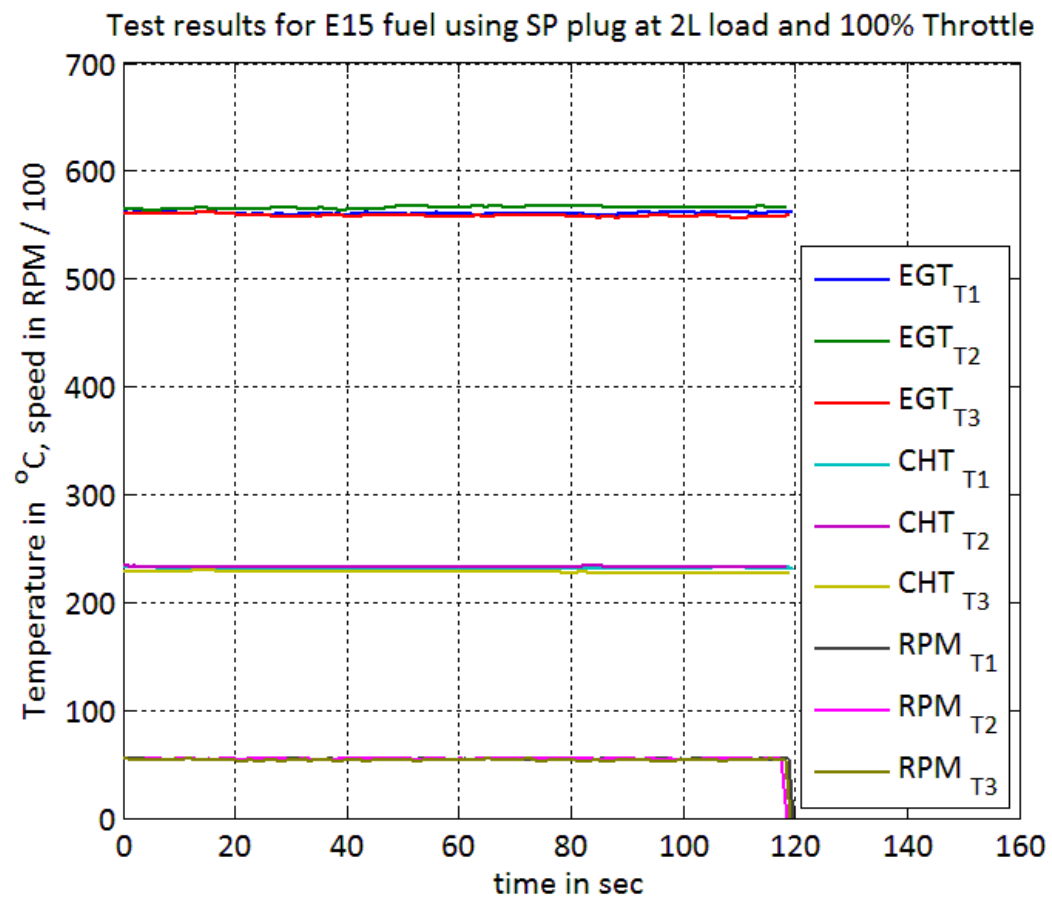

Figure A.26

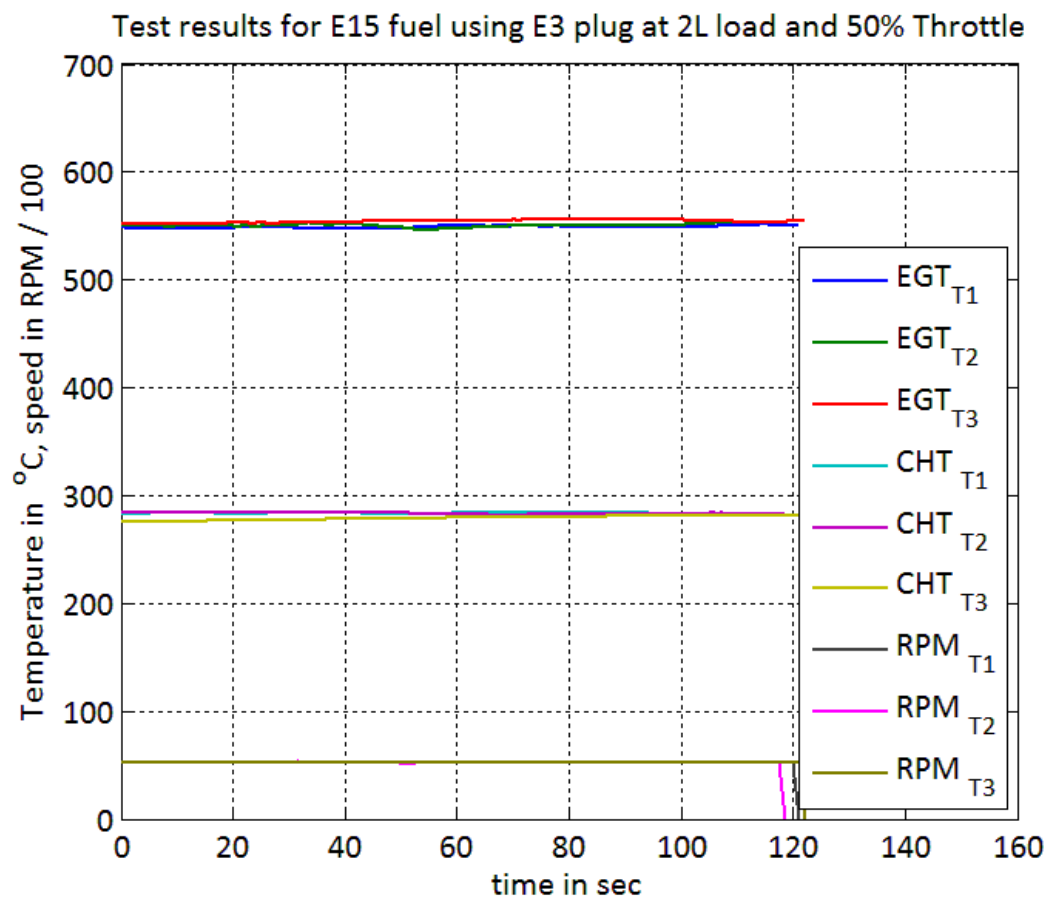

Figure A.27 


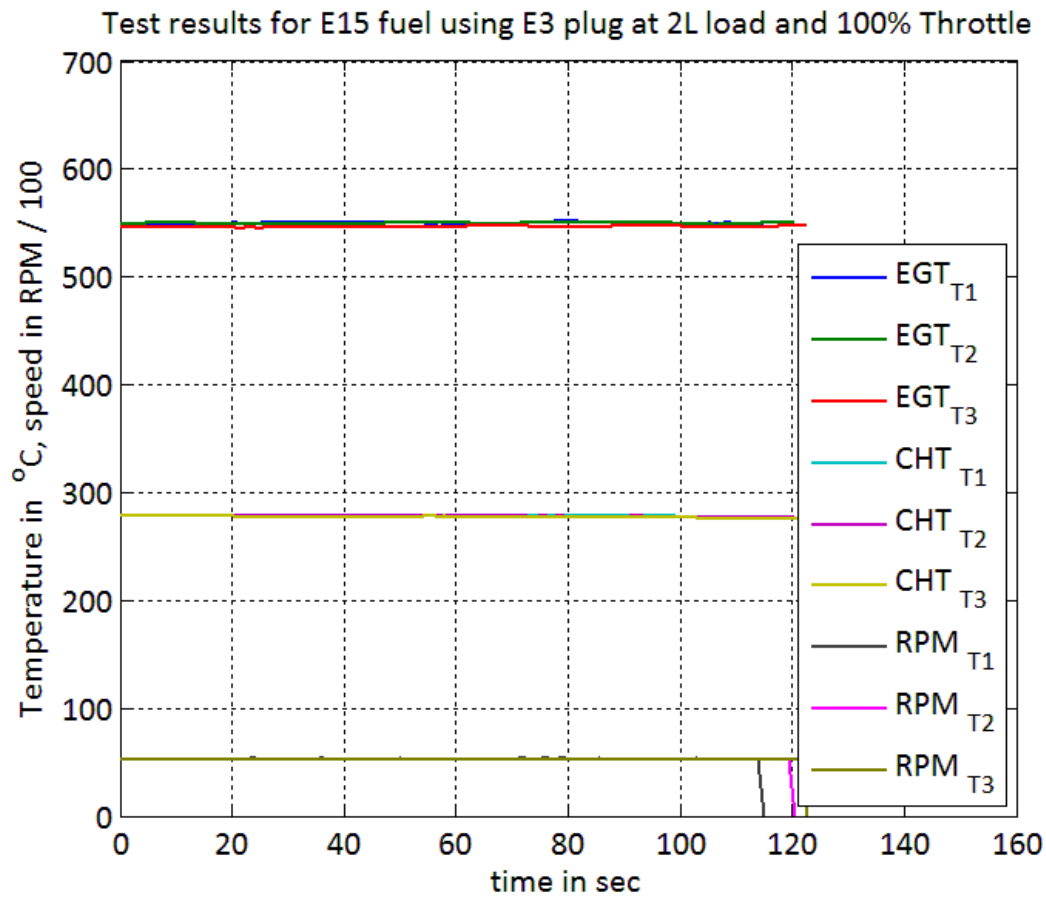

Figure A.28 


\section{A.2.4 3L load}

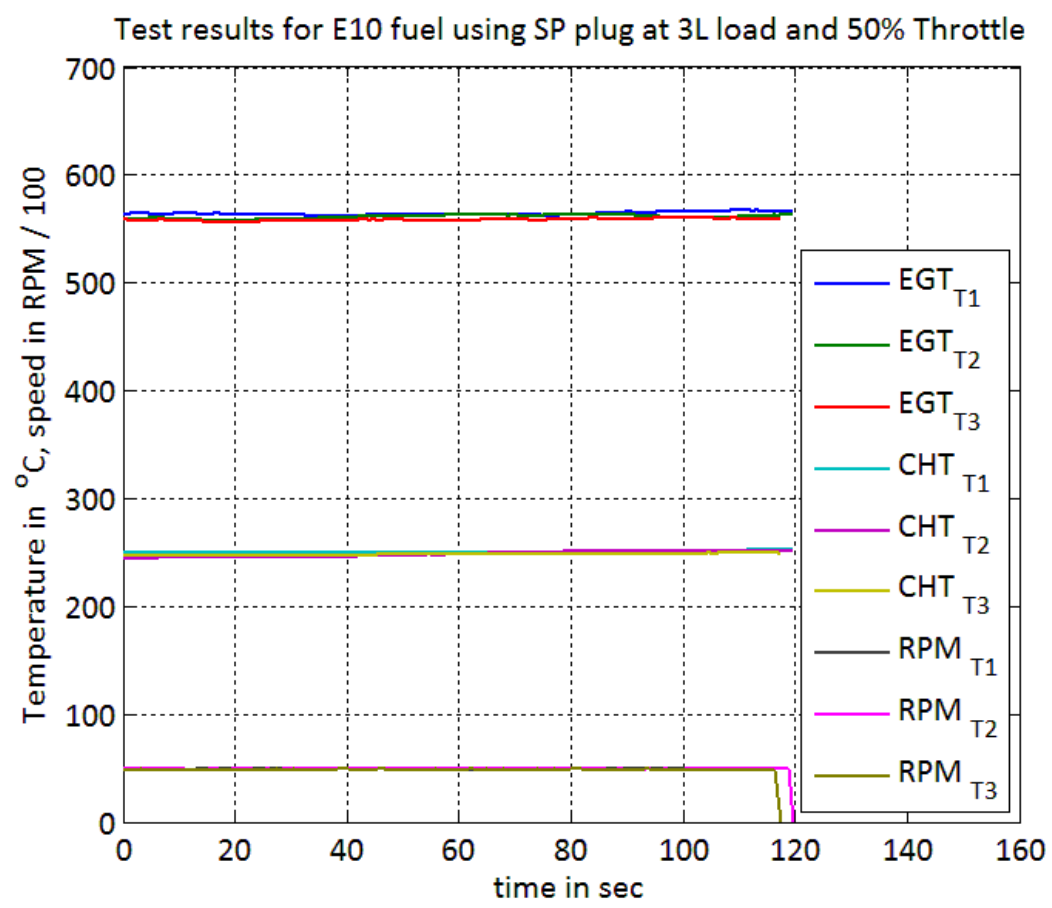

Figure A.29 


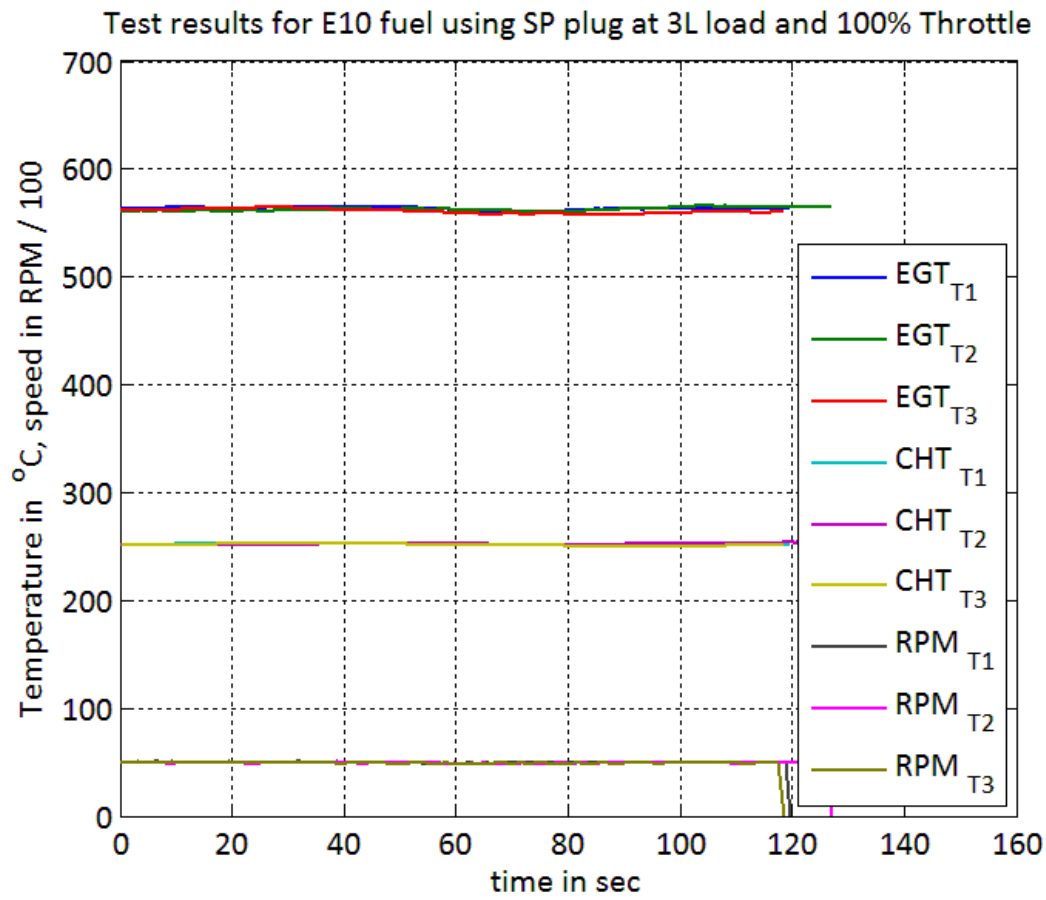

Figure A.30

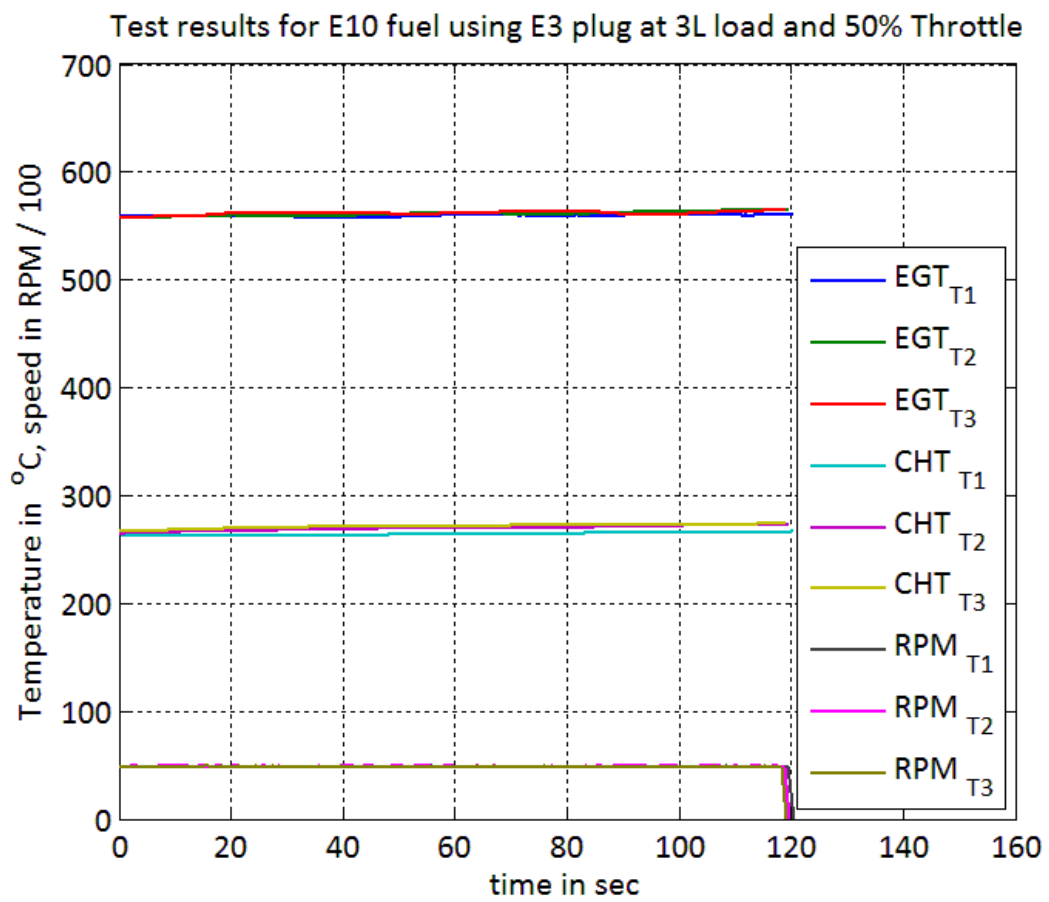

Figure A.31 


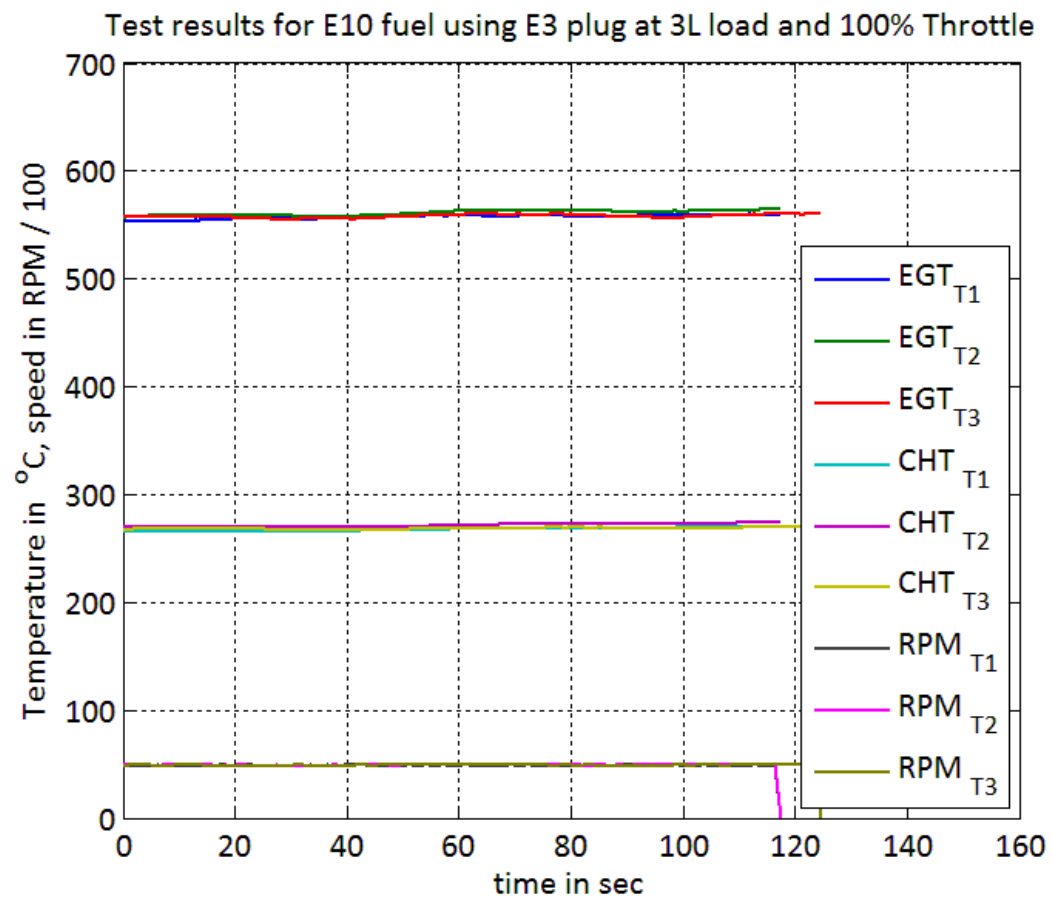

Figure A.32

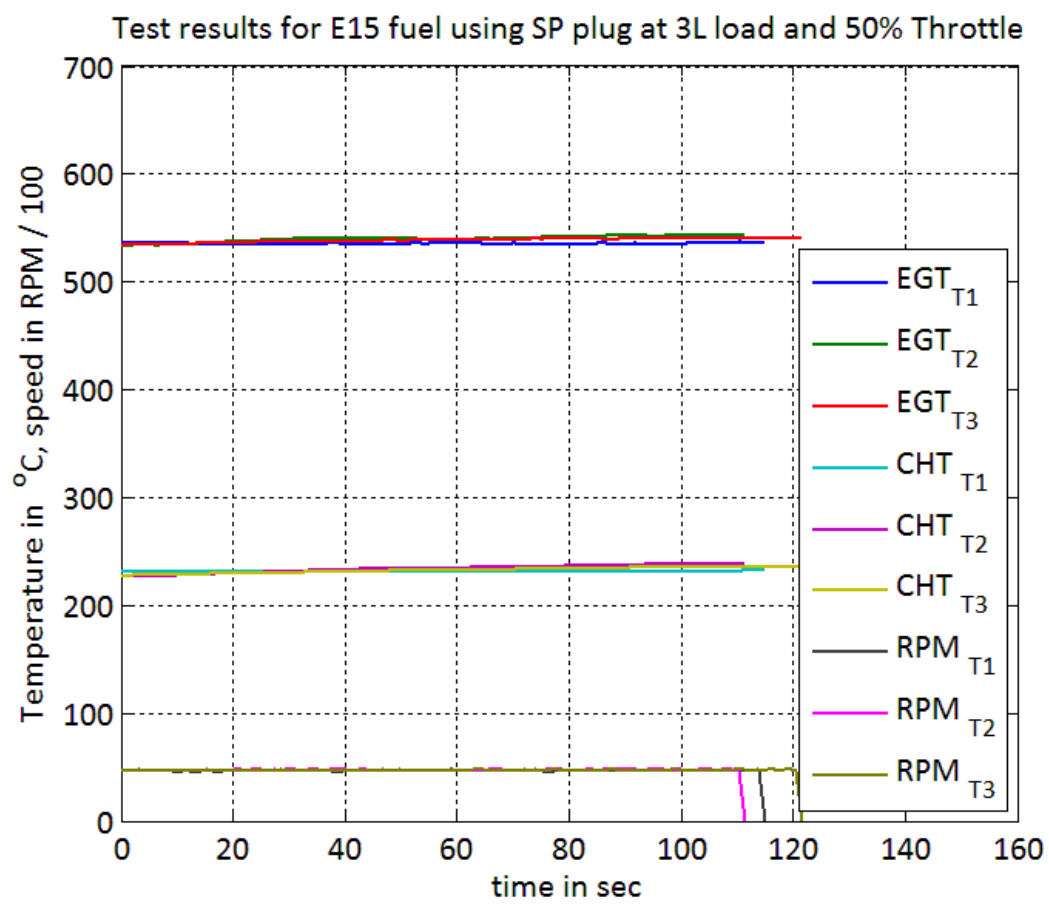

Figure A.33 


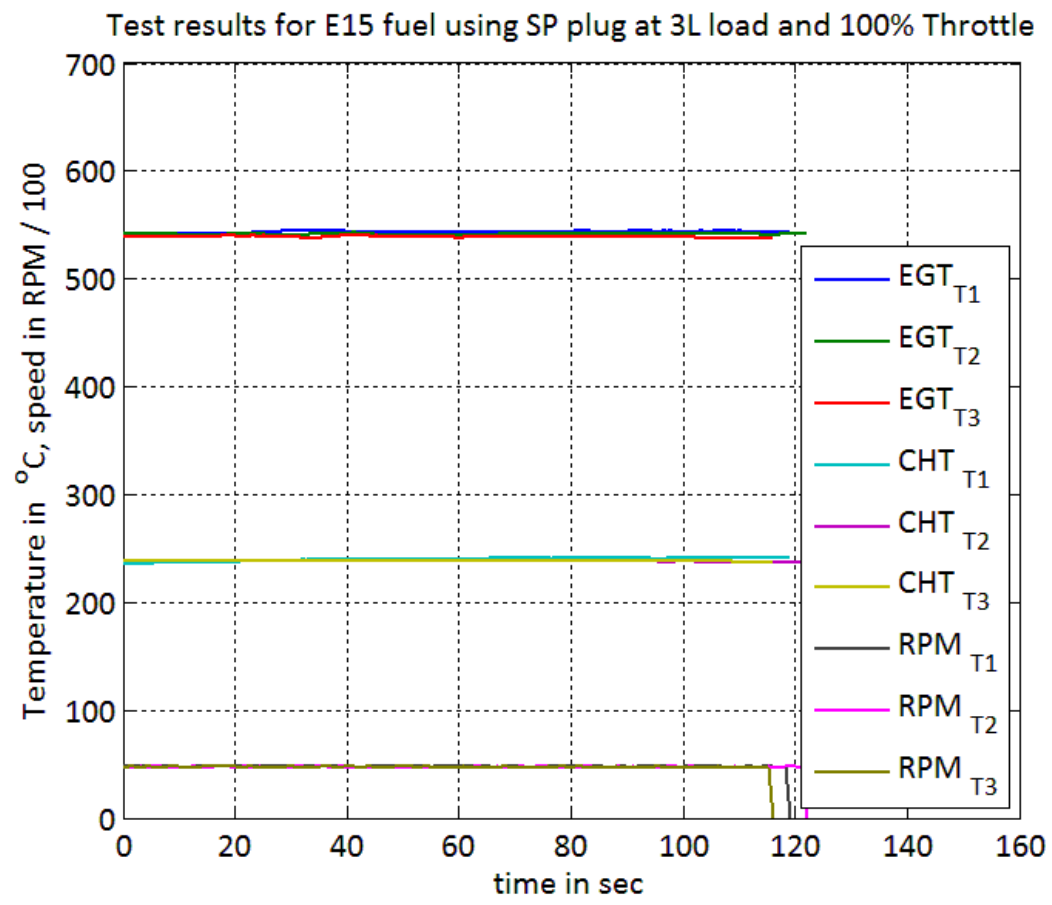

Figure A.34

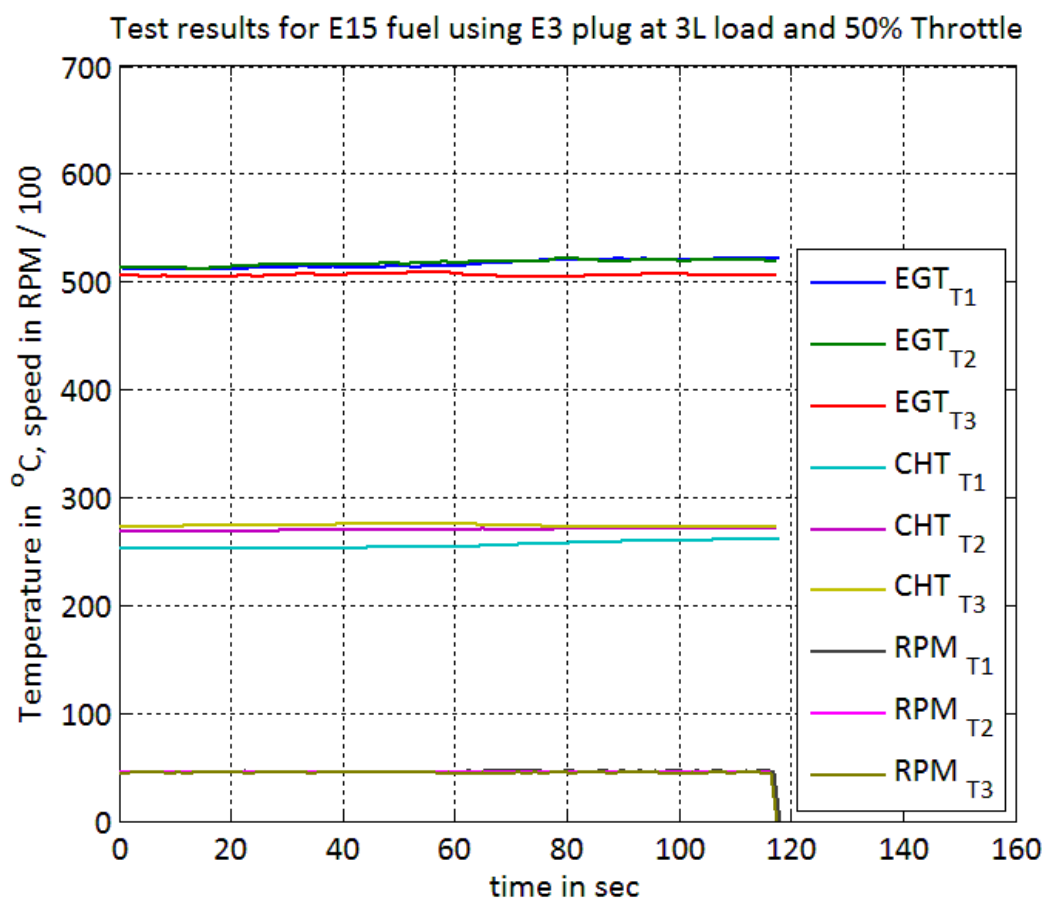

Figure A.35 


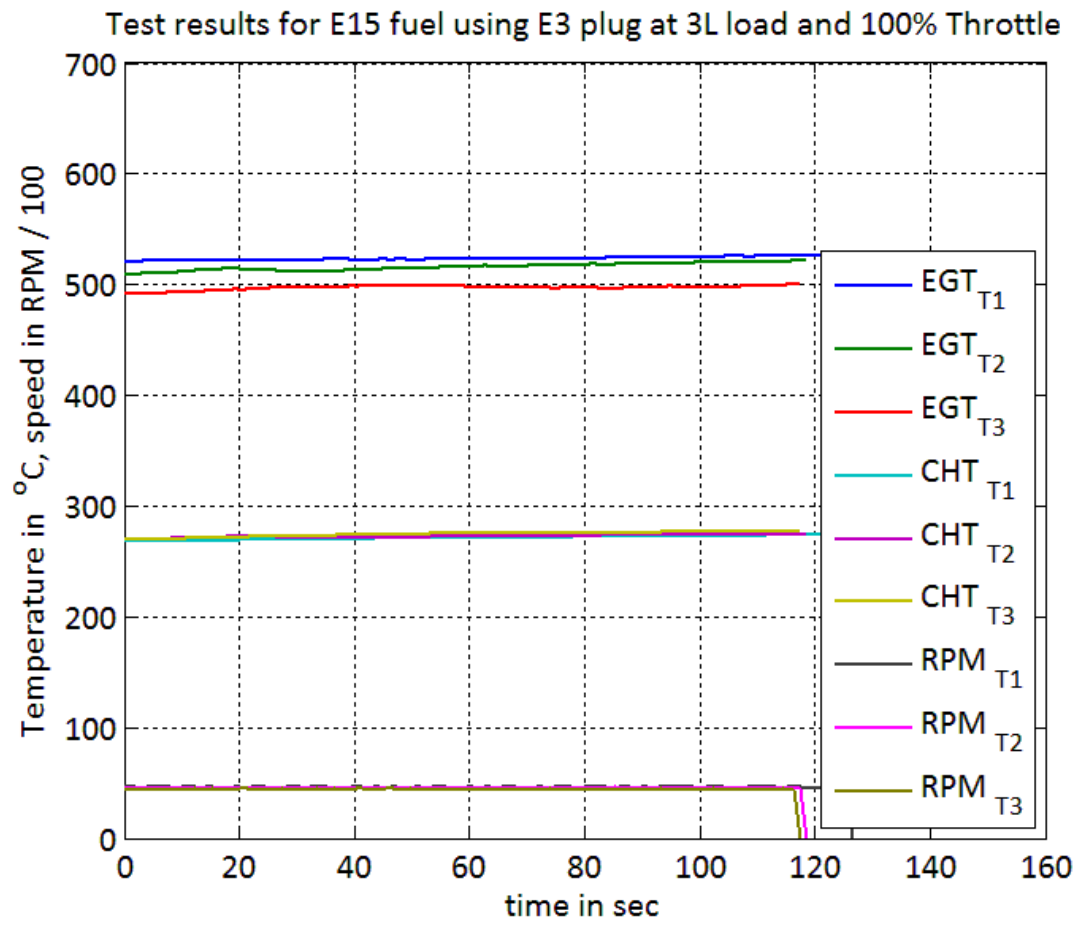

Figure A.36 


\section{A.2.5 3L Emissions}

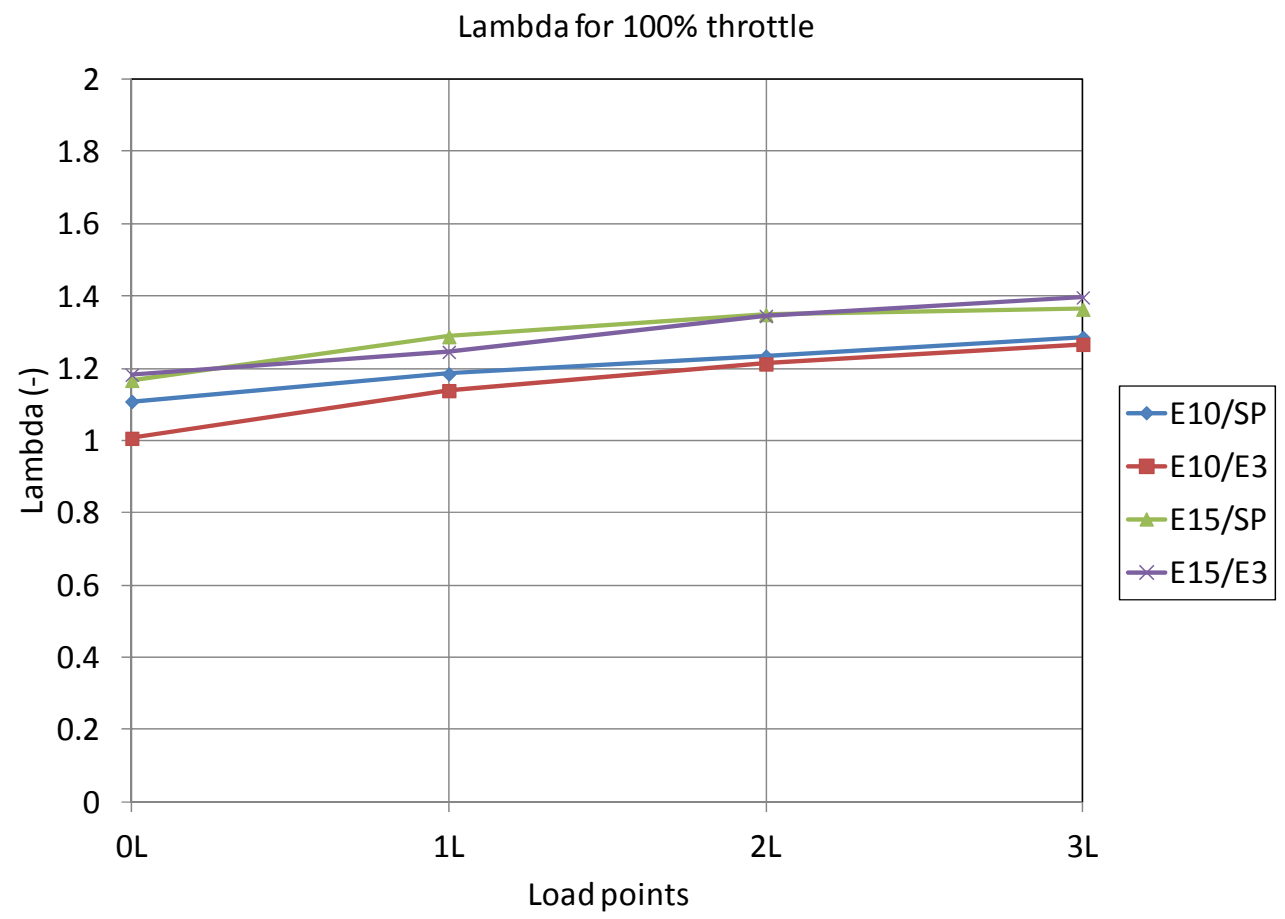

Figure A.37 
Fuel consumption for $100 \%$ throttle

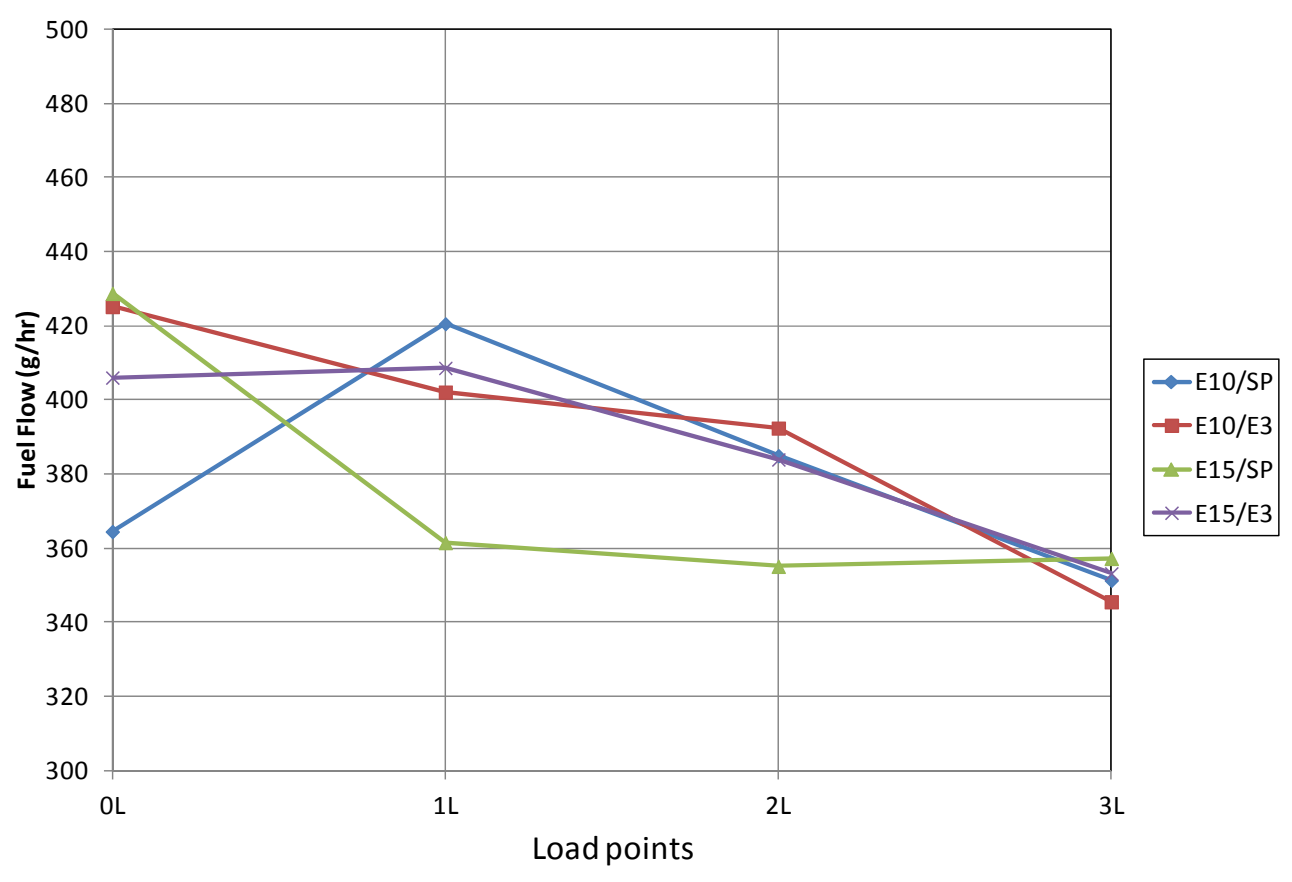

Figure A.38

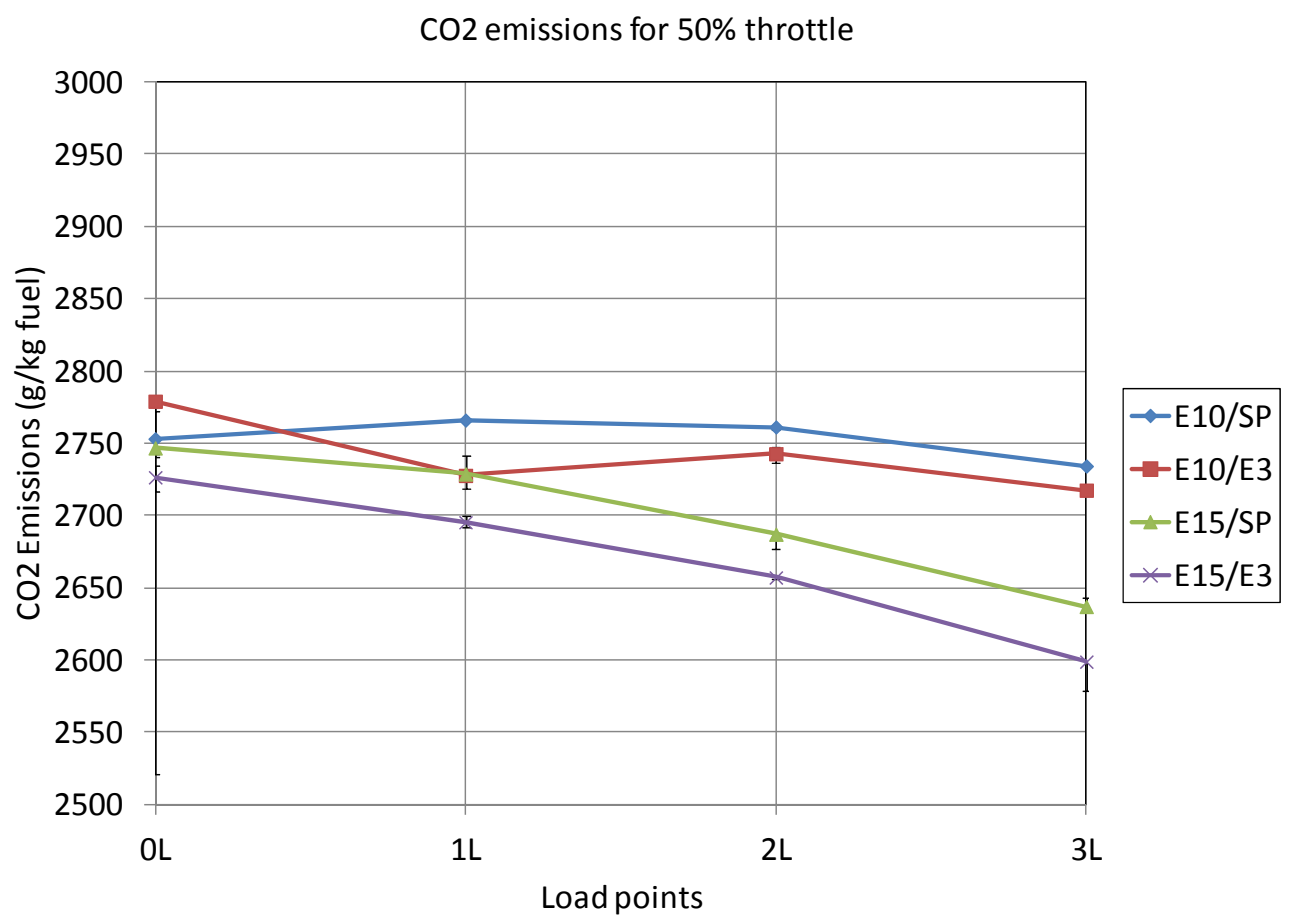

Figure A.39 


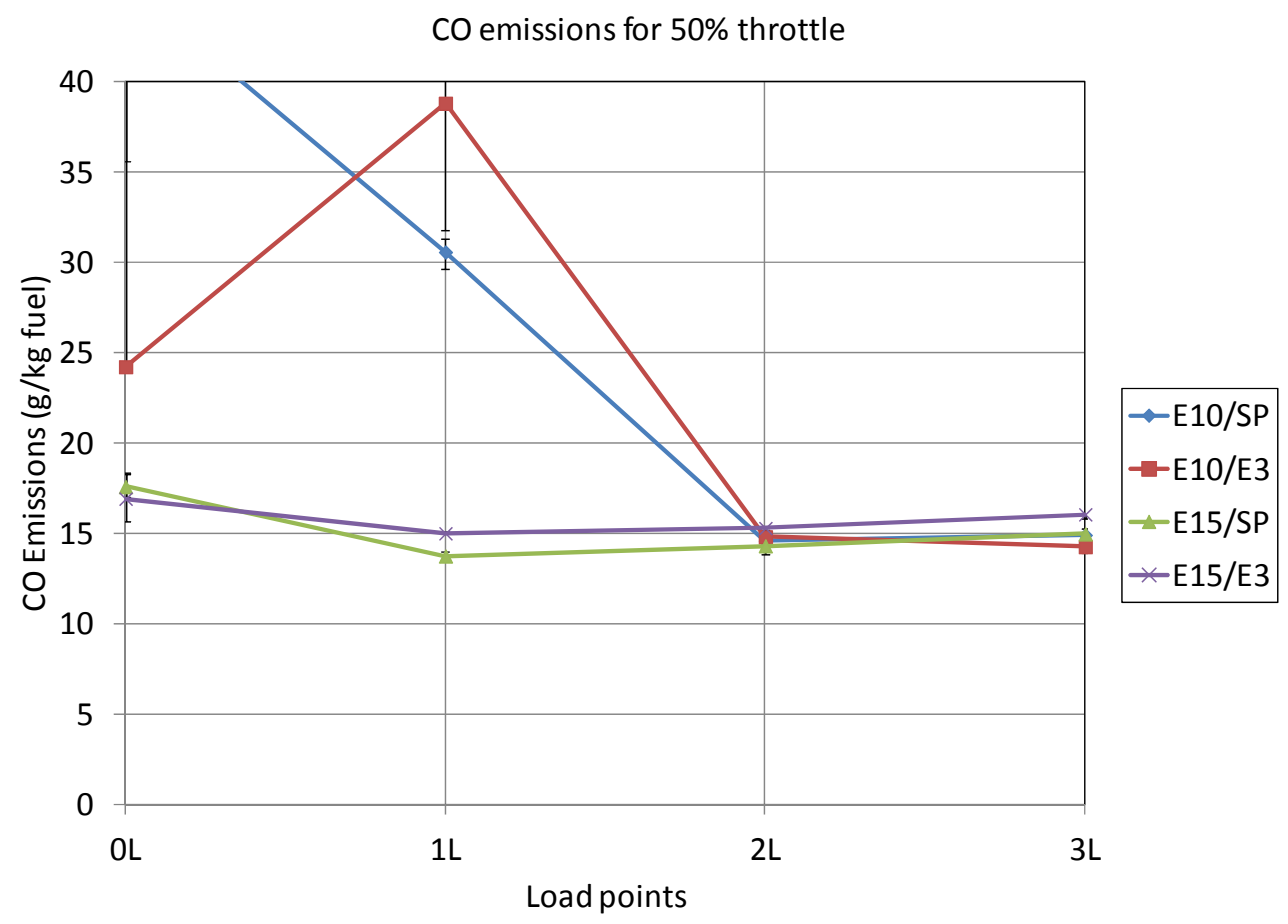

Figure A.40

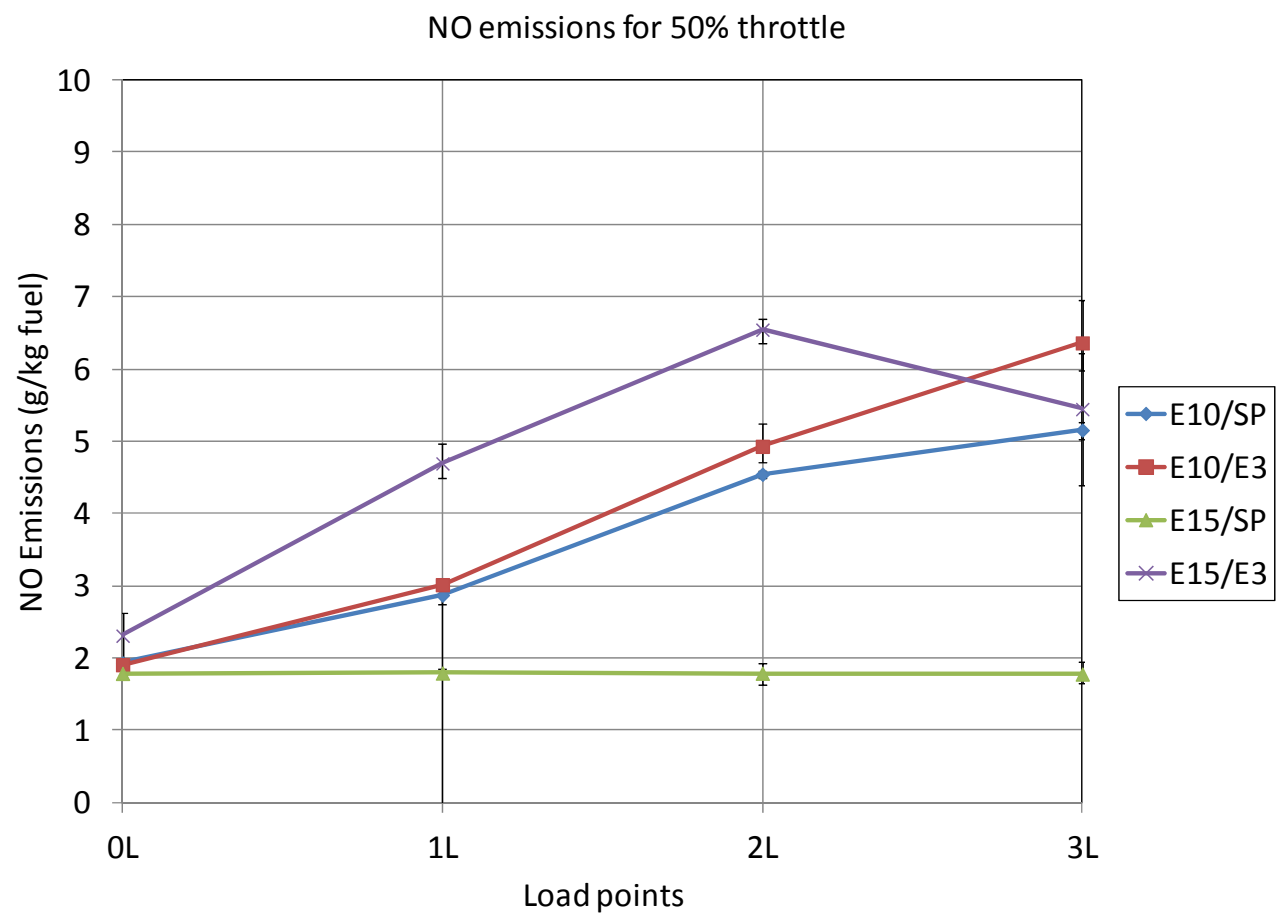

Figure A.41 
HC emissions for $50 \%$ throttle

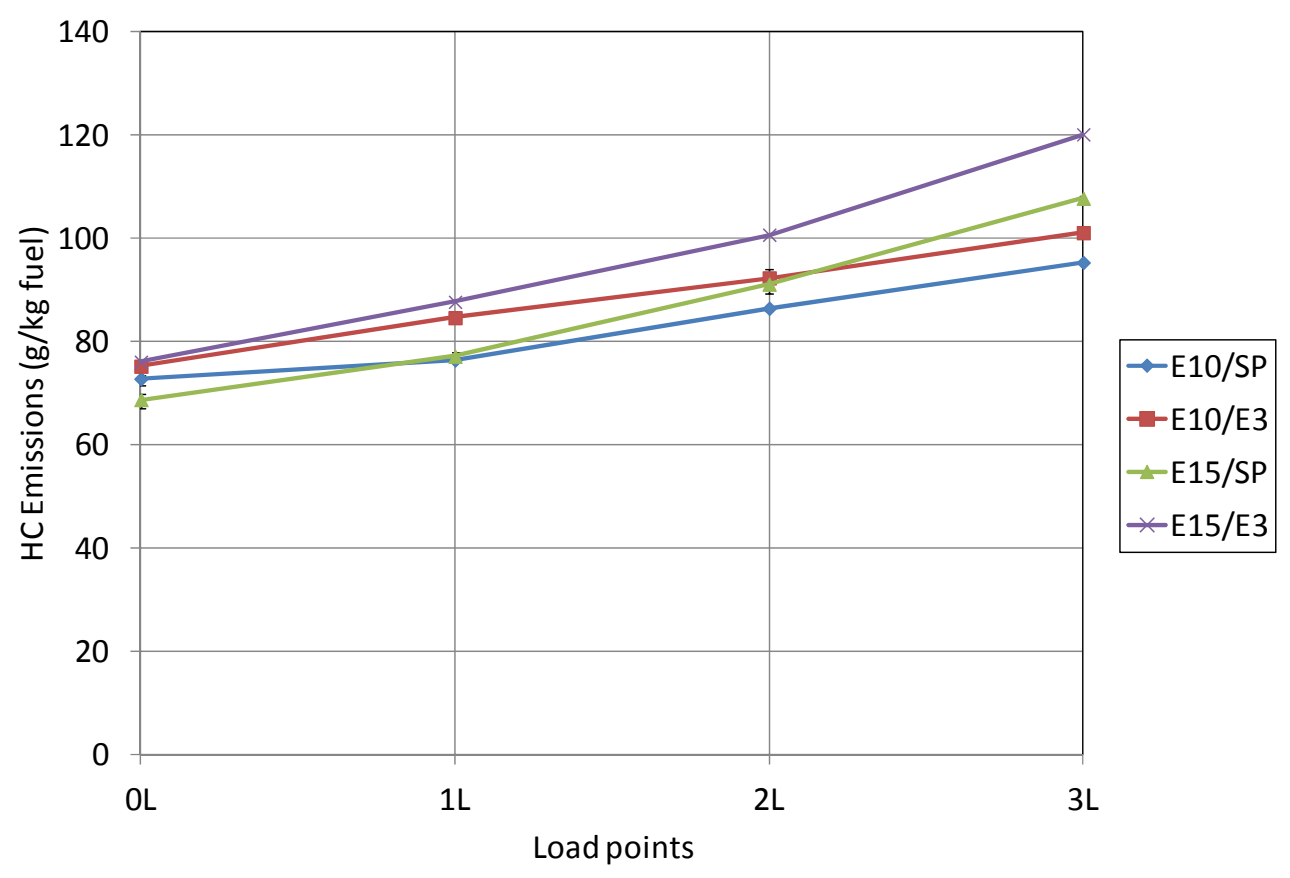

Figure A.42

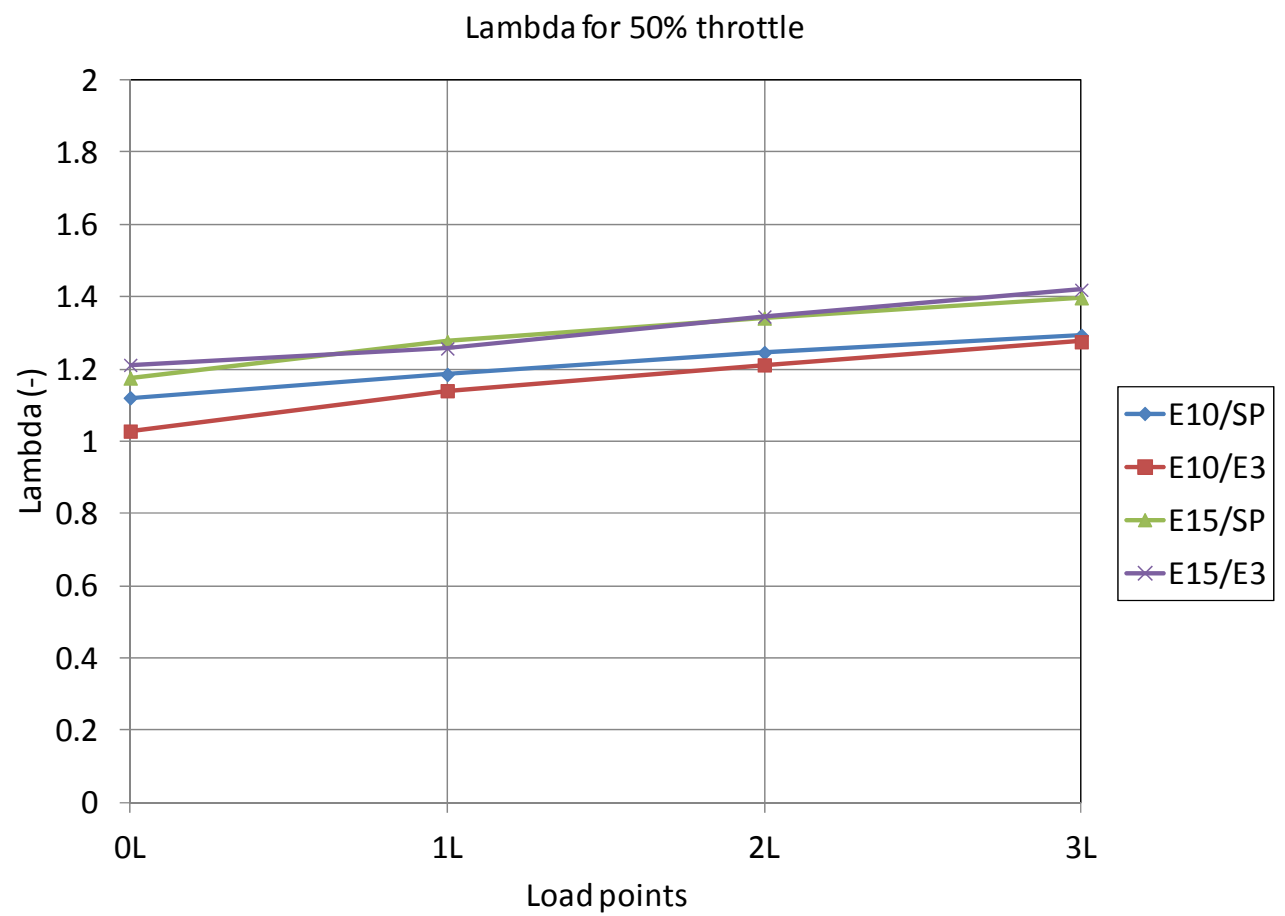

Figure A.43 
Fuel consumption for $50 \%$ throttle

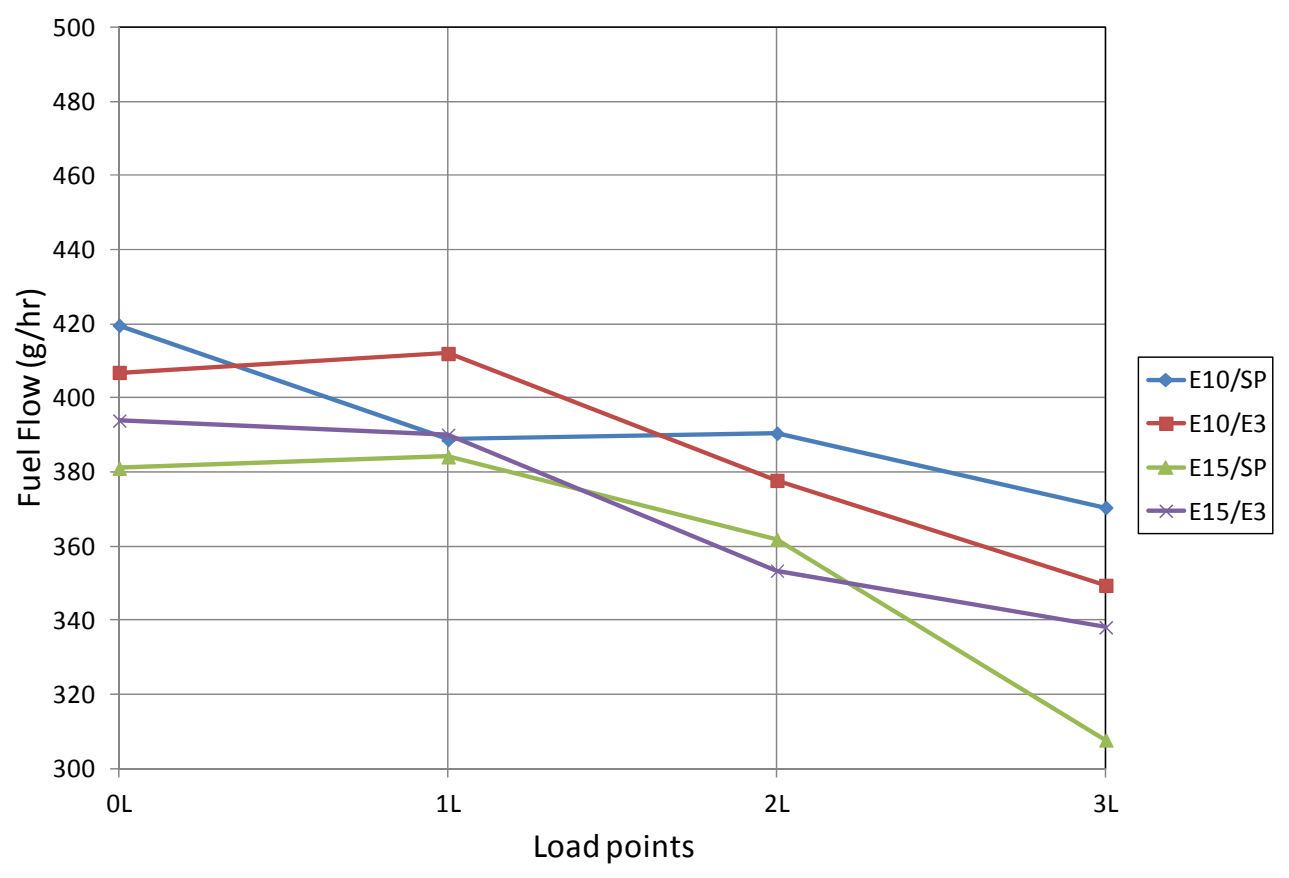

Figure A.44 


\section{A.2.6 Statistical plots}

Main Effects Plot for Cylinder Head Temperature (C)

Data Means

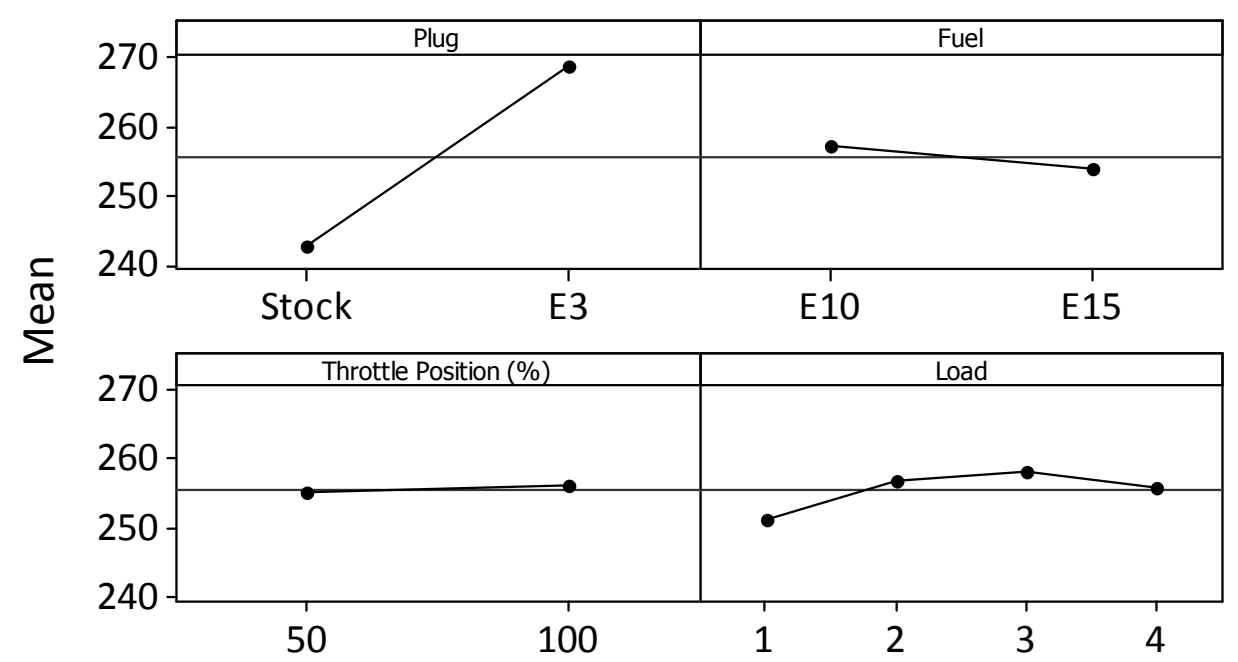

Figure A.45

Main Effects Plot for Exhaust Gas Temperature (C) Data Means

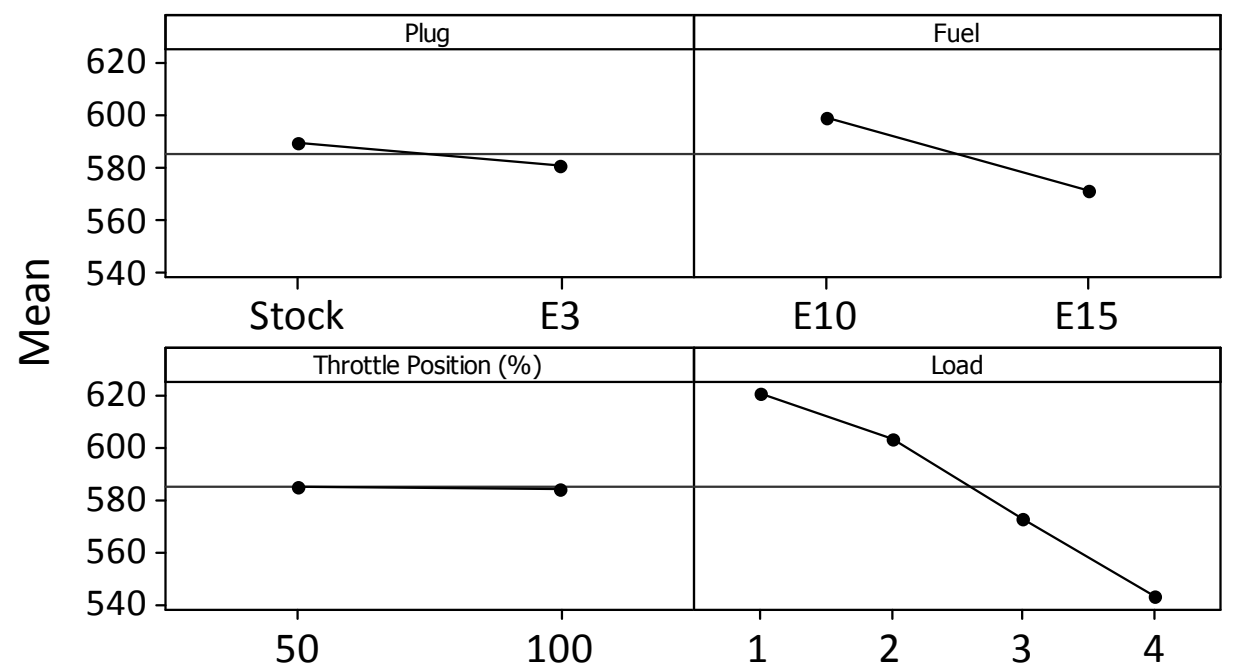

Figure A.46 


\section{Main Effects Plot for $\mathrm{CO} 2$ (g/kg fuel)}

Data Means

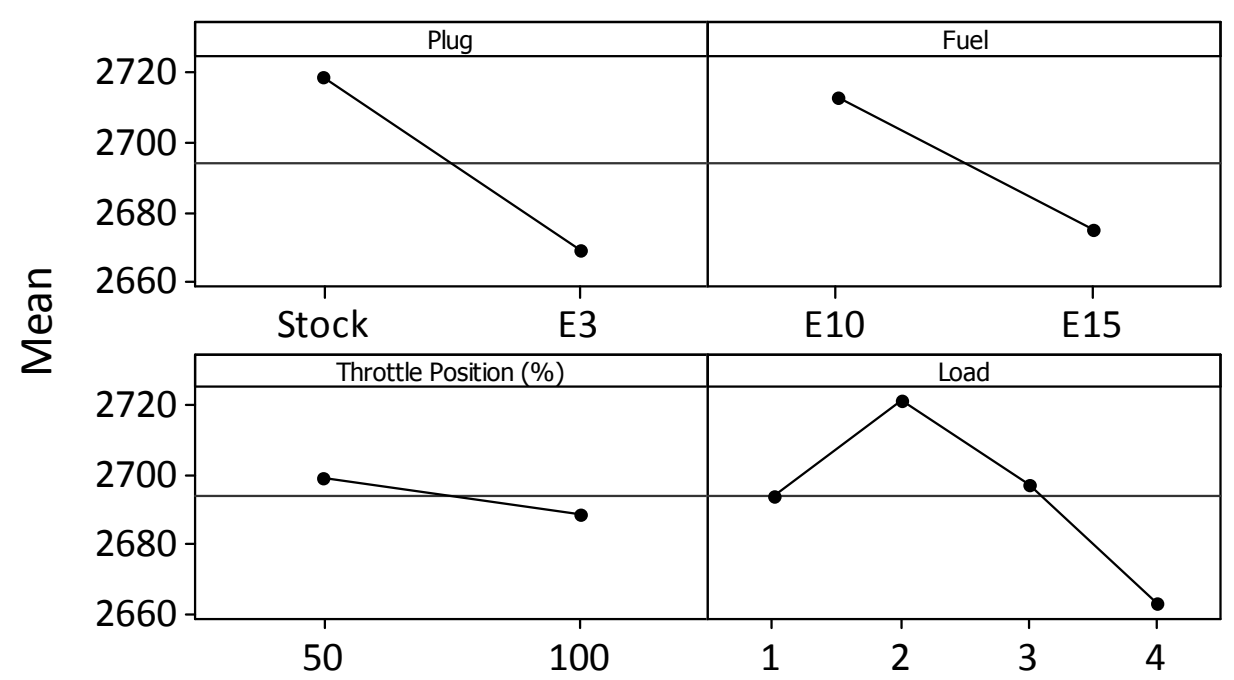

Figure A.47

Main Effects Plot for CO (g/kg fuel)

Data Means

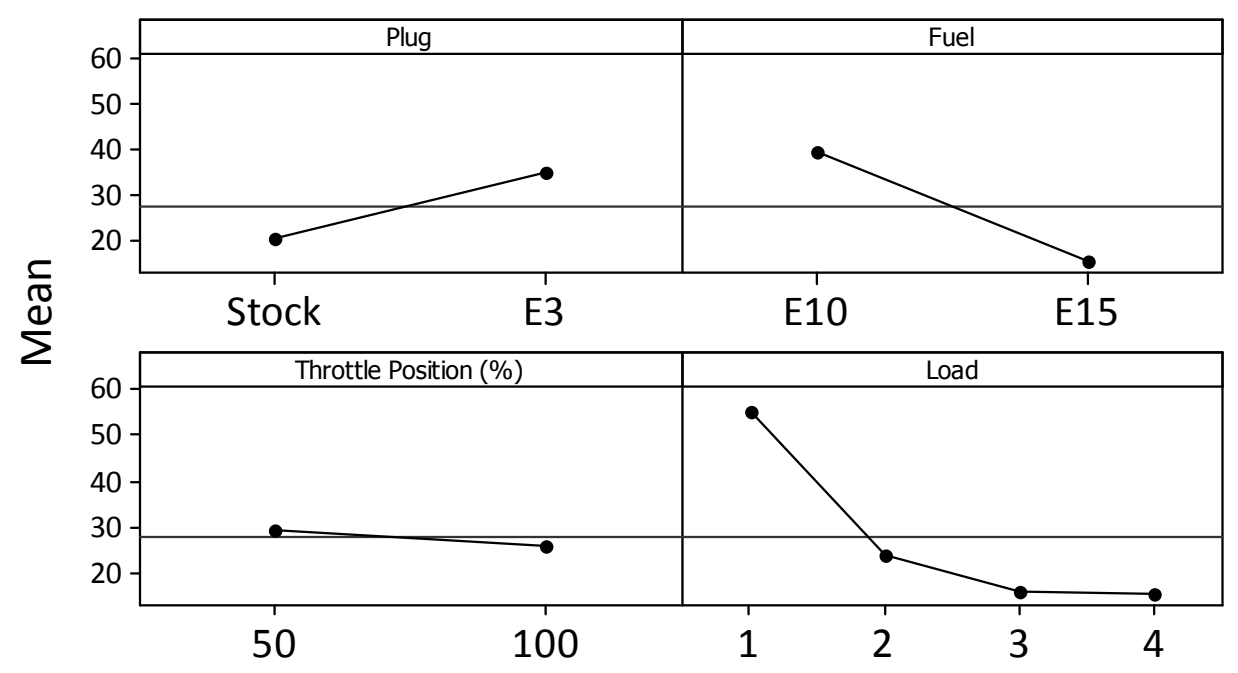

Figure 5.48 
Main Effects Plot for NO (g/kg fuel)

Data Means

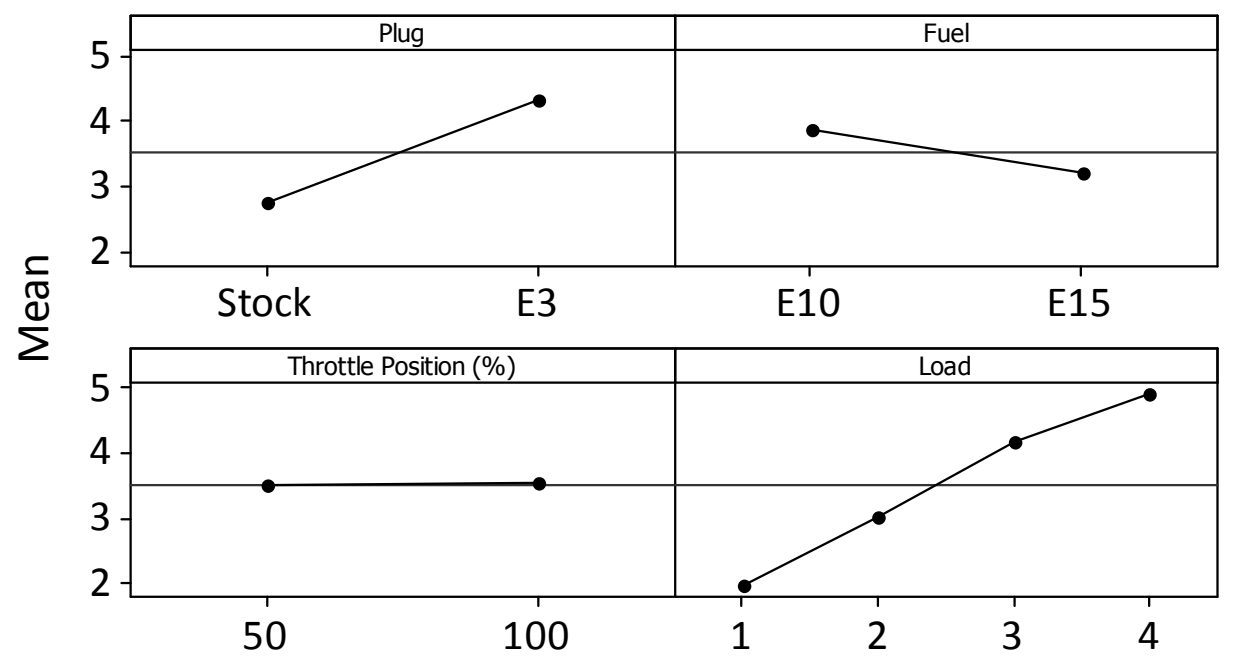

Figure A.49

Main Effects Plot for $\mathrm{HC}(\mathrm{g} / \mathrm{kg}$ fuel)

Data Means

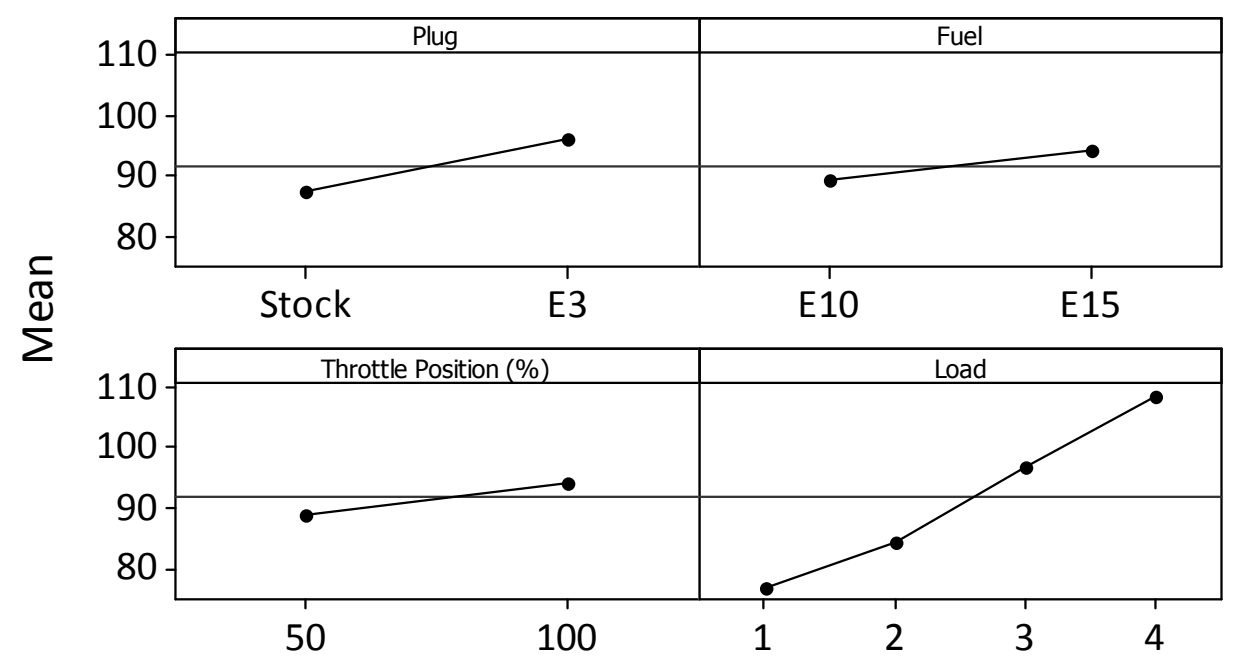

Figure A.50 